\title{
Versuche zur Adaptation der Fische im normalen Temperaturbereich ${ }^{1}$
}

\author{
H.-D. JaNKOWSKY \\ Zoologisches Institut der Universität Kiel, Lehrstubl für Zoophysiologie, Kiel
}

\begin{abstract}
Experiments on the adaptation of fish within the normal range of temperature. In most teleosts the metabolism of the intact individual and its isolated tissues have the ability for partial compensation. The metabolic rates of fish kept at colder acclimation temperatures are higher than the rates of fish kept for the same time at a higher temperature, when measured at the same test temperature. In this study a similar pattern of temperature acclimation is demonstrated in the golden orfe (Idus idus L.) for the rates of oxygen uptake of excised gill and muscle tissue, the activity of cytochrome oxidase in skeletal muscle, and the activities of aldolase and malic dehydrogenase in gill, liver and muscle homogenates. In contrast, the anaerobic acid production of excised gills and the succinate oxidation in the liver homogenates are not changed in the process of cold acclimation. Treatments with TSH increased the activity of malic dehydrogenase only in the liver of cold-adapted fish. As in the eel (Anguilla vulgaris L.) the metabolic rate of muscle in vitro does not completely reflect the capacity adaptation of the intact fish and, as the latter mainly depends on the temperature conditions of the head, the following parameters of metabolic capacity were estimated: the frequencies of opercular and cardiac cycles, the local oxygen pressure in the dorsal skeletal muscle, the heart cavity and the caudal blood vessels. In addition, structure and oxidative capacity of body muscles were investigated. The frequencies of opercular movements and heart beats were significantly higher for cold-adapted eels; but the local oxygen pressure in the white muscle and the oxygen tension in the arterial blood were independent of adaptation temperature. An analysis of the oxygen pressure in the venous bloodstream, in respect to changing test temperatures and different adaptation conditions, showed a lower oxygen tension in cold-acclimated eels than in warm-acclimated ones. This difference became more pronounced at higher test temperatures, showing a close correlation between breathing rate and the partial pressure of oxygen. The results are discussed in relation to other work on temperature adaptation in the eel.
\end{abstract}

\section{EINLEITUNG}

Über den Einfluß der Adaptationstemperatur auf Leistungen der Fische gibt es eine Fülle von Veröffentlichungen (vgl. Prosser 1958, 1962, FRY 1964, 1967). Bei dem am häufigsten untersuchten Sauerstoffverbrauch zeigt sich bei vielen Fischarten, daß die

${ }^{1}$ Habilitationsschrift, angenommen von der Mathematisch-Naturwissenschaftlichen Fakultät der Universität Kiel. 
Wirkung der Außentemperatur mehr oder weniger kompensiert wird. Beim Erhöhen der Vorbehandlungstemperatur kommt es zum Absinken des Stoffwechsels, erniedrigte Temperaturen führen zu seiner Steigerung. Eine gewisse Unabhängigkeit von schwankenden Umwelttemperaturen können die Fische auch durch ihr thermotaktisches Verhalten erreichen; es kommt hinzu, daß die Vorzugstemperatur häufig von der Adaptationstemperatur abhängt (Ferguson 1958, Sullivan \& Fisher 1953, Zahn 1962). Bei der Forelle verhindert ein Zerstören des Vorderhirns oder ein Betäuben der Hautrezeptoren diesen Einfluß der Adaptationstemperatur auf die Wahl der Vorzugstemperatur (FISHer 1958, Frsher \& Sullivan 1958). Vereinzelt ist direkt ein Anpassen nervöser Leistungen der Fische an die thermischen Milieubedingungen nachgewiesen worden, insbesondere eine sinnvolle Kälteadaptation (Roots \& Prosser 1962, Konishr \& Hickman jr. 1964, Prosser \& Farhi 1965).

Beim Vorliegen einer Temperatur-Leistungsadaptation des Nervensystems der Fische muß man damit rechnen, daß die Adaptation ihres Gesamtstoffwechsels in starkem Maße von der des Nervensystems beeinflußt wird. Die Bedeutung der Hormone für die Temperaturanpassung des Stoffwechsels ist noch weitgehend ungeklärt (vgl. JANKowsky 1964a) und wird teilweise ganz bezweifelt (KLICKa 1965). Viele Autoren bestätigen dagegen, daß der Sauerstoffverbrauch isolierter Gewebe und die Aktivität einzelner Enzyme durch die Vorbehandlungstemperatur der Fische geändert werden (vgl. Prosser 1962, 1967a, Freed 1965, Hochachka \& Hayes 1962). In einigen Fällen führt die Anpassungstemperatur im Stoffwechsel des Ganztieres und der untersuchten Gewebe zu gleichen Änderungen (KRüGER 1962, BER KHOLz 1966). Bei manchen Fischen ist jedoch die Adaptation der Gewebe gering, uneinheitlich oder verläuft sogar entgegengesetzt zur Ganztieratmung. So bleibt beim Goldfisch die Gewebeatmung des Gehirns, der Leber und des Herzens unbeeinflußt von der Vorbehandlungstemperatur der Tiere (EKBERg 1958, MuRPHY 1961), während bei der Regenbogenforelle der Gehirnstoffwechsel eine ideale, der Sauerstoffverbrauch der Leber eine überoptimale Kompensation aufweisen (Evans et al. 1962, vgl. Precht 1964b). Auch zeigt die Ganztieratmung der Schleie eine Leistungsadaptation im Sinne einer Kompensation, eine solche findet sich nicht beim Sauerstoffverbrauch des Muskelgewebes und der Kiemen (JANкоwSKy 1964b). Setzt man aber der isolierten Schleimuskulatur geringe Blutmengen verschieden adaptierter Fische zu, so wird gleichfalls eine Kompensation des Sauerstoffverbrauchs sichtbar (vg1. RAO 1967). Diese Stoffwechselsteigerung beim Zusatz von Blut kaltgehaltener Fische erstreckt sich nicht nur auf arteigenes Gewebe (РRECHT 1964a). Der wirksame Faktor im Blut der Fische ist unbekannt; nach eigenen unveröffentlichten Untersuchungen hat veraschtes Blut keinen Einfluß, beim Erhitzen auf $100^{\circ} \mathrm{C}$ bleibt die katalytische Wirkung aber erhalten. Sie kann ebenfalls nicht durch geringe Substratmengen vorgetäuscht sein. Nach RAO (1966) findet sich in der Körperflüssigkeit und im Nervensystem kaltadaptierter Regenwürmer, Skorpione und Fische eine Sterolfraktion, die für die in-vitro-Effekte auf die Gewebeatmung verantwortlich gemacht wird. Bei Säugern ist die Förderung der Zellatmung durch Blutzusätze mehrfach nachgewiesen worden (vgl. JAEGER et al. 1965). Aus Untersuchungen des Gewebestoffwechsels der Fische in künstlichen Nährmedien können daher nur begrenzt Schlußfolgerungen auf die Temperaturadaptation der Ganztiere gezogen werden.

Auf Grund obiger Befunde stellt sich die Frage, ob der Sauerstoffverbrauch der 
Fische von temperaturinduzierten Veränderungen des Gewebestoffwechsels abhängt oder ob umgekehrt die Leistungsadaptation der Ganztiere zu Umstellungen in den Geweben führt. Tiefere Einblicke in zelluläre Mechanismen sind bei guter Kenntnis der Biochemie des Stoffwechsels vieler Fischgewebe zu erwarten. Bislang wurden nur vereinzelt biochemische Untersuchungen in Hinblick auf die Temperaturadaptation der Fische unternommen (Ekberg 1958, Kanungo \& Prosser 1959, Hochachka \& Hayes 1962, Hochachka 1965, Dean \& Goodnight 1964, Rao 1966, Das 1967).

Eine mögliche Änderung des Gesamtstoffwechsels durch Anpassungen der Gewebe kann weiterhin überprüft werden, wenn man die Wirkung mehrerer Umweltfaktoren wie Temperatur, Salz- und Sauerstoffgehalt des Mediums und Photoperiode auf den Stoffwechsel des Ganztieres und den der isolierten Gewebe verfolgt (vgl. KInNE 1964). Beim Sonnenbarsch, Lepomis gibbosus, spricht die Abhängigkeit der Leistungsadaptation von der Photoperiode für eine Stoffwechselsteuerung durch übergeordnete Systeme (RobER Ts 1964, 1966; vgl. auch КАSвонм 1967).

Probleme der Temperaturadaptation sind an dem auch von mir als Versuchstier gewählten Aal (Anguilla vulgaris L.) bereits mehrfach untersucht worden (CARLSEN 1953, Precht 1951, 1961, Palayer 1963, Prosser et al. 1965, Schultze 1965). Unter anderem wurde eine vergleichbare Kompensation der Ganztieratmung und der Sauerstoffaufnahme des Muskelgewebes nachgewiesen; unter denselben Versuchsverhältnissen liegt der Sauerstoffverbrauch bei kaltgehaltenen Fischen höher als bei warmadaptierten. Setzt man jedoch vor den Messungen Vorder- und Hinterkörper des Aales verschiedenen Temperaturen aus, so wird die Ganztieratmung nur von der Adaptation des Vorderkörpers beeinflußt. Sie ist unabhängig vom Sauerstoffverbrauch der Schwanzmuskulatur, wie er bei Messungen in vitro bestimmt wird. Aus diesen Untersuchungen folgert Schultze, daß zumindest bei dieser Art die Leistungsadaptation des Muskelgewebes für den Gesamtstoffwechsel bedeutungslos ist. Er weist ferner darauf hin, daß man bei Succinatveratmung die Succinodehydrogenaseaktivität des Muskelgewebes im Warburg-Versuch ermittelt. Dies erschwert einen quantitativen Vergleich der Werte für die Gewebeatmung der Muskulatur mit der Höhe der Ganztieratmung; es bleibt aber zu bedenken, daß mit der Aktivität mitochondrialer Enzyme ein gewisses Maß für die oxydative Kapazität des Gewebes gegeben ist.

Begrenzend für den Sauerstoff verbrauch der Zellen ist der Sauerstoffdruck in dem sie umgebenden Milieu. Bei niedriger Sauerstoffspannung können die Gewebe ihre maximale Stoff wechselkapazität nicht ausschöpfen, letztere wird jedoch bei Fermentbestimmungen in vitro erfaßt. Die Unsicherheiten der bisherigen Befunde über die Temperaturadaptation des Aales gaben Anlaß, am gleichen Versuchstier erneut die Frage nach dem Einfluß des Gewebestoffwechsels auf den Sauerstoffverbrauch des Fisches in vivo zu überprüfen. Als Methode bieten sich hierzu Messungen des Sauerstoffdrucks im Blut und Gewebe an. Auch die Temperaturadaptation des Zellstoffwechsels in vitro ist weiterhin untersucht worden. 


\title{
UNTERSUCHUNGEN DES GEWEBESTOFFWECHSELS IN VITRO
}

\author{
Methoden
}

Tie rmateria l: Die untersuchten Orfen (Idus idus L.) stammten aus Zuchtteichen in Schleswig-Holstein. Hinsichtlich der Leistungsadaptation des Stoffwechsels bestehen zwischen der Silberorfe, der Wildform, und der Goldorfe, ihrer gelbroten Zuchtform, keine Unterschiede (bis auf die in Tabelle 3 aufgeführten Messungen wurden nur Goldorfen verwendet). Die Versuchstiere wurden in großen, mit Leitungswasser durchströmten Kachelbecken und Plastikwannen bei 16stündigem, künstlichem Langtag gehalten und täglich mit Vita-Teichfutter und Tubificiden gefüttert. Ihre Anpassung an eine konstante Vorbehandlungstemperatur (AT) erfolgte in den Hälterungsbecken; die Adaptationsdauer betrug mehr als drei Wochen. $\mathrm{Zu}$ Versuchen verwendete Jungaale (Körperlänge 8 bis $10 \mathrm{~cm}$ ) erhielten ausschließlich Tubificiden als Futter, Silberaale (Körperlänge um $50 \mathrm{~cm}$ ) blieben dagegen ungefüttert.

Messungen des Gewebestoffwechsels der Orfe: Den Sauerstoffverbrauch der Gewebe, ihre glykolytische Aktivität und die enzymatische Aktivität der Cytochromoxydase bestimmten wir manometrisch mit Hilfe des Warburg-Apparates. Je nach Art des Gewebes war die Aufarbeitung verschieden; isolierte Kiemenblättchen wurden unzerteilt in die Tröge eingebracht, das Muskelgewebe untersuchten wir als Schabebrei oder Homogenat, die Leber wurde ebenfalls homogenisiert. Zur Herstellung des Muskelschabebreies zerkleinerten wir das Gewebe grob mit einer Schere, preßten es durch das Scherblatt eines Elektrorasierapparates und schabten es mit einem Skalpell ab. Die Bereitung der 5- oder 10\% igen Homogenate erfolgte - wenn nicht anders angegeben - in einem Homogenisator des Potter-Elvehjem-Typs bei ca. 1000 $\mathrm{U} / \mathrm{min}$. Die Verwendung von Gewebebreien oder Homogenaten bot den Vorteil, daß auf Grund der erleichterten Diffusion bei Bestimmung der Sauerstoffaufnahme als Gasphase Luft verwendet werden konnte; wegen der bei dieser Aufarbeitung schnell sinkenden Stoff wechselaktivität wurde aber stets auf gute Kühlung und möglichst kurze Präparationszeit geachtet. Die Schüttelfrequenz betrug in allen Fällen 74/min. Es wurden Reaktionsgefäße mit einem Volumen von etwa $14 \mathrm{ml}$ verwendet (Absorptionsmittel für $\mathrm{CO}_{2}: 0,20 \mathrm{ml}$ einer $20 \%$ igen $\mathrm{NaOH}$ ). Einzelheiten der Inkubationsbedingungen sind in den jeweiligen Tabellen angegeben.

Als Maß für die glykolytische Aktivität wählten wir die anaerobe Säurebildung, die am freigesetzten Kohlendioxyd unter Verwendung von Bicarbonat-Puffer und einer Stickstoff-Kohlendioxyd-Atmosphäre im Reaktionssystem bestimmt wurde. In den Hauptraum des Warburg-Gefäßes pipettierten wir $3 \mathrm{ml}$ Suspensionsmedium folgender Zusammensetzung: 17,5 mM KHCO $3 ; 6,7 \mathrm{mM} \mathrm{MgCl}_{2} ; 2,4 \mathrm{mM} \mathrm{K}_{3} \mathrm{PO}_{4} ; 10 \mathrm{mM} \mathrm{KF}$; $50 \mathrm{mM} \mathrm{KCl}$. In die Ansatzbirne des Troges kamen jeweils $1 \mathrm{ml}$ einer Lösung, enthaltend $30 \mathrm{mM}$ Glucose, $6 \mathrm{mM}$ Fructose-1,6-diphosphat, 22,5 mM Natriumpyruvat sowie $120 \mathrm{mM}$ Nicotinsäureamid. Suspensionsmedium und Nährmedium wurden vor der Messung mit einem Gasgemisch von 4,6 \% $\mathrm{CO}_{2}$ und $95,4 \% \mathrm{~N}_{2}$ gesättigt. Jeden Trog beschickten wir mit 250-300 mg Kiemengewebe bzw. $220 \mathrm{mg}$ Muskelschabebrei oder $1 \mathrm{ml}$ eines 20\% oigen Muskelhomogenats; bei der Verwendung von Homogenaten enthielt das Suspensionsmedium kein $\mathrm{KCl}$, dafür wurde das Gewebe in $150 \mathrm{mM} \mathrm{KCl}$ 
homogenisiert. Nach Einhängen der Tröge in den Thermostaten von $25^{\circ} \mathrm{C}$ und $5 \mathrm{~min}$ Temperieren wurde 20 min lang ein Gasgemisch der oben angeführten Zusammensetzung unter ständigem Schütteln durchgeleitet. Die freigesetzte Kohlensäure haben wir jeweils $45 \mathrm{~min}$ lang vor Zugabe und $75 \mathrm{~min}$ lang nach Zugabe des Substrats bestimmt.

Die enzymatische Aktivität der Cytochromoxydase ermittelten wir manometrisch in Anlehnung an РоттеR (1957) bei einer Versuchstemperatur von $23^{\circ} \mathrm{C}$ durch Messung des Sauerstoffverbrauchs bei einem Uberschuß an reduziertem Cytochrom-c. Die Autoxydation des zur Reduktion verwendeten Ascorbats eliminierten wir durch Extrapolieren auf die Konzentration $\mathrm{O}$ unter Verwendung verschiedener Homogenatmengen.

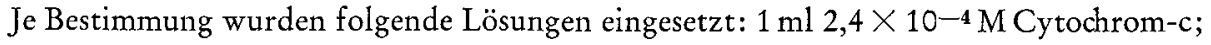
0,5 $\mathrm{ml}$ 0,114 M Natriumascorbat; $1 \mathrm{ml}$ Homogenat der Konzentrationen $67 \mathrm{mg}, 100 \mathrm{mg}$, $133 \mathrm{mg}, 200 \mathrm{mg}$ Gewebe/ml. Zur Herstellung der Homogenate wurde $1 \mathrm{~g}$ Gewebe in der zehnfachen Menge Homogenisationsmedium suspendiert und unter Eiskühlung 5 mal $5 \mathrm{sec}$ sowie $1 \times 15 \mathrm{sec}$ mit dem „Ultra-Turrax“ (Fa. Janke \& Kunkel, Stauffen) zerkleinert. Das Homogenisationsmedium enthielt $12 \mathrm{mM}$ Phosphatpuffer $\mathrm{pH} 7,4$ und $0,1 \mathrm{mM} \mathrm{AlCl} 3$ in Aqua dest. Den Sauerstoffverbrauch verfolgten wir 90 Minuten lang, wobei jeweils alle 10 Minuten die Manometerstände abgelesen wurden.

Die Aktivitätsbestimmung der Fructose-1,6-diphosphat-Aldolase (ALD) und der Malatdehydrogenase (MDH) erfolgte nach BERGMEYER (1962) mit Hilfe der Boehringer-Testkombinationen TC-D bzw. TC-L (Photometer „Eppendorf“, Meßstrahlung: $366 \mathrm{~nm}$; Schichtdicke: $1 \mathrm{~cm}$; Testvolumen: $3 \mathrm{ml}$; Temperatur: $25^{\circ} \mathrm{C}$ ). Die für Blutserum vorgesehene Zusammensetzung der Testansätze behielten wir bei, statt Serum wurden gleiche Mengen verdünnter Gewebeextrakte eingesetzt. Um die Extrakte zu gewinnen, homogenisierten wir jeweils $100 \mathrm{mg}$ Gewebe in $1,9 \mathrm{ml}$ eiskaltem $67 \mathrm{mM}$

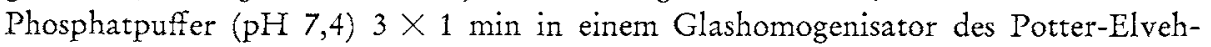
jem-Typs (Glas in Glas), ließen das Homogenat 20 min eisgekühlt stehen und zentrifugierten es dann $10 \mathrm{~min}$ bei $5000 \mathrm{U} / \mathrm{min}$. Den Überstand verdünnten wir mit Phosphatpuffer so, daß bei der Messung die Extinktionsdifferenzen pro min etwa 0,02 betrugen. Die Aktivitäten der ALD und der MDH sind einheitlich in Milli-Einheiten pro Extrakt von $10 \mathrm{mg}$ Frischgewebe angegeben. Als Einheit ist dabei diejenige Enzymmenge definiert, die bei $25^{\circ} \mathrm{C}$ in $1 \mathrm{~min} 1 \mu \mathrm{Mol}$ Substrat umsetzt, d. h. bei $366 \mathrm{~nm}$ in der 10 Millimeter-Küvette bei $3 \mathrm{ml}$ Testvolumen zu einer Extinktionsabnahme um 1,1 pro Minute führt. (Bei der Messung der ALD ist der Verbrauch von $2 \mathrm{M} \mathrm{NADH}$ je Mol

\section{Tabelle 1}

Der Eiweißgehalt in Extrakten von Goldorfengeweben, bestimmt als Biuret-Protein nach Beisenherz et al. (1953). Angaben als mg Protein, extrahiert unter oben angeführten Bedingungen aus $100 \mathrm{mg}$ Frischgewebe. Anzahl der Messungen jeweils 10; Körpergewicht der Fische zwischen 14 und $24 \mathrm{~g}$

\begin{tabular}{|lcc|}
\hline Gewebe & $\mathrm{AT}=10^{\circ} \mathrm{C}$ & $\mathrm{AT}=20^{\circ} \mathrm{C}$ \\
\hline Kieme & $5,94 \pm 0,21$ & $5,61 \pm 0,39$ \\
Muskel & $4,73 \pm 0,23$ & $4,51 \pm 0,17$ \\
Leber & $8,14 \pm 0,23$ & $8,14 \pm 0,45$ \\
\hline
\end{tabular}


Substrat berücksichtigt worden.) Eine Berechnung der Enzymaktivitäten - bezogen auf den Eiweißgehalt der Gewebeextrakte - führte zu keiner Erniedrigung der Streuung der Meßwerte. Es konnte auch keine Abhängigkeit des extrahierbaren Eiweißes von der Adaptationstemperatur der Fische festgestellt werden (Tab. 1).

Messungen der Cytochromoxydaseaktivität und des $\mathrm{Nucleins} a ̈ u r e g e h a 1 \mathrm{ts}$ in der Aalmuskulatur: Die Aktivität der Cytochromoxydase im Aalgewebe wurde ähnlich wie bei der Goldorfe bestimmt. Das Homogenisationsmedium enthielt jedoch höhere Konzentrationen an Phosphatpuffer $(20 \mathrm{mM})$ und Aluminiumchlorid $(2,5 \mathrm{mM})$. Geringer waren dagegen die eingesetzten Homogenatkonzentrationen ( $30 \mathrm{mg}, 45 \mathrm{mg}$ und $90 \mathrm{mg}$ Gewebe/ml). Bis auf diese Ausnahmen erfolgte die Versuchsdurchführung in gleicher Weise wie für die Orfe angegeben (vgl. p. 321). Die Extraktion der Nucleinsäuren aus Proben der Aalmuskulatur wurde nach der Methode von Ogur \& Rosen (1950) vorgenommen. Das Gewebe wurde bei $4^{0} \mathrm{C}$ in $95 \%$ igem Athanol homogenisiert, das abzentrifugierte Sediment mit 70\%igem Athanol (enthaltend $0,1 \%$ Perchlorsäure) gewaschen und mehrmals mit einem Gemisch Athanol:Ather (3:1) extrahiert. Die säurelösliche Phosphatfraktion ist mit eisgekühlter $0,2 \mathrm{~N}$ Perchlorsäure durch Waschen entfernt worden; die Nucleotide wurden dann in $6 \%$ iger Perchlorsäure bei $90^{\circ} \mathrm{C}$ hydrolysiert. Die Bestimmung der gesamten Nucleinsäuren erfolgte nach Mејвачм (1939), die der DNS nach Dische (1930).

In den Tabellen sind außer den Mittelwerten ihre mittleren Fehler vermerkt. Die statistische Sicherung der Unterschiede ( $P$-Werte) nahmen wir nach der graphischen Methode von PäTAU (1943) vor.

\section{Ergebnisse}

\section{Der Einfluß der Adaptationstemperatur auf den Gewebestoffwechsel der Orfe}

Untersuchungen des Sauerstoffverbrauchs der Fischgewebe in vitro wurden, wie erwähnt, vielfach mit Succinatzusatz zum Inkubationsmedium durchgeführt (KRÜGER 1962, Jankowsky 1964b, PRECHT 1964a). Da hierbei in erster Linie die Aktivität der Succinatdehydrogenase erfaßt wird, untersuchten wir an Geweben der Orfe, die als Ganztier eine ausgesprochene Leistungsadaptation zeigt (BERKHOlz 1966), weitere Stoffwechselgrößen in Abhängigkeit von der Adaptationstemperatur, und zwar den Sauerstoffverbrauch von Kieme, Muskel und Leber unter Zusatz verschiedener Substrate, die glykolytische Aktivität des Kiemen- und Muskelgewebes, die Aktivitäten der Fructosediphosphat-Aldolase und der Malatdehydrogenase im Kiemen-, Muskelund Lebergewebe sowie die Aktivität der Cytochromoxydase in der Muskulatur.

Nach den Werten der Tabelle 2 zeigen verschieden adaptierte Goldorfen in der Sauerstoffaufnahme der Rumpfmuskulatur einen Unterschied, der unabhängig von der Art des zugesetzten Substrats ist. Ausschließlich das Succinat vermag die Atmung zu steigern; offensichtlich werden die anderen Substrate unter den gegebenen Bedingungen nicht veratmet. Ahnlich wie bei der Muskulatur wird auch die Sauerstoffaufnahme von Kieme und Leber durch Succinat gefördert. Lediglich das Kiemengewebe kann 
Fructose-1,6-diphosphat in etwa gleich starkem Ausmaß verwerten. Muskelbrei ist dazu nicht in der Lage. Dagegen zeigt die Succinatveratmung der Leberhomogenate keinen Einfluß der Vorbehandlungstemperatur; Fructose-1,6-diphosphat wird als Substrat sogar besser von Homogenaten warmadaptierter Fische verwertet (Tab. 3). Dieser Befund verdeutlicht, in wie starkem Ausmaß in-vitro-Messungen nach der Warburg-Methode von den Inkubationsbedingungen abhängen. Die Atmungswerte der Tabellen 2 und 3 können nicht direkt verglichen werden, weil die Versuchstemperaturen, die Substratmengen und die Inkubationsmedien differieren.

\section{Tabelle 2}

Die Sauerstoffaufnahme von Homogenaten der Rumpfmuskulatur kalt- und warmadaptierter Goldorfen bei Zusatz verschiedener Substrate. Das Homogenisations- und Inkubationsmedium enthielt: $13 \mathrm{mM}$ Phosphatpuffer $\mathrm{pH} 7,4 ; 5 \mathrm{mM} \mathrm{MgCl}$; $40 \mathrm{mM}$ Nicotinsäureamid; $250 \mathrm{mM}$ Saccharose; $10 \mathrm{mM}$ Substrat; $400 \mathrm{mg}$ Gewebe. Endvolumen $3 \mathrm{ml}$. Gasphase Luft. Versuchstemperatur $25^{\circ} \mathrm{C}$. Gewicht der Fische: 21 bis $37 \mathrm{~g}$ (ihre Zahl ist in Klammern angegeben). Die Prozentzahlen der Spalte 4 geben die Gewebearmung warmadaptierter Fische - bezogen auf die der kaltadaptierten Tiere - wieder. Die Sauerstoffaufnahme ist berechnet in $\mu 1 / 100 \mathrm{mg}$ Frischgewicht und Stunde. Versuchszeit: März bis April 1965

\begin{tabular}{|c|c|c|c|}
\hline Substratzusatz & $\mathrm{AT} 14^{\circ} \mathrm{C}$ & $\mathrm{AT} 22^{\circ} \mathrm{C}$ & $0 \%$ \\
\hline $\begin{array}{l}\text { Endogene Atmung } \\
\text { (ohne Substratzusatz) }\end{array}$ & $14,1 \pm 0,5$ & $5,6 \pm 0,4$ & 40,0 \\
\hline $10 \mathrm{mM}$ Succinat & ${ }_{(11)}^{34,5 \pm 1,5}$ & ${ }_{(11)}^{15,1 \pm 0,3}$ & 43,5 \\
\hline $5 \mathrm{mM}$ Pyruvat $+5 \mathrm{mM}$ Fumarat & $12,4 \underset{(6)}{ \pm} 0,1$ & $4,5 \pm 0,2$ & 36,2 \\
\hline $10 \mathrm{mM} \alpha$-Glycerophosphat & $12,1 \pm 0,4$ & $4,6 \pm 0,3$ & 38,0 \\
\hline $10 \mathrm{mM} \beta$-Hydroxybutyrat & $12,3 \underset{(5)}{ \pm} 0,2$ & $4,7 \underset{(5)}{ \pm} 0,2$ & 38,2 \\
\hline
\end{tabular}

Es ist weiter zu berücksichtigen, daß eine Leistungssteigerung des Leberstoffwechsels durch eine Anderung der Organgröße erfolgen kann; sie wird nicht erfaßt, wenn man den Sauerstoffverbrauch auf gleiche Gewebemengen bezieht. Zwischen verschieden adaptierten Orfen ließen sich aber keine Unterschiede in der Relation Lebergewicht zu Körpergewicht feststellen. Unabhängig von der Vorbehandlungstemperatur beträgt der Anteil der Leber am Körpergewicht 1,4 bis 1,8\% (ermittelt an Fischen der Gewichtsgruppe 10 bis $20 \mathrm{~g}$ ). Vom Goldfisch wird dagegen eine Zunahme der Relation Lebergewicht zu Körpergewicht bei tiefen Adaptationstemperaturen (AT $5^{\circ} \mathrm{C}$ zu AT $25^{\circ} \mathrm{C}$ berichtet (DAs 1967).

Wir verglichen ferner den glykolytischen Stoffwechselweg im Kiemen- und Muskelgewebe verschieden adaptierter Orfen. Einen Einfluß der Vorbehandlungstemperatur auf die Glykolyse von Fischgeweben stellten Trifonova (1958) und EkвERG (1962) fest.

Ohne Zusatz von Substrat zeigt nur das Kiemengewebe eine glykolytische Aktivität, sie erreicht bei warm- und kaltadaptierten Orfen die gleiche Höhe. Die Säure- 
Tabelle 3

Die Sauerstoffaufnahme von Geweben unterschiedlich adaptierter Silberorfen bei Zusatz von Natriumsuccinat und Fructose-1,6-diphosphat (FDP) als Substrat. Das Inkubationsmedium enthielt: $20 \mathrm{mM}$ Phosphatpuffer $\mathrm{pH} 7,4 ; 5 \mathrm{mM} \mathrm{MgCl} ; 100 \mathrm{mM}$ Saccharose; $20 \mathrm{mM}$ Substrat; $200 \mathrm{mg}$ Gewebe-Einwaage; Endvolumen $3 \mathrm{ml}$; Gasphase Luft. Versuchstemperatur $30^{\circ} \mathrm{C}$; Gewicht der Fische: 10,2 bis 16,7 g. Angabe der Sauerstoffaufnahme in $\mu 1 / 100 \mathrm{mg}$ Frischgewicht und Stunde; Versuchszeit: September bis Oktober 1964

\begin{tabular}{|c|c|c|c|c|}
\hline AT & $\begin{array}{l}\text { Gewebe/Zahl } \\
\text { der Tiere }\end{array}$ & $\begin{array}{c}\text { A } \\
\text { Succinat }\end{array}$ & $\begin{array}{l}\text { B } \\
\text { FDP }\end{array}$ & $\mathrm{B}$ in $\%$ von $\mathrm{A}$ \\
\hline \multirow{3}{*}{$15^{\circ} \mathrm{C}$} & Kiemen/5 & $64 \pm 3,6$ & $53 \pm 3,3$ & 83 \\
\hline & Muskelbrei/6 & $53 \pm 1,4$ & $15 \pm 0,7$ & 28 \\
\hline & Leberhomogenat/5 & $96 \pm 7,3$ & $31 \pm 2,8$ & 32 \\
\hline \multirow{3}{*}{$22^{\circ} \mathrm{C}$} & Kiemen/5 & $52 \pm 1,2$ & $48 \pm 0,9$ & 92 \\
\hline & Muskelbrei/6 & $38 \pm 1,2$ & $10 \pm 0,4$ & 26 \\
\hline & Leberhomogenat/5 & $87 \pm 7,6$ & $62 \pm 4,4$ & 71 \\
\hline \multicolumn{5}{|c|}{$\begin{array}{l}P \text {-Werte für die durch die AT bedingten Unterschiede: } \\
\text { Succinatveratmung der Kiemen }-0,014 ; \\
\text { Succinatyeratmung der Kiemen } 0,014 ;\end{array}$} \\
\hline
\end{tabular}

Tabelle 4

Die Glykolyse von Geweben verschieden adaptierter Goldorfen, gemessen an der Säurebildung unter anaeroben Bedingungen. Gasphase: $95,4 \% \mathrm{~N}_{2}$ und 4,6\% $\mathrm{CO}_{2}$; Versuchstemperatur: $25^{\circ}$ C. Anzahl der untersuchten Fische jeweils 6; Tiergewichte 24 bis $41 \mathrm{~g}$. Die Kohlendioxydausscheidung ist angegeben in $\mu 1 / 100 \mathrm{mg}$ Frischgewicht und Stunde. Versuchszeit: Juni 1965

\begin{tabular}{|lllc|}
\hline Gewebe & $\mathrm{AT}=8^{\circ} \mathrm{C}$ & $\mathrm{AT}=22^{\circ} \mathrm{C}$ & $P$-Werte \\
\hline Kieme (endogen) & $17,3 \pm 1,46$ & $15,2 \pm 1,25$ & $-\overline{0}$ \\
Kieme (mit Substrat) & $14,1 \pm 0,64$ & $11,0 \pm 0,56$ & 0,005 \\
Muskelbrei (mit Substrat) & $31,0 \pm 1,48$ & $25,7 \pm 0,91$ & 0,03 \\
Muskel-Homogenat (mit Substrat) & $33,6 \pm 1,33$ & $21,2 \pm 1,20$ & $<0,0002$ \\
\hline
\end{tabular}

bildung nach Substratzugabe $(30 \mathrm{mM}$ Glucose, $6 \mathrm{mM}$ Fructose-1,6-diphosphat, 22,5 $\mathrm{mM}$ Natriumpyruvat) wurde $45 \mathrm{~min}$ nach dem Messen der endogenen Glykolyse ermittelt. Zu diesem Zeitpunkt erniedrigt sich bereits die Säurebildung des Kiemengewebes etwas und schreitet progressiv fort, falls kein Substrat zugesetzt wird. Der Unterschied zwischen warm- und kaltadaptierten Fischen wächst mit zunehmender Schädigung der Gewebe. Im zweiten Versuchsabschnitt beträgt die prozentuale Differenz zwischen den Werten für kaltadaptierte $(=100 \%)$ und warmadaptierte Fische beim Muskelbrei $17 \%$, beim Homogenat $37 \%$.

Bei der Untersuchung einzelner Enzymaktivitäten fällt dagegen eine beginnende Gewebeschädigung nicht ins Gewicht. $\mathrm{Da}$ die oxydative Stoffwechselkapazität eines Gewebes hauptsächlich von den Aktivitäten seiner mitochondrialen Enzyme abhängt, überrascht es nicht, daß ähnlich wie die Succinodehydrogenase auch die Cytochromoxydase mit fallender Adaptationstemperatur an Aktivität zunimmt (Tab. 5).

Die Fermentaktivität in der Muskulatur der wärmer adaptierten Fische erreichte 
Tabelle 5

Die Aktivität der Cytochromoxydase in der Skelettmuskulatur von Goldorfen in Abhängigkeit von der Adaptationstemperatur. Angabe der Enzymaktivität als $\mathrm{O}_{2}$-Verbrauch in $\mu \mathrm{l} / 100 \mathrm{mg}$ Frischgewicht und Stunde. Anzahl der untersuchten Fische jeweils 5; Versuchszeit: April bis Mai 1965

\begin{tabular}{|rccc|}
\hline AT & Tiergewicht & $\begin{array}{c}\text { Enzym- } \\
\text { aktivität }\end{array}$ & P-Wert \\
\hline $8^{\circ} \mathrm{C}$ & 18 bis $42 \mathrm{~g}$ & $70 \pm 4,3$ & 0,005 \\
$16^{\circ} \mathrm{C}$ & 20 bis $28 \mathrm{~g}$ & $50 \pm 2,9$ & \\
\hline
\end{tabular}

nur $75 \%$ der Aktivität kaltgehaltener Tiere. Bei einer Erhöhung der Vorbehandlungstemperatur auf $22^{\circ} \mathrm{C}$ nahm dagegen die Cytochromoxydaseaktivität nicht weiter ab.

Auch an den Aktivitäten der Fructose-Aldolase, einem cytoplasmatischen Enzym, und der Malatdehydrogenase, einem in beiden Kompartimenten der Zelle vorkommenden Enzym, kann der Einfluß der thermalen Vorbehandlung nachgewiesen werden. Die Fermentaktivitäten im Kiemen-, Muskel- und Lebergewebe sind bei kaltgehaltenen Goldorfen höher als bei warmadaptierten Orfen (Tab. 6 und 7).

Tabelle 6

Die Aktivität der Fructose-1,6-diphosphat-Aldolase in Geweben der Goldorfe in Abhängigkeit von der Adaptationstemperatur der Fische. Aktivitätsangabe in Millieinheiten pro $10 \mathrm{mg}$ Frischgewicht. In Klammern: Anzahl der Messungen/Zahl der Fische. Körpergewicht zwischen 13 und $28 \mathrm{~g}$

\begin{tabular}{|lrcr|}
\hline Gewebe & AT $10^{\circ} \mathrm{C}$ & AT $20^{\circ} \mathrm{C}$ & P-Werte \\
\hline Kieme & $40 \pm 1,5(11 / 6)$ & $30 \pm 1,1(15 / 8)$ & $<0,0002$ \\
Muskel & $197 \pm 3,2(14 / 7)$ & $171 \pm 3,6(20 / 10)$ & $<0,0002$ \\
Leber & $116 \pm 2,1(12 / 7)$ & $103 \pm 2,2(14 / 7)$ & 0,0007 \\
\hline
\end{tabular}

Hinsichtlich der Vorbehandlungstemperatur verhält sich die Aldolaseaktivität im Kiemengewebe der Karausche ähnlich wie bei der Goldorfe (EkBERG 1962). Dagegen berichtet MuRPHX (1961) rom Goldfisch eine Zunahme der Malatdehydrogenaseaktivität im Lebergewebe mit steigender Adaptationstemperatur. Auch beim Bitterling zeigt die Aldolase des Muskelgewebes neben großen jahreszeitlichen Schwankungen eine inverse Kompensation, d. h. höhere Werte bei warmadaptierten Fischen (KRüGER 1962). Die Aldolase ist kein Schlüsselenzym im glykolytischen Abbauweg der Kohlenhydrate; in der Skelettmuskulatur findet sie sich in sehr großem Überschuß. Daher kann man aus den berichteten Aktivitätsänderungen nicht schließen, inwieweit die gesamte glykolytische Kapazität von der Adaptationstemperatur beeinflußt wird.

Bei den angewandten Untersuchungsmethoden wurden wohl quantitative Unterschiede der Enzyme erfaßt; die Messungen erfolgten bei Substratüberschuß. Höhere Meßwerte finden sich bei den kaltadaptierten Orfen, bei ihnen kann man daher mit einer gewissen Berechtigung eine verstärkte Proteinsynthese annehmen. Diese Syntheseprozesse werden in starkem Maße von Hormonen gesteuert (vgl. LITwaCK \& KRITCHEvsky 1964). Des öfteren wurde bei Fischen die Wirkung von Hormonen, insbeson- 


\section{Tabelle 7}

Die Aktivität der Malatdehydrogenase in Geweben der Goldorfe in Abhängigkeit von der Adaptationstemperatur der Fische. Aktivitätsangabe in Millieinheiten pro $10 \mathrm{mg}$ Frischgewicht. In Klammern: Zahl der untersuchten Fische; der Mittelwert von Parallelproben wurde der Berechnung zugrunde gelegt. Körpergewicht $\mathrm{zwischen} 14$ und $24 \mathrm{~g}$

\begin{tabular}{lllll|}
\hline Gewrebe & AT $10^{\circ} \mathrm{C}$ & \multicolumn{2}{c|}{ AT $20^{\circ} \mathrm{C}$} & $P$-Werte \\
\hline Kieme & $1818 \pm 82(10)$ & $1227 \pm 29(8)$ & $<0,0002$ \\
Muskel & $1309 \pm 10(10)$ & $1091 \pm 45(10)$ & 0,002 \\
Leber & $4909 \pm 109(10)$ & $3681 \pm 168(8)$ & $<0,0002$ \\
\hline
\end{tabular}

Tabelle 8

Die Aktivität der Malatdehydrogenase in Geweben der Goldorfe nach Thyreotropin-Gaben. Aktivitätsangabe in Millieinheiten pro $10 \mathrm{mg}$ Frischgewicht. In Klammern: Zahl der Versuche. Körpergewicht zwischen 13 und $21 \mathrm{~g}$

\begin{tabular}{|lll|}
\hline Gewebe & AT $10^{\circ} \mathrm{C}$ & \multicolumn{1}{c|}{ AT $20^{\circ} \mathrm{C}$} \\
\hline Kieme & $2045 \pm 141(6)$ & $1318 \pm 105(10)$ \\
Muskel & $1345 \pm 62(6)$ & $1164 \pm 73(9)$ \\
Leber & $6499 \pm 250(6)$ & $4272 \pm 186 \quad(8)$ \\
\hline
\end{tabular}

dere der Schilddrüsenhormone, auf Baustoffwechselprozesse untersucht (BARRINGTON et al. 1961, Gross et al. 1963, LA Roche et al. 1966, vgl. auch HoAr 1966). Eine hormonale Beeinflussung des Kohlenhydratstoffwechsels in Fischgeweben gelang HocHaCHKa (1962).

Wir prüften daher, ob sich die Aktivität der Malatdehydrogenase bei der Goldorfe durch Hormongaben ändern läßt. Hierzu erhielten die Versuchstiere Injektionen von Thyreotropin (Thyratrop, Fa. Ferring, Düsseldorf), und zwar 5 I. E. pro $100 \mathrm{~g}$ Körpergewicht, verteilt auf mehrere Tage.

Zehn bis vierzehn Tage nach der letzten Injektion wurde die Aktivität der Malatdehydrogenase im Kiemen-, Muskel- und Lebergewebe bestimmt; die Werte sind in Tabelle 8 zusammengestellt. Vergleicht man die Mittelwerte der Tabellen 7 und 8 , so zeigt nur die Malatdehydrogenase in der Leber kaltadaptierter Orfen einen signifikanten Anstieg nach der Behandlung mit Thyreotropin, welche sich demnach besonders im stoffwechselaktivsten Gewebe ausprägt. Da der Enzymumsatz eines Gewebes eng mit seiner Stoffwechselhöhe verbunden ist, kann man obigen Befund als Einflußnahme der Schilddrüsenhormone auf die Proteinsynthese interpretieren. Bei einer Beteiligung der Schilddrüse an der Leistungsadaptation der Orfen wäre ihre höhere Aktivität bei kaltadaptierten Fischen zu erwarten. Man konnte daher mit einer stärkeren Wirkung des Thyreotropins bei den warmadaptierten Fischen rechnen. Die Befunde stützen diese Annahme nicht.

Die hier vorgetragenen Ergebnisse an Goldorfengeweben beweisen eine Aktivitätszunahme oxydativer Enzyme mit fallender Adaptationstemperatur. Durch histologische Untersuchungen konnte gezeigt werden, daß in der Muskulatur der Orfe diese Enzymvermehrung mit einer Anderung der Mitochondrienzahl verbunden ist 
(JANKowsky \& Korn 1965). Der Anstieg der Enzymaktivitäten wird mit einer verstärkten Proteinsynthese während der Kälteanpassung zusammenhängen. So steigt der Einbau markierter Aminosäuren in Muskel-, Leber- und Kiemengewebe des Goldfisches mit sinkender Adaptationstemperatur (DAs \& Prosser 1967, DAs 1967, vgl. PROSSER 1967b); ein ähnlicher Befund wurde bei vergleichbaren Messungen des Eiweißstoffwechsels in der Froschmuskulatur gewonnen (Mews 1957, Jankowsky 1960). Auch BERLIN \& DeAN (1967) nehmen auf Grund elektronenoptischer Untersuchungen an Leberzellen der Regenbogenforelle eine größere Proteinsynthese bei tiefen Vorbehandlungstemperaturen an.

\section{Die Stoffwechselaktivität der Skelettmuskulatur des Aales}

Nach den Untersuchungen von Precht (1961) und Schultze (1965) weist der Sauerstoffverbrauch der dorsalen Skelettmuskulatur des Aales je nach Lage des Gewebes im Körper unterschiedliche Höhen auf, wobei die Atmungsaktivität der Rumpfmuskulatur nur $74 \%$ der des Schwanzgewebes erreicht. Eine Erklärung konnten die Autoren hierfür nicht geben. Dieser lagebedingte Unterschied in der Stoffwechselaktivität ist nicht korreliert mit Änderungen im Wasser-, Eiweiß- oder Fettgehalt (Thurow 1957, Schultze 1965) und unabhängig von der Adaptationstemperatur des Tieres. Eine orientierende histologische Untersuchung der Aalmuskulatur erschien somit angebracht, da in den Geweben vieler Tiere die Höhe des Stoffwechsels eine enge Beziehung zu ihrer morphologischen Struktur zeigt.

Um einen Überblick über die Muskulatur des Aales in den einzelnen Körperabschnitten zu gewinnen, entnahmen wir 8 bis $10 \mathrm{~cm}$ langen Steigaalen Stücke der dorsalen Körpermuskulatur und fertigten 10 bis $30 \mu$ dicke Querschnitte im Kryostaten an. Die Gefrierschnitte untersuchten wir histochemisch auf ihre Succinodehydrogenase-Aktivität und den Kohlenhydrat- und Fettgehalt (SDH-Reaktion mit nitro-BT, PAS- und Scharlachrot-Färbung in Anlehnung an BurcK 1966).

Dicht unter dem Corium befindet sich lateral im Rumpf- und Schwanzbereich eine 100 bis $120 \mu$ starke Muskelschicht, die aus 3 oder 4 nebeneinanderliegenden Fasern aufgebaut wird. Diese sarkoplasmareichen roten Fasern enthalten viel Fett und Polysaccharide und weisen eine hohe SDH-Aktivität auf; ihr Durchmesser beträgt ungefähr $37 \mu$. Im zentral gelegenen Hauptanteil der Rumpfmuskulatur beider Körperbereiche ist die SDH-Aktivität wesentlich geringer als in der äußeren Schicht. Hier finden sich weiße Muskelfasern mit einem Durchmesser von 77 bis $110 \mu$ (verglichen wurden jeweils die maximalen Durchmesser von Fasern in benachbarten Bereichen der Schnitte). Ferner ergab sich aus den Querschnittsbildern, daß im Schwanz nur 5 bis $8 \%$ der gesamten Dorsalmuskulatur auf die äußere, stoffwechselaktive rote Muskelschicht entfallen; im Vorderkörper beträgt ihr Anteil 1 bis $2 \%$. Ahnlich ist die Körpermuskulatur adulter Aale (Körperlänge etwa $50 \mathrm{~cm}$ ) aufgegliedert. Im Schwanz liegen unter dem fetthaltigen subcutanen Bindegewebe 0,8 bis $1,2 \mathrm{~mm}$ starke Muskelbündel, die aus 10 bis 15 roten Fasern bestehen. Der mittlere Durchmesser der Einzelfaser schwankt zwischen 86 und $141 \mu$. Die Fasern der inneren Muskulatur sind ungefähr $200 \mu$ stark. Bereits makroskopisch ist die Gliederung der somatischen Aal- 
muskulatur in rote und weiße Anteile zu erkennen. An Lupenaufnahmen von Körperquerschnitten wurde bei adulten Aalen ein ähnliches Mengenverhältnis zwischen weißen und roten Muskelfasern wie bei Jungaalen gefunden.

Un diese histologischen Gegebenheiten mit den Angaben von ScHultze (1965) über die in-vitro-Atmung der Aalmuskulatur vergleichen zu können, führten wir Bestimmungen der Cytochromoxydaseaktivität durch. Die Aktivität dieses Ferments gilt als Maß für die maximale oxydative Stoffwechselkapazität eines Gewebes (JANSKY 1963). Entnommen wurden die Muskelproben an den gleichen Körperstellen, wie sie Schultze angibt. Diese Proben der epaxonischen Rumpfmuskulatur oberhalb des Septum laterale werden in den 'Tabellen 9 und 10 als "gesamte Muskulatur" bezeichnet. Einen Teil der Muskelstücke trennte ich in eine „äußere“, rote Fasern enthaltende, und in eine „innere“, nur weiße Fasern enthaltende Muskulatur. Im Rumpfbereich wurden 20 bis $25 \%$ der "gesamten Muskulatur" dem peripheren Anteil zugeordnet, beim Muskelstück aus dem Schwanzbereich ungefähr $44 \%$ als „äußere Muskulatur“ eingesetzt. Somit enthielt der „äußere Muskel“ noch beträchtliche Mengen an weißen Muskelfasern.

Bestimmungen der Cytochromoxydaseaktivität in den so benannten Muskelanteilen kaltadaptierter Aale sind in Tabelle 9 zusammengefaßt. Der Unterschied zwischen den Fermentaktivitäten in der gesamten Vorderkörpermuskulatur und der gesamten

\section{Tabelle 9}

Die Aktivität der Cytochromoxydase in verschiedenen Bereichen der Skelettmuskulatur des Aales. Die Enzymaktivität ist angegeben als $\mathrm{O}_{2}$-Verbrauch in $\mu \mathrm{l} / 100 \mathrm{mg}$ Muskelfrischgewicht und Stunde. Adaptationstemperatur 8 bis $10^{\circ} \mathrm{C}$. Zahl der Versuchstiere 6; ihr Gewicht lag zwischen 251 und $306 \mathrm{~g}$, ihre Länge betrug 53 bis $56 \mathrm{~cm}$. Versuchszeit April 1967. Die Bezeichnung der Gewebeproben ist im Text erläutert

\begin{tabular}{|lcc|}
\hline & Vorderkörpermuskulatur & Hinterkörpermuskulatur \\
\hline gesamte Muskulatur & $173 \pm 5,6$ & $295 \pm 13,0$ \\
äußere Muskulatur & $160 \pm 19,4$ & $347 \pm 15,9$ \\
innere Muskulatur & $155 \pm 10,2$ & $162 \pm 13,1$ \\
\hline
\end{tabular}

Tabelle 10

Prozentuale Unterschiede der Cytochromoxydaseaktivität und des Nucleinsäuregehalts in verschiedenen Bereichen der Aalmuskulatur. Die Prozentwerte wurden für jedes Versuchstier gesondert bestimmt; die Mittelwerte für die Cytochromoxydase beruhen auf den Messungen der Tabelle 9; der Nucleinsäuregehalt wurde an 5 Aalen ermittelt

\begin{tabular}{|c|c|c|c|c|c|}
\hline \multirow{3}{*}{$\begin{array}{l}\text { Enzyme } \\
\text { bzw. Stoffe }\end{array}$} & \multicolumn{3}{|c|}{$\begin{array}{l}\text { Vorderkörpermuskulatur } \\
\text { Angaben in \%, bezogen auf den } \\
\text { Gehalt entsprechender Muskeln } \\
\text { des Hinterkörpers }\end{array}$} & \multicolumn{2}{|c|}{$\begin{array}{l}\text { Hinterkörpermuskulatur } \\
\text { Prozentuale Unterschiede in } \\
\text { den Muskelschichten; ge- } \\
\text { samte Muskulatur }=100 \%\end{array}$} \\
\hline & gesamte & $\begin{array}{c}\text { äußere } \\
\text { Muskulatur }\end{array}$ & & $\begin{array}{r}\text { äußere } \\
M_{u}\end{array}$ & $\begin{array}{l}\text { innere } \\
\text { ur }\end{array}$ \\
\hline & $62 \pm 2,0$ & $50 \pm 6,3$ & $100 \pm 5,3$ & $123 \pm 3,0$ & $57 \pm 3,4$ \\
\hline Nucleinsäuren & $90 \pm 2,6$ & $80 \pm 4,3$ & $97 \pm 3,0$ & $107 \pm 2,3$ & $95 \pm 1,8$ \\
\hline DNS & $90 \pm 4,0$ & $84 \pm 3,2$ & $96 \pm 6,2$ & $106 \pm 4,7$ & $96 \pm 4,6$ \\
\hline
\end{tabular}


Muskulatur des Schwanzes (in der Mitte zwischen Schwanzspitze und After) entspricht annähernd der für die Aktivität der Succinodehydrogenase ermittelten Differenz (Schultze 1965). Wie aus den Werten für die „äußere Muskulatur" ersichtlich, ist der Unterschied aber ausschließlich auf abweichende Fermentaktivitäten dieser Muskelschicht zurückzuführen. Der „innere" Anteil der Dorsalmuskulatur zeigt im Vorderund Hinterkörper eine gleich hohe Aktivität der Cytochromoxydase.

Gemessen am Gesamtstickstoff, ist der Eiweißgehalt der Aalmuskeln im Vorderkörper etwas höher als im Schwanzbereich; er kann somit nicht für das lagebedingte Verhältnis in der Gewebeatmung verantwortlich sein. Der Nucleinsäuregehalt eines Gewebes stellt häufig einen besseren Bezugspunkt für Stoffwechseluntersuchungen dar als das Frisch-oder Trockengewicht bzw. der Eiweißgehalt (THomson et al. 1953, Gray \& Deluka 1956). Der DNS-Gehalt pro Zelle ist eine relativ konstante Größe, die kaum von exogenen Einflüssen, z. B. einer geänderten Ernährung, abhängt. Tabelle 10 zeigt, daß leichte prozentuale Unterschiede im Nucleinsäuregehalt zwischen den verschiedenen Bereichen der Aalmuskulatur bestehen; die höheren Werte für die DNS und die Summe der Nucleinsäuren in der äußeren Muskulatur entsprechen ihrer größeren Faserzahl. Auch stimmt mit den histologischen Befunden überein, daß in der Muskulatur des Vorderkörpers relativ weniger Nucleinsäuren enthalten sind als in der des Hinterkörpers; die Zahl der roten Muskelfasern ist im Rumpfbereich niedriger. Die Signifikanz dieser Differenzen wird bei strenger Trennung beider Fasertypen zunehmen.

Weiße und rote Muskelfasern bauen die Skelettmuskulatur der Vertebraten auf, wobei der aktivere Muskel häufig einen höheren Anteil an roten Fasern enthält (WaLLs 1960). Bei den Muskelfasern der Warmblütler besteht ein Zusammenhang zwischen dem oxydativen Stoffwechsel und dem Faserdurchmesser; die schmaleren roten Fasern haben mehr Mitochondrien und eine höhere Gewebeatmung (George \& Scaria 1958). Nach neueren Untersuchungen an Säugern erscheint es überhaupt nicht zulässig, von einem Stoffwechsel der Muskulatur an sich zu sprechen, sondern nur vom Stoff wechsel eines einzelnen Muskels. Die Funktion weißer Muskeln wird vorwiegend durch Glykolyse getragen; die tonische Funktion roter Muskeln stützt sich auf die Energie des aeroben Kohlenhydratabbaus. Das Stoffwechselverhältnis zwischen Glykolyse und Zellatmung kann sich bei beiden Funktionstypen um das 20-bis 30 fache unterscheiden (vgl. PetTe 1966).

Auch bei Fischen differieren weiße und tote Skelettmuskelfasern in Struktur und Funktion (BARETs 1961, Bone 1966). Beim Karpfen ist nach KROMPECHER et al. (1966) die Cytochromoxydaseaktivität in der roten Muskulatur mehr als doppelt so groß wie in der weißen; nach PARTMANN (1965) enthält auch nur die rote Karpfenmuskulatur wesentliche Mengen an Glutathion, welches bei der Zellatmung eine Rolle spielt. Einen höheren Mitochondriengehalt in der roten Fischmuskulatur fand UEMATSU (1954). Kürzlich von mir begonnene elektronenoptische Untersuchungen der roten und weißen Aalmuskulatur bekräftigen die enzymatischen Befunde. In Längsschnitten weißer Fasern liegt der Flächenanteil angeschnittener Mitochondrien unter $1 \%$, in den roten Fasern erreicht er dagegen Werte um $15 \%$. Lediglich in der roten Muskulatur finden sich zwischen den Fibrillen langgestreckte Mitochondrien von erheblicher Größe; bei einer Breite um $1 \mu$ werden Längen bis zu 8,5 $\mu$ erreicht. Dicht neben und zwi- 
schen diesen Mitochondrien liegen häufig Fetttropfen. Insbesondere in der Nähe von Kapillaren fällt der Mitochondrienreichtum im Sarkoplasmamantel der roten Fasern auf. Die Fasern der weißen Aalmuskulatur enthalten nur unter dem Sarkolemm wenige kleine Mitochondrien (JANKOWSKY 1968).

Bei niederen Wirbeltieren kommen rote Fasern meist nur in stark beanspruchten Muskeln vor (MAximow \& Bloom 1957). In der Rumpfmuskulatur der Cypriniden und Salmoniden ist der Musculus superficiales trunci rot; er ist an der Seitenlinie am dicksten entwickelt und wird dorsal- sowie ventralwärts allmählich dünner (NISHI 1938). Die stärkere Ausbildung roter Muskelbündel beim Aal ist im Zusammenhang mit seiner typischen Körperform und Fortbewegungsweise zu sehen. Hinweise auf die funktionelle Bedeutung der roten Aalmuskeln geben die Untersuchungen von Prosser et al. (1965). Danach zeigen die tonischen Potentiale in der dorsalen Rumpfmuskulatur den gleichen lagebedingten Unterschied zwischen dem Vorderkörper und dem Schwanz wie die Gewebeatmung. Es wurden in erster Linie Muskelpotentiale der roten Fasern erfaßt, da die Elektroden 2 bis $4 \mathrm{~mm}$ tief inseriert wurden. Beim Trennen des Rückenmarks etwa in der Körpermitte bleibt der lagebedingte Unterschied bestehen. Adaptiert man den Vorderkörper eines Aales an $14^{\circ} \mathrm{C}$ und seinen Hinterkörper an $25^{\circ} \mathrm{C}$, so ändern sich die Gewebeatmung und die Zahl der tonischen Muskelpotentiale gleichsinnig. Obwohl bei diesen Messungen die Gliederung in weiße und rote Fasern unberücksichtigt blieb, geben sie indirekt Auskunf über den Einfluß der Adaptationstemperatur auf die rote Muskulatur.

Bewertet man das Anpassungsvermögen eines Gewebes an seinem Sauerstoffverbrauch, so liegt es auf der Hand, daß sich diese Leistungsadaptation hauptsächlich an Geweben mit überwiegend oxydativem Stoffwechsel manifestiert. ScHultze ging von folgender Uberlegung aus: „Falls es möglich ist, den Sauerstoffverbrauch eines großen Teiles des Körpergewebes eines Tieres nachweisbar zu verändern, müßte sich diese Stoffwechseländerung auf den Gesamtsauerstoffverbrauch des betreffenden Tieres auswirken." Er sah in der Skelettmuskulatur d a s Organsystem mit anteilmäßig bedeutendem Sauerstoffverbrauch. Diese Annahme erscheint unberechtigt, wenn man berücksichtigt, daß nur ein kleiner Teil der Muskulatur, nämlich die roten Fasern, oxydativ, der überwiegende Anteil glykolytisch arbeitet. Wittenberger \& Diaciuc (1965) folgern aus ihren Untersuchungen am Karpfen eine „Leberfunktion“ der roten Fasern. Auf Grund ihrer guten Durchblutung und des Mitochondrienreichtums dürfte die rote Muskulatur in der Lage sein, zugeführte Glykolyseprodukte der weißen Fasern oxydativ zu verwerten.

\section{UNTERSUCHUNGEN DER SAUERSTOFFSPANNUNG IM BLUT UND IN DER MUSKULATUR DES AALES}

\section{Methoden}

Materia I : Die Versuche wurden in der Zeit von August 1964 bis März 1967 an Silberaalen durchgeführt. Das Gewicht der Fische lag zwischen 250 und $300 \mathrm{~g}$ (Extremwerte 150 bis $580 \mathrm{~g}$ ). Ihre durchschnittliche Länge betrug $54 \mathrm{~cm}$ (Extrem- 
werte 45 bis $65 \mathrm{~cm}$ ). Die in den Küstengewässern der Ostsee gefangenen Aale hälterten wir in großen, von Leitungswasser durchströmten Kachelbecken bei 16stündigem Langtag. Eine Fütterung unterblieb. Die Anpassung an die Adaptationstemperaturen erfolgte in den Hälterungsbecken.

Me $ß$ w e r t e : Gemessen wurden Atemfrequenz, Herzfrequenz und Sauerstoffdrucke im Blut und Gewebe der Aale. Zur Bestimmung der Atemfrequenz haben wir mehrfach hintereinander die Zeit für 10 Kiemendeckelbewegungen (KD) gestoppt und

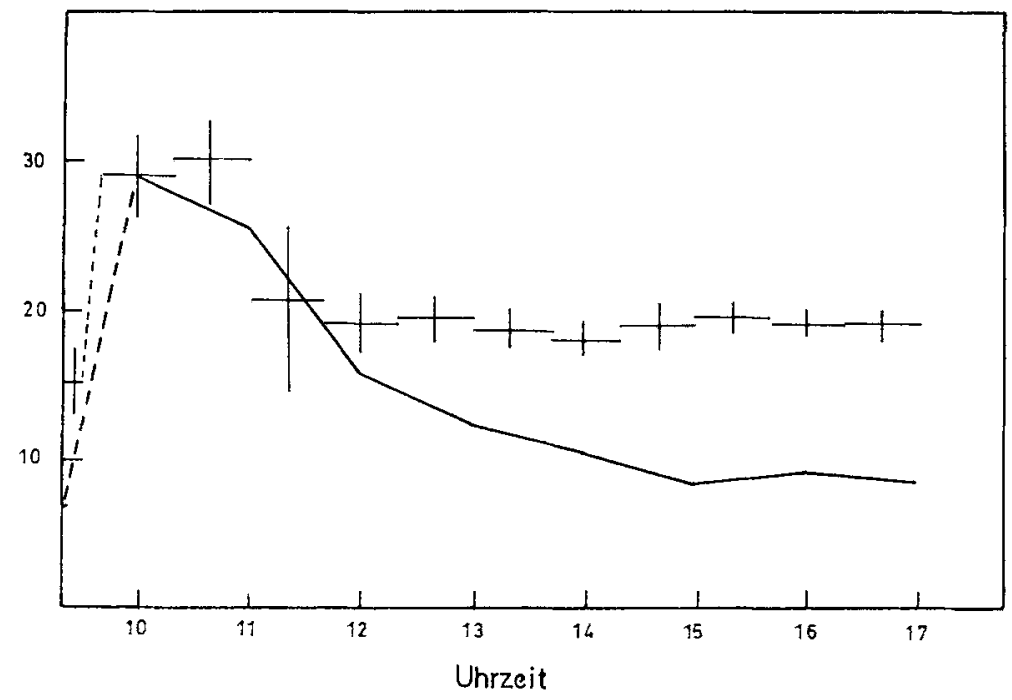

Abb. 1: Anderung der Kiemendeckelfrequenz beim Umsetzen eines Aales aus dem Hälterungsbecken (Wassertemperatur $10,5^{\circ} \mathrm{C}$ ) in ein Aquarium (Wassertemperatur 12,60 $\mathrm{C}$ ). Die ausgezogene Linie gibt die tatsächliche Zahl der Kiemendeckelbewegungen pro min unter Berücksichtigung der Atempausen wieder. Angegeben ist ferner die aus der Zeit für 10 Kiemendeckelbewegungen errechnete Atemfrequenz $(\mathrm{KD} / \mathrm{min})$ und ihre Streuung

aus dem Mittelwert ihre Frequenz pro Minute ( $\mathrm{KD} / \mathrm{min})$ errechnet. Die Ventilation der Fische, insbesondere des Aales, ist nicht gleichmäßig; auf Perioden hoher Atemfrequenz folgen mehr oder weniger lange Atempausen (vgl. van DaM 1938).

Bei nicht gestörten Aalen ist diese Erscheinung besonders ausgeprägt. Beunruhigte Tiere weisen selten Ventilationspausen auf. In Abbildung 1 ist der Unterschied zwischen der tatsächlichen Zahl der Kiemendeckelbewegungen pro min und der nach oben angeführten Methode berechneten Atemfrequenz graphisch dargestellt.

$\mathrm{Da}$ bei Durchführung unserer Messungen eine Beunruhigung der Tiere nicht zu vermeiden war, wird in den meisten Fällen die angegebene Atemfrequenz nicht wesentlich von der tatsächlichen abweichen. Eine kontinuierliche Registrierung der Atmung war leider nicht möglich. Die Herzfrequenz wurde in gleicher Weise wie die Atemfrequenz bestimmt und berechnet ( $\mathrm{HF} / \mathrm{min})$.

Zur Messung der Sauerstoffdrucke im Respirationswasser, Blut und Gewebe standen ein „Physiological Gas Analyser 160" und drei Mikro-Elektroden zur Verfügung; die Mehrzahl der Meßwerte wurde fortlaufend mit einem Laborschreiber registriert 
(alle Geräte sind Produkte der Fa. Beckman Instruments Inc., CaI., USA). Die Elektrodeneichung, Beziehung zwischen Sauerstoffdruck und Reduktionsstrom, erfolgte vor und nach jedem Versuch. Als Eichlösungen dienten mit Stickstoff (reinst) äquilibriertes Wasser, sauerstofffreie Glucoselösung (enzymatischer $\mathrm{O}_{2}$-Verbrauch mit Glucoseoxydase) und mit Außenluft äquilibriertes Wasser. Weiterhin wurden mit Wasserdampf gesättigte Luft und Wasserproben verschiedenen Sauerstoffgehalts verwendet. Den absoluten Sauerstoffgehalt der Eichlösungen kontrollierten wir nach der Winklermethode. Eine Linearität der Eichkurven und die Übereinstimmung zwischen Gas- und Flüssigkeitseichung war in allen Fällen gewährleistet. Bei Mehrfachanalysen der gleichen Probe lag die Streuung unter $1 \%$; bei Berücksichtigung der Genauigkeit des Meßverstärkers und der Analysengenauigkeit der Eichlösungen ist aber mit einem relativen Fehler von ca. $2 \%$ bei den Meßwerten zu rechnen. In allen Fällen, in denen Eich- und Meßtemperatur voneinander abwichen, wurde der Temperaturkoeffizient der Elektroden bestimmt und der Meßwert gemäß der Vorschrift PG-TB-002 der Fa. Beckman graphisch korrigiert. Eine Bluteichung der Elektroden erfolgte nicht. Da bekanntlich im Blut das Verhältnis zwischen gelöster Gasmenge und Gasdruck nicht konstant ist, können die gemessenen Sauerstoffdrucke nicht direkt zur Berechnung des Sauerstoffgehaltes im Aalblut herangezogen werden. Die Sauerstoffdrucke sind in allen Fällen in mmHg angegeben.

$\mathrm{Narkose}$ : Vor der Narkose in gut durchlüfteter 0,7\% \% iger Urethan-Lösung hielten wir die Aale 1 Stunde lang bei der Labortemperatur von 20 bis $22^{\circ} \mathrm{C}$ in luftgesättigtem Leitungswasser. Je nach Art des vorgesehenen Eingriffs verblieben die Fische unterschiedlich lange im Narkosebad. Im allgemeinen genügte ein 60 minütiger Aufenthalt, um eine ausreichende Narkosetiefe zu erzielen und jede aktive Bewegung der Fische auszuschließen. Kaltadaptierte Aale benötigten meist eine etwas kürzere Narkosedauer als warmgehaltene Fische (vgl. E. v. BudDENBrock 1960). Gemessen an der prozentualen Abnahme der Atemfrequenz war jedoch bei unterschiedlich adaptierten Aalen keine Differenz im Narkoseverlauf festzustellen (Abb. 2).

Durchführung der Messungen: Zur Bestimmung der Sauerstoffspannung in der Muskulatur bzw. im Wasser der Kiemenhöhle wurden leicht narkotisierte Aale auf einem Aalhalter (vgl. Abb. 3; AH) in normaler Bauchlage festgebunden und in ein Wasserbad eingebracht. Die Temperatur des Wasserbades konnte durch zwei Tauchkühler (TK 64, Fa. Colora, Lorch) und zwei Heizer beliebig verändert werden (vgl. Abb. 3). Mit Hilfe der als Injektionskanüle ausgebildeten Elektrodenhalterung (riley needle) durchstießen wir die Haut des Aales und führten durch diese Offnung die Mikro-Elektrode ohne Kanüle ca. $3 \mathrm{~cm}$ in die Muskulatur ein. Zur Messung des Sauerstoffdrucks in der Kiemenhöhle wurde die Elektrode durch eine Opercularöffnung vorsichtig etwa $2 \mathrm{~cm}$ vorgeschoben und unter fortlaufender Kontrolle der Atemfrequenz die Minima der Meßwerte registriert.

Um den Sauerstoffdruck im Ventrikelblut zu bestimmen, mußte der Aal in Rückenlage auf dem Aalhalter festgebunden werden. Durch einen 3 bis $4 \mathrm{~cm}$ langen medianen Schnitt, cranial vom Brustflossenansatz, legten wir das Herz bei zunächst ungeöffnetem Pericard frei und warteten bei abflachender Narkose eine regelmäßige Atemtätigkeit $a b$. Nach Offfnung des Pericards wurde die riley needle mit der MikroElektrode in den Ventrikel eingestochen und über einen Zeitraum von mehreren 
Minuten in 15-Sekunden-Abständen der $\mathrm{pO}_{2}$ abgelesen; eine Möglichkeit zur kontinuierlichen Registrierung war seinerzeit nicht gegeben. Die vor der Messung des Sauerstoffdrucks in den caudalen Hauptgefäßen erforderlichen Eingriffe und Präparationen konnten nur am tief narkotisierten Aal vorgenommen werden. Während dieser Zeit

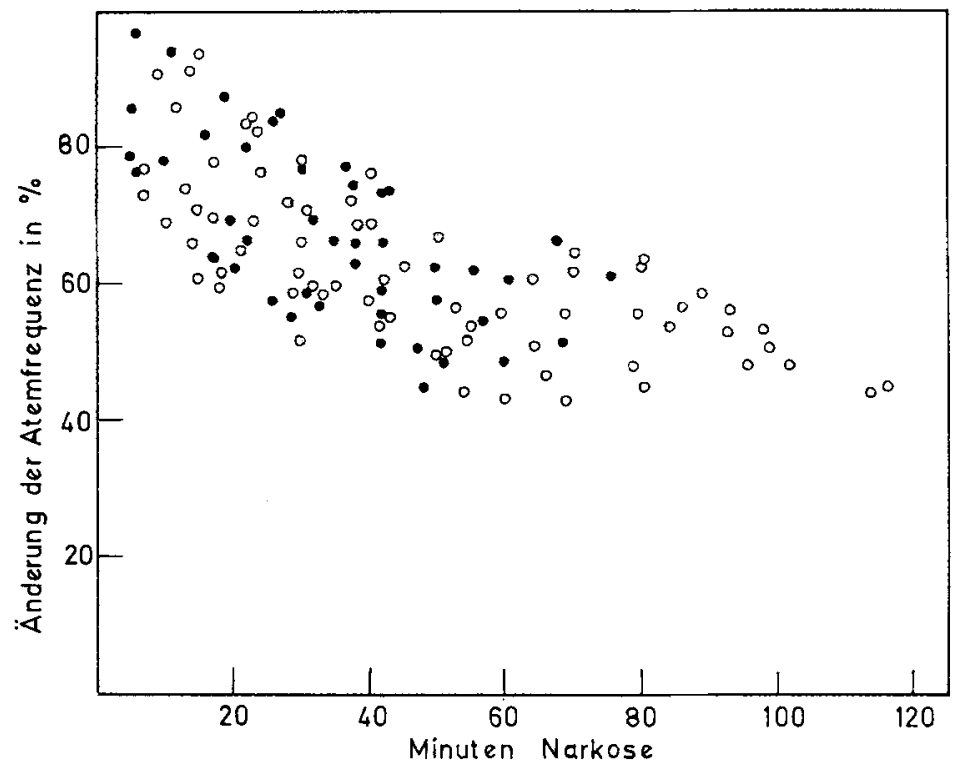

Abb. 2: Anderung der Atemfrequenz verschieden adaptierter Aale während einer Narkose in $0,7^{0} \%$ iger Urethan-Lösung. Versuchstemperatur $22^{\circ} \mathrm{C}$. $=$ bei $9^{\circ} \mathrm{C}$ gehälterte Aale (7 Tiere); $\circ=$ bei $22^{\circ} \mathrm{C}$ gehälterte Aale (12 Tiere)

wurde der Fisch künstlich beatmet; hierzu führten wir einen Plastikschlauch in die Mundöffnung des in Rückenlage auf dem Aalhalter befestigten Versuchstieres ein und leiteten $0,7 \%$ ige Urethan-Lösung über die Kiemen (vgl. Abb. 3). Drohte die Herztätigkeit des Fisches zu erlahmen, wechselten wir die Narkoselösung gegen gleich temperiertes Leitungswasser aus. Der Wasserzufluß konnte je nach Bedarf variiert werden (Drosselventil in Abb. 3). Die Caudalgefäße mußten selbstverständlich außerhalb des Wasserbades freigelegt werden. Zunächst injizierten wir in die hypaxonische Muskulatur - 3 bis $10 \mathrm{~cm}$ hinter dem Anus - $1 \mathrm{ml}$ Xylocain-Epinephrin (2\% $/ \mathrm{ig}$, Pharma-Stern AG, Wedel) in 0,2-ml-Dosen an mehreren Stellen.

Die Injektion des Lokalanästhetikums verringerte die Blutung bei der nach 15 bis 20 min beginnenden Präparation des Hämalkanals. $5 \mathrm{~cm}$ hinter der Analöffnung wurde mit einem Mikrotommesser entlang des medianen ventralen Septums beiderseits der Hämalbögen die Muskulatur auf eine Länge von 4 bis $5 \mathrm{~cm}$ eingeschnitten. Senkrecht zu obiger Schnittrichtung führten wir ca. $8 \mathrm{~mm}$ oberhalb des horizontalen Myoseptums waagerechte Schnitte bis zum Hämalkanal. Die dadurch abgelöste Muskulatur wurde auf eine Länge von 5 bis $6 \mathrm{~cm}$ herausgeschnitten. Hauptsächlich im Bereich der peripheren roten Muskulatur auftretende Blutungen stillten wir mit Eisen- 
III-Chlorid und einem großflächigen Thermokauter. Durch die gewählte Schnittführung zerstörten wir nicht die in Höhe des Seitenlinienorgans abgehenden Gefäße. Mit einer erhitzten Drahtschlinge verödeten wir vorsichtig die zwischen den Hämalbögen verlaufenden feinen Adern und öffneten dann die Knochenspannungen des Hämalkanals mit Hilfe starker Klemmen.

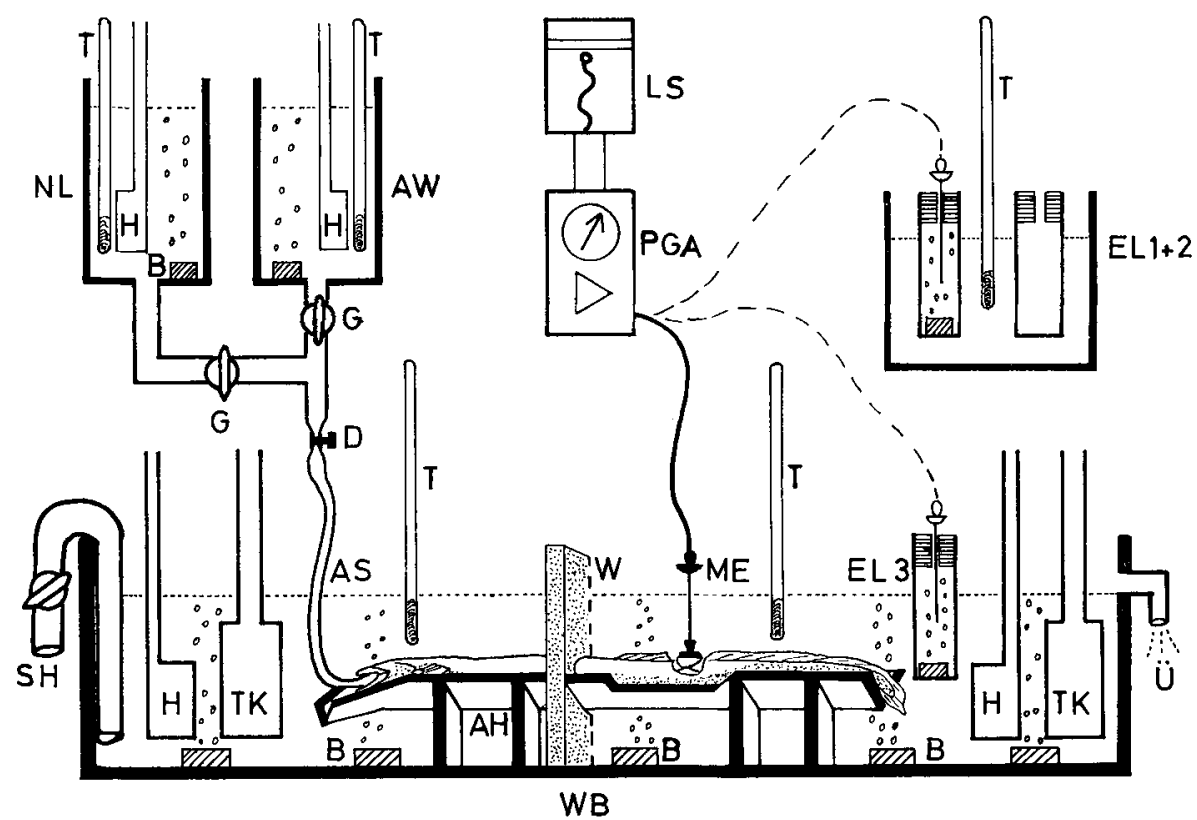

Abb. 3: Schema der Versuchsanordnung zur fortlaufenden Messung des Sauerstoffdrucks im Blut der Caudalvene. AH: Aalhalter; AS: Atemschlauch; AW: Atenzwasser; B: Beliuftung; D: Drosselventil; EL: Eichlösungen (1+3 luftgesätrigt, 2 sauerstoff frei); G: Glashähne; H: Heizung; LS: Laborschreiber; ME: Mikro-Elektrode; NL: Narkoselösung; PGA: physiologischer Gas-Analysator; SH: Saugheber; T: Thermometer; TK: Tauchkühler; Ü: Úberlauf; W: Trennwand; WB: Wasserbad

$\mathrm{Um}$ den $\mathrm{pO}_{2}$ in der Schwanzvene kontinuierlich zu registrieren, wurde das Blut durch Plastikkanülen an der Mikro-Elektrode in einer Meßkammer vorbeigeführt (s. unten) und das auf dem V-förmigen Aalhalter festgebundene Versuchstier in das Wasserbad eingebracht. Das Schema der Abbildung 4 entspricht diesem Präparationszustand. Bis zum Auftreten spontaner Atembewegungen leiteten wir durch den Atemschlauch (AS) temperiertes Wasser in die Mundhöhle des Aales ein; während der Messungen ventilierte der Aal das gut durchliiftete Wasser des etwa 601 fassenden Versuchsbeckens. Eine Plastiktrennwand konnte beliebig in die Versuchswanne eingesetzt und dadurch das vordere Drittel des Tieres einer bis zu $10^{\circ} \mathrm{C}$ gegenüber dem restlichen Körper differierenden Temperatur ausgesetzt werden. Eine schnelle Abkühlung der Kopfregion und Einleiten von Narkoselösung waren immer dann notwendig, wenn das Tier mit aktiven Bewegungen begann, nämlich nach langer Versuchszeit und bei hohen Wassertemperaturen. Die zugeführte Narkoselösung leiteten wir durch einen 
Saugheber $(\mathrm{SH})$ ab. Im Schema ist ferner die Anordnung der Eichlösung $\left(\mathrm{E}_{1}, 2,3\right)$ zur Bestimmung des Temperaturkoeffizienten der Elektrode angedeutet. Der $\mathrm{pO}_{2}$ wurde unter Kontrolle der Atemfrequenz und möglichst flacher Narkose des Aales bei verschiedenen Versuchstemperaturen über mehrere Stunden (längste Versuchsdauer 9 Stunden) gemessen. Zur Auswertung gelangten nur Registrierungen, die mindestens 6 min, durchschnittlich 10 bis $15 \mathrm{~min}$, konstant blieben.

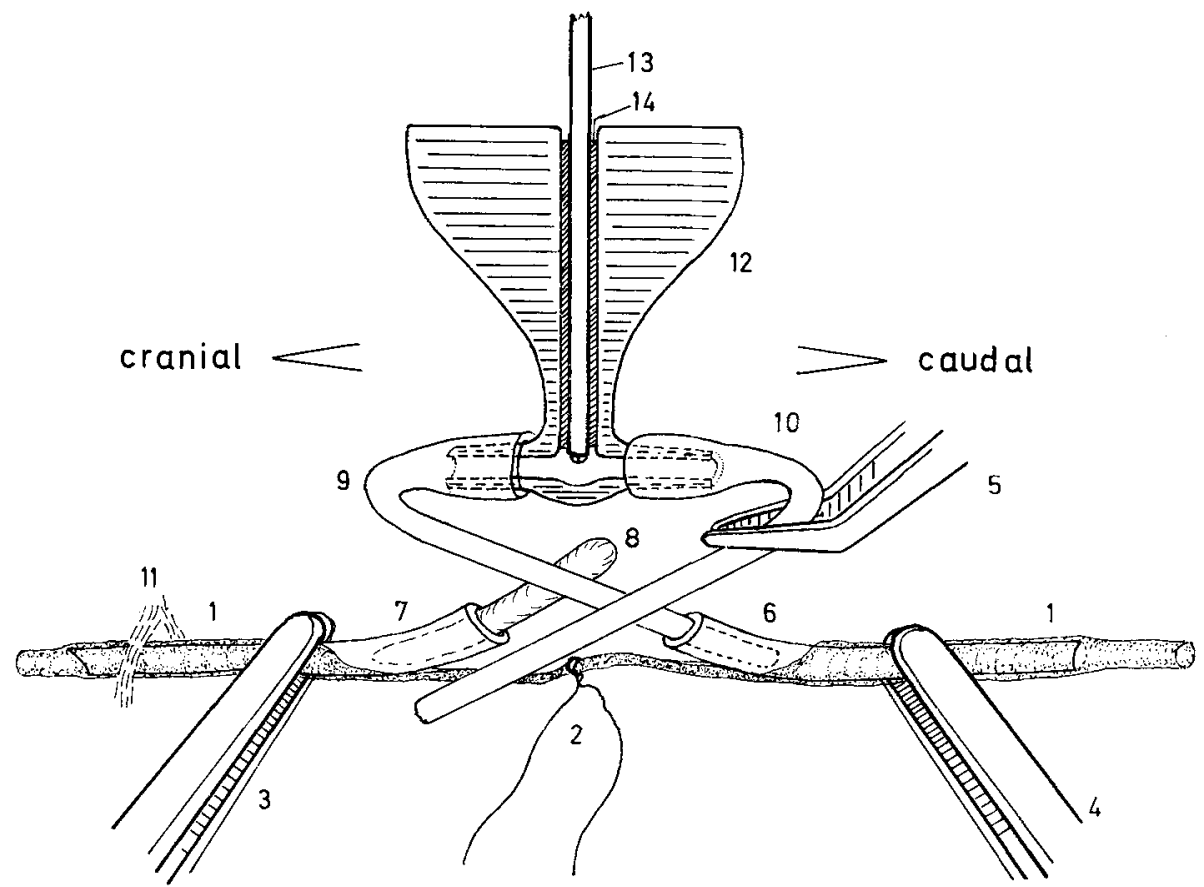

Abb. 4: Schematische Darstellung der Präparation beim Einfügen der Meßkammer in den Blutstrom der Caudalvene. (Zeichenerklärungen im Text)

Die Form der Meßkammer (12) aus $4 \mathrm{~mm}$ starkem Plexiglas ist der Abbildung 4 zu entnehmen.

Zwei Bohrungen sind T-förmig angeordnet. Der rohrförmig ausgearbeitete, waagerechte Schenkel des $T$ enthält eine $1 \mathrm{~mm}$ starke Bohrung, die während der Messung von venösem Blut durchströmt wird. In die längere, $2 \mathrm{~mm}$ starke Bohrung wird die Mikro-Elektrode (13) einschließlich ihrer Halterung mit einer Gummidichtung (14) gasdicht eingepaßt. Die eigentliche Spitze der Mikro-Elektrode ragt frei in den Blutstrom hinein; ein Blutstau an der Elektrode trat nicht auf, da an der Kreuzung beider Bohrungen das Lumen erweitert war. Um die Meßkammer in den Blutkreislauf des Aales einzufügen, wurde die freigelegte Vene (1) etwa in der Mitte mit einem doppelten Seidenfaden (2) abgebunden. Damit das Gefäß nicht kollabierte, klemmten wir kurz vor dem Abbinden seinen cranialen Teil mit einer starken Pinzette (3) ab. Zwischen der Pinzette und der Fadenschlinge wurde die Vene mit einer feinen Irisschere geöffnet und eine mit einem Kunststoffstopfen (8) verschlossene Polyäthylen- 
kanüle (7) so weit eingeführt, daß die Spitze der Kanüle in den ungeöffneten Hämalkanal (11) hineinreichte. Die Kanüle erhielt hierdurch einen Halt und wurde nicht bei lateralen Verschiebungen verschlossen. In gleicher Weise brachten wir in caudaler Richtung eine zweite Kanüle (6) in das Gefäß ein. Mit einer Pinzette (4) klemmten wir die caudale Kanüle ab und verbanden sie durch den Kunststoffschlauch (9) mit der Meßkammer (12). Beim Ơffnen der Pinzette (4) strömte das Blut in die Meßkammer. Die Arterienklemme (5) stoppte den Blutfluß, bis auch die craniale Kanüle (7) mit der Meßkammer verbunden war. Durch diese Anordnung ließ sich der Blutweg luftblasenfrei füllen. Einzelne Teile wechselten wir beim Auftreten von Gerinnseln aus. Trotzdem konnte leider die Mehrzahl der Versuche nicht verwertet werden, weil Blutgerinnsel innerhalb der Vene oder größere Blutungen aus Nebengefäßen auftraten. Es gelang uns nicht, die caudale Arterie in ähnlicher Weise zu überbrücken, da die Wandung dieses Gefäßes viel dünner und der Blutdruck in ihm erheblich größer ist.

Eine vereinfachte Versuchsdurchführung diente zum Messen des $\mathrm{pO}_{2}$ in der Schwanzarterie; sie wird im folgenden als "Kanülenmethode“ bezeichnet. Es wurden ähnliche Meßkammern wie in Abbildung 4 verwendet. Ein kurzer Schenkel der Tförmigen Bohrung enthielt die $1 \mathrm{~cm}$ lange Spitze einer Injektionskanüle, der andere kurze Schenkel war durch einen Polyäthylenschlauch mit einer Tuberkulinspritze verbunden. Wir stachen die Kanülenspitze in die caudalen Hauptgefäße ein und saugten die Meßkammer sowie einen Teil der Tuberkulinspritze voll Blut. Über einen Zeitraum von mehreren Minuten wurde der $\mathrm{pO}_{2}$ alle $15 \mathrm{sec}$ registriert. Der Totraum der Spritze enthielt vor den Bestimmungen sauerstofffreie Eichlösung.

Während der Messungen nach der Kanülenmethode (Tab. 12) und im Herzen (Abb. 5, Tab. 11) tauchte nur der Kopf - im Gegensatz zum übrigen Körper - in Atemwasser ein. Daher war es schwierig, die Atem- und Kreislauftätigkeit der Aale so einzustellen, wie sie unter natürlichen Bedingungen aufrechterhalten wird. Obwohl sich beide Funktionen mit der Vorbehandlungstemperatur ändern, haben wir die Einzelbestimmungen an unterschiedlich adaptierten Aalen bei möglichst gleich hohen Ventilations- und Herzleistungen vorgenommen. Indem weiter die Messungen bei starker Ventilation und kräftigem Herzschlag erfolgten, sollte vermieden werden, daß die Höhe des venösen Sauerstoffdrucks von Unterschieden im arteriellen Angebot abhängt.

Die Fehlerangabe in den folgenden Tabellen bezieht sich auf den mittleren Fehler der Mittelwerte; als Abkürzungen wurden für die Adaptationstemperatur "AT" und für die Versuchstemperatur „VT“ verwendet.

\section{Ergebnisse}

\section{Der Sauerstoffdruck im Herzblut}

Das Herz der Fische fördert nur venöses Blut. Der Sauerstoffdruck im Ventrikel gibt daher summarisch Auskunft über die Ausnutzung des Blutsauerstoffs im Körper. Nach Tabelle 11 weisen langfristig bei $14^{\circ} \mathrm{C}$ gehälterte Aale einen niedrigeren $\mathrm{pO}_{2}$ im Herzblut auf als die an $25^{\circ} \mathrm{C}$ adaptierten Fische; bei ersteren beträgt der $\mathrm{pO}_{2}$ im 
Mittel $11 \mathrm{mmHg}$, bei letzteren dagegen $17 \mathrm{mmHg}$; der Unterschied ist signifikant. Die vor der Narkose gemessenen Atemfrequenzen zeigen, daß bei gleicher Versuchstemperatur $\left(22^{\circ} \mathrm{C}\right)$ die Atemtätigkeit kaltadaptierter Aale die der warmadaptierten um $28 \%$ übersteigt. Zur Freilegung des Herzens wurden die Aale relativ stark narkotisiert. Während der Zeit, in der die Narkose abflachte, haben wir bei beiden Tiergruppen Perioden etwa gleicher und krättiger Atemtätigkeit abgewartet, um dann die Elektrode in das Herz einzustechen. Unter diesen Bedingungen war auch die Herztätigkeit bei den kaltadaptierten Aalen nur wenig höher als die der bei $25^{\circ} \mathrm{C}$ gehälterten Tiere.

Tabelle 11

Sauerstoffdruck des Ventrikelblutes und Atemfrequenz verschieden adaptierter, narkotisierter Aale. Die Messung erfolgte 2 Minuten nach Einstich der Elektrode in das Lumen der Herzkammer (vgl. Abb. 5). Ferner sind angegeben: die Atemfrequenz vor der Narkose und die Herzfrequenz während der Narkose bei intaktem und geöffnetem Pericard. Zahl der untersuchten Fische jeweils 6. Temperatur des luftgesättigten Atemwassers $22^{\circ} \mathrm{C}$. Versuchszeit: September bis November 1964

\begin{tabular}{|lcll|}
\hline $\begin{array}{l}\text { AT } \\
\text { Länge } \\
\text { Gewicht }\end{array}$ & $\mathrm{pO}_{2}(\mathrm{mmHg})$ & $\begin{array}{l}\text { Atemfrequenz } \\
\text { (a) vor der Narkose } \\
\text { (b) während der Messung } \\
\text { (c) b in \% von a }\end{array}$ & $\begin{array}{l}\text { (a) Herzfrequenz } \\
\text { (b) bei offenem Pericard } \\
\text { (c) b in \% von a }\end{array}$ \\
\hline $14^{\circ} \mathrm{C}$ & $11 \pm 0,8$ & (a) $45 \pm 2,7$ & (a) $39 \pm 2,9$ \\
$49-54 \mathrm{~cm}$ & & (b) $32 \pm 1,7$ & (b) $59 \pm 2,4$ \\
$186-255 \mathrm{~g}$ & & (c) $72 \pm 3,3 \%$ & (c) $155 \pm 5,1 \%$ \\
$250 \mathrm{C}$ & $17 \pm 0,8$ & (a) $35 \pm 1,6$ & (a) $32 \pm 1,9$ \\
$49-55 \mathrm{~cm}$ & & (b) $29 \pm 2,9$ & (b) $50 \pm 4,2$ \\
$206-267 \mathrm{~g}$ & & (c) $80 \pm 4,5 \%$ & (c) $160 \pm 5,5 \%$ \\
\hline
\end{tabular}

Der unterschiedliche Sauerstoffdruck im Ventrikelblut dürfte bei obigen Versuchen somit nicht auf Veränderungen im arteriellen Sauerstoffangebot beruhen, sondern vielmehr auf einen größeren Sauerstoffverbrauch der Gewebe der kaltadaptierten Aale zurückzuführen sein.

Die Abhängigkeit der ermittelten Sauerstoffdrucke von der Meßdauer veranschaulicht Abbildung 5.

Die Elektrode benötigt etwa $75 \mathrm{sec}$, um sich auf den niedrigen Partialdruck des venösen Blutes einzustellen; deshalb findet man kurz nach ihrem Einführen in den Ventrikel höhere und stärker streuende Werte. Zur Berechnung der Mittelwerte (Tab. 11) wurden aus diesem Grunde die nach 2 Minuten abgelesenen Sauerstoffdrucke verwendet.

Der starke Anstieg der Herzfrequenz nach Offnung des Pericards um 60\% (vgl. Tab. 11) ist wohl in einer reflektorischen Regelung der Herztätigkeit durch den Blutdruck in den Kiemengefäßen begründet. Beim Aal leitet ein verringerter Blutdruck eine schnellere Herztätigkeit ein (MотT 1951); nach SudAK (1965) führt eine Pericardiotomie zu einem Absinken des systolischen Blutdrucks in der Herzkammer von Mustelus canis. Eine Beeinträchtigung des Vagus beim Freilegen des Herzens muß auch in Erwägung gezogen werden.

Da die Werte für die Herzfrequenz an narkotisierten Aalen ermittelt wurden, sind sie nur schwer mit Daten in der Literatur zu vergleichen. GITTER (1933) fand bei 


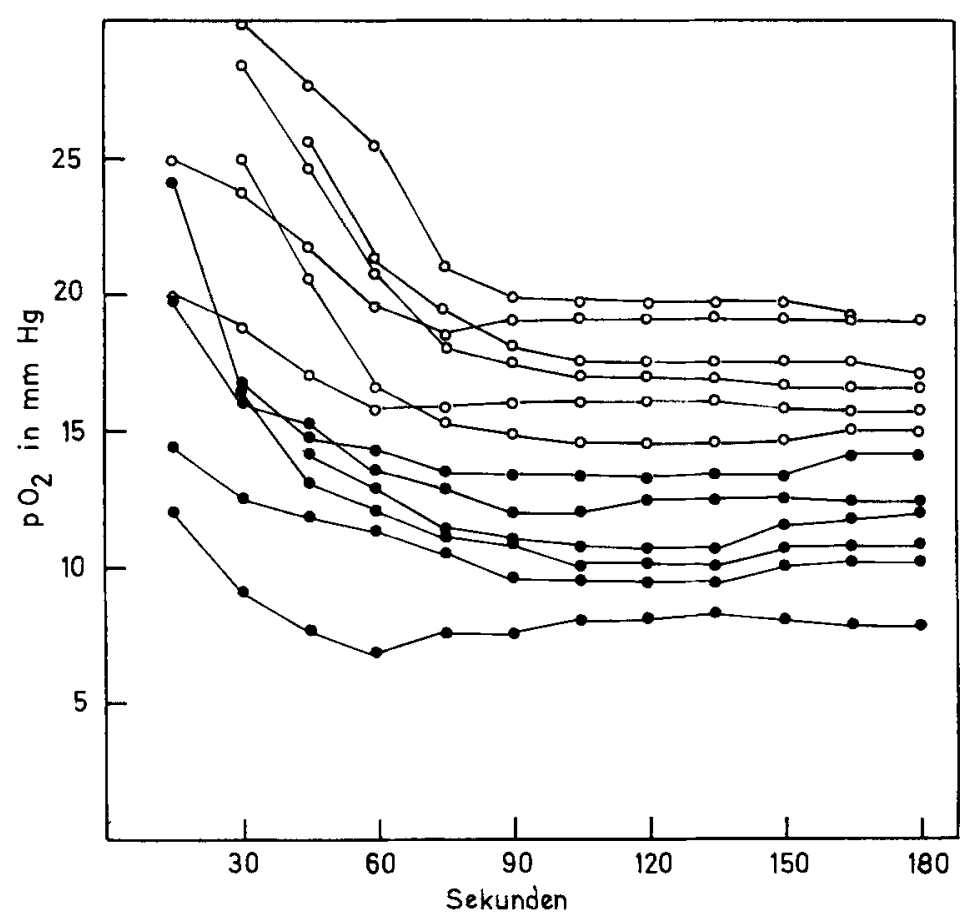

Abb. 5: Sauerstoffdruck des Ventrikelblutes verschieden adaptierter Aale während einer Meßzeit von $3 \mathrm{~min}$. Versuchstemperatur $22^{\circ} \mathrm{C} .=$ Adaptationstemperatur $14^{\circ} \mathrm{C} ; 0=$ Adaptationstemperatur $22^{\circ} \mathrm{C}$. Abszisse: Zeit nach Einstich der Elektrode in die Herzkammer

unnarkotisierten Aalen eine Herzfrequenz von 27 Schlägen pro Minute bei einer Wassertemperatur von $20^{\circ} \mathrm{C}$. Nach Shelton \& Randall (1962) sowie Berg \& Steen (1965) beträgt die Herzfrequenz 40 bis 50 Schläge pro Minute bereits bei Versuchstemperaturen um $15^{\circ} \mathrm{C}$.

\section{Der Sauerstoffdruck im Blut der caudalen Hauptgefäße}

Die Ausnutzung des Sauerstoffs wird an der arterio-venösen Differenz sichtbar; bei ihrer Kenntnis und der des Durchströmungsvolumens kann der Sauerstoffbedarf eines Organs berechnet werden. Unter Annahme einer gleichbleibenden Durchblutung spiegelt die arterio-venöse Differenz direkt die Stoffwechselhöhe des jeweils versorgten Gewebes wider. Da wir den Sauerstoffbedarf der Muskulatur erfassen wollten, mußte die arterio-venöse Differenz an Stellen des Blutkreislaufs gemessen werden, wo nur solche Gefäße anzutreffen sind, die hauptsächlich Muskeln versorgen. Bei Fischen trifft dies für die Adern des Schwanzes zu. Dagegen wird die Sauerstoffspannung im Herzblut durch den Stoffwechsel aller Körperorgane beeinflußt.

Nach den Werten der Tabelle 12 weisen verschieden adaptierte Aale einen Sauerstoffdruck von ca. $80 \mathrm{mmHg}$ in der Schwanzarterie auf, wenn die Messungen bei etwa 


\section{Tabelle 12}

Der Sauerstoffdruck im arteriellen und venösen Blut der caudalen Hauptgefäße verschieden adaptierter Aale. Die Atemfrequenzen während der Messungen sind angegeben. „Kanülenmethode." Temperatur des luftgesättigten Atemwassers $22^{\circ} \mathrm{C}$, Raumtemperatur 20 bis $21^{0} \mathrm{C}$. Gewicht der Tiere 150 bis $580 \mathrm{~g}$, Länge zwischen 45 und $65 \mathrm{~cm}$. Versuchszeit: November 1964 bis Februar 1965. In runden Klammern: Zahl der untersuchten Tiere. In eckigen Klammern sind die Extremwerte angegeben

\begin{tabular}{|c|c|c|c|c|c|c|}
\hline \multirow{2}{*}{$\mathrm{AT}$} & \multicolumn{3}{|c|}{ Arterie } & \multicolumn{3}{|c|}{ Vene } \\
\hline & $\mathrm{pO}_{2}(\mathrm{mmHg})$ & & $\mathrm{KD} / \mathrm{min}$ & $\mathrm{pO}_{2}(\mathrm{mmHg}$ & & $\mathrm{KD} / \mathrm{min}$ \\
\hline $8-9^{\circ} \mathrm{C}$ & $\begin{array}{c}82 \pm 13,9 \\
{[38-125]}\end{array}$ & (8) & $\begin{array}{c}49 \pm 5,5 \\
{[30-72]}\end{array}$ & - & & - \\
\hline $14^{0} \mathrm{C}$ & $\begin{array}{c}85 \pm 9,8 \\
{[56-113]}\end{array}$ & (5) & $\begin{array}{r}52 \pm 4,0 \\
{[39-61]}\end{array}$ & $\begin{array}{r}38 \pm 3,6 \\
{[18-51]}\end{array}$ & (10) & $\begin{array}{c}47 \pm 2,9 \\
{[32-65]}\end{array}$ \\
\hline $22^{\circ} \mathrm{C}$ & $\begin{array}{c}78 \pm 6,5 \\
{[46-111]}\end{array}$ & (9) & $\begin{array}{c}55 \pm 3,4 \\
{[37-71]}\end{array}$ & $\begin{array}{c}59 \pm 4,1 \\
{[47=77]}\end{array}$ & (7) & $\begin{array}{c}47 \pm 3,0 \\
{[32-54]}\end{array}$ \\
\hline
\end{tabular}

gleicher Atemfrequenz und luftgesättigtem Atemwasser vorgenommen werden. Dieser Wert ist einem Gefälle im Sauerstoffdruck von $70 \mathrm{mmHg} z$ wischen dem Atemwasser und dem arteriellen Blut gleichzusetzen (vgl. hierzu Tab. 14). Wie die angegebenen Extremwerte zeigen, ist die Streuung der gemessenen Drucke beträchtlich. Individuelle Schwankungen im Ausnutzungsvermögen des Atemwassers werden hieran beteiligt sein, da nach Steen \& Kruysse (1964) die Durchblutung der Aalkiemen und damit der Sauerstoffaustausch im respiratorischen Gewebe stark verändert und dem Bedarf der Fische angepaßst werden. Das den Kiemen zuströmende venöse Blut kann durch sich öffnende Anastomosen an den feinen Austauschflächen der Kiemenlamellen vorbei und direkt in die dorsale Aorta fließen. Hauptsächlich dürfte die unterschiedliche Atmungsintensität der Versuchstiere während der Messungen die Variabilität der Werte bedingen. Eine eindeutige Zuordnung der arteriellen Sauerstoffdrucke zur Höhe der jeweils gemessenen Atemfrequenz ließ sich aber nicht durchführen. Neben der Atemfrequenz bestimmt das bei jeder Respirationsbewegung geförderte Wasservolumen, das Atemzugvolumen, die Ventilationsleistung der Fische. Berücksichtigt man ferner, daß Änderungen des arteriellen Sauerstoffgehalts in der Kiemenregion sich wegen der geringen Strömungsgeschwindigkeit des Blutes im Fischkreislauf erst nach 1 min in der Caudalarterie erfassen lassen, so werden die Schwierigkeiten verständlich, die Streuung zu vermindern.

In der Literatur finden sich nur wenige Angaben über die arterielle Sauerstoffspannung des Fischblutes; sehr aktive Fische wie Salmoniden sollen einen hohen Sauerstoffdruck, ruhige Fische, beispielsweise Cypriniden, einen niedrigeren besitzen. Dieser Unterschied wird aus dem differierenden Verlauf der Sauerstoffbindungskurven ihrer Hämoglobine verständlich (vgl. W. v. BudDENBRock 1967). Es können deshalb nur die an Aalen gewonnenen Ergebnisse zum Vergleich mit den Werten der Tabelle 12 herangezogen werden. Nach Berg \& STEen (1965) beträgt bei Anguilla vulgaris der Sauerstoffgehalt von Blutproben, die der dorsalen Arterie entnommen wurden, 5 bis 10 Vol.- $\%$, wobei der arterielle $\mathrm{O}_{2}$-Druck selten $0,1 \mathrm{~atm}$ übersteigen soll (STEEN \& KRUYSSE 1964). Dieser Wert ist etwas niedriger als der Sättigungsdruck des Aal- 
hämoglobins, wie er von STEEN (1963) bestimmt wurde. Dagegen stellte RiggS (1951) bei Anguilla rostrata bereits eine $90 \%$ ige Sättigung des Hämoglobins bei einem $\mathrm{pO}_{2}$ von $46 \mathrm{mmHg}$ fest. KRоGH \& Leitch (1919) ermittelten sogar den Sättigungsdruck des Aalblutes bei $10 \mathrm{mmHg}$. Die Literaturangaben über die Sauerstoffkapazität des Aalblutes in vitro sind einheitlicher; bei vergleichbaren Versuchsbedingungen (Hämotokrit ca. $40 \%$; pH 7,3 bis 7,5; $\mathrm{pO}_{2} 160 \mathrm{mmHg}$; Versuchstemperatur 17 bis $20^{\circ} \mathrm{C}$ ) fanden Kawamoto (1929), Itazawa (1959) und Steen (1963) Werte zwischen 10,5 und 12 Vol.-0\%. ITAzAWA hat den arteriellen Sauerstoffgehalt im Aalblut mit seiner totalen Sättigung in vitro verglichen. Das Blut der Schwanzarterie erreichte 60 bis $98 \%$ des maximalen Sauerstoffgehalts; zu diesem Wert kam es bereits bei einem $\mathrm{pO}_{2}$ von $50 \mathrm{mmHg}$ im Atemwasser. Nach seinen Messungen führte ein höherer Sauerstoffdruck im Atemwasser keine Steigerung des arteriellen $\mathrm{pO}_{2}$ herbei. Dieses Ergebnis überrascht, da z. B. eine 95\% \% ige Sättigung des Aalblutes nach den Untersuchungen von STEEN einer Sauerstoffspannung von ca. $110 \mathrm{mmHg}$ entspricht.

Im Blut der Vene ist nach den vorliegenden Messungen der Sauerstoffdruck von der Temperaturvorbehandlung der Aale abhängig; die höhere Sauerstoffspannung wird im Blut warmadaptierter Fische gefunden. Die Differenz zwischen den Mittelwerten der venösen Sauerstoffdrucke ist signifikant $(P=0,002)$. Gründe für die Variabilität wurden bereits bei der Diskussion des arteriellen $\mathrm{pO}_{2}$ erörtert; sie treffen in gleicher Weise für die venösen Meßwerte zu. Da bei den Versuchen nach der "Kaniilenmethode" die Blutgefäße angestochen werden mußten, war ein Blutverlust bei der Messung nicht zu vermeiden. Wenn man am selben Tier zuerst die Kanüle in die Arterie einführte und den $\mathrm{pO}_{2}$ bestimmte, zeigte sich bei der anschließend in der Vene durchgeführten Messung nach sehr kurzer Zeit ein starker Abfall der Sauerstoffspannung. Deshalb ermittelten wir die arterio-venöse Differenz an verschiedenen Tieren unter möglichst identischen Versuchsbedingungen. Nach den Mittelwerten der Tabelle 12 kann man für die an $14^{\circ} \mathrm{C}$ adaptierten Aale eine Sauerstoffausnutzung von etwa $55 \%$ errechnen, bei warmgehaltenen Tieren beträgt sie ca. $24 \%$. Da bei diesen Versuchen - ähnlich wie bei den Messungen im Herzen - eine gleich hohe Atemfrequenz der warm- und kaltadaptierten Fische in etwa eingehalten wurde, spiegelt die Anderung der arterio-venösen Differenz den Sauerstoffverbrauch der Gewebe wider. Wir haben nur ca. $40 \%$ des arteriellen Sauerstoffdrucks in der Schwanzvene der an 8 bis $9^{\circ} \mathrm{C}$ angepaßten Aale gemessen, wenn die Kanüle am selben Tier zunächst in der Arterie und dann in die Vene eingeführt wurde. Der Nachteil dieser Methode ist oben erwähnt; deshalb sind diese Versuche in der Tabelle 12 auch nicht berücksichtigt.

Der Sauerstoffdruck im venösen Blut der Schwanzadern ist erheblich höher als der des Ventrikelblutes. Dies ist offensichtlich darauf zurückzuführen, daß das Blut der Schwanzvene nur zum Teil seinen Sauerstoff in der Muskulatur des Hinterkörpers abgegeben hat. Bei Gegenüberstellung verschieden adaptierter Tiere stimimt die prozentuale Differenz der Sauerstoffspannungen im Herzen und in der Caudalvene gut überein. Die Atmungshöhe bei beiden Versuchsreihen ist jedoch schwer zu vergleichen, außerdem besteht ein Unterschied in den Adaptationstemperaturen. 
Der Einfluß der Versuchstemperatur auf Atem-und Herzfrequenz narkotisierter Aale

Jede Steigerung der Versuchstemperatur ist mit einer Intensivierung der Atmungsund Kreislaufarbeit der Fische verbunden. Wegen der Bedeutung beider Organsysteme für die Sauerstoffversorgung soll hier ihre Temperaturabhängigkeit dargestellt werden. Die Atmungsleistung hängt von der Frequenz und der Amplitude der Ventilationsbewegungen $a b$; das beste Maß ist daher das Minutenvolumen, nämlich die Wassermenge, die in einer Minute ventiliert wird. Auch das Fischherz antwortet auf einen gesteigerten Sauerstoffbedarf mit einer erhöhten Pulsfrequenz und einem vermehrten Schlagvolumen.

Eingehende Untersuchungen des Temperatureinflusses auf die Ventilation des Aales führte VAN DAM (1938) durch. Bei Anstieg der Versuchstemperatur geht der Fisch von einseitiger zu beidseitiger Ventilation über, die Atempausen werden kürzer,

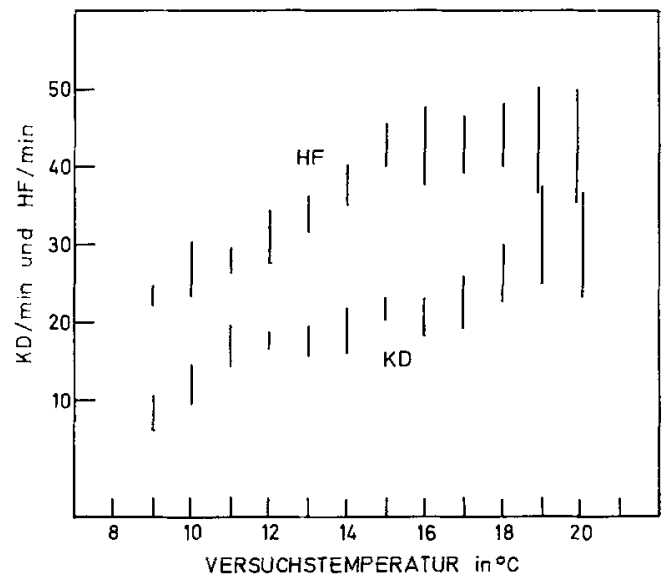

Abb. 6: Die Atemfrequenz (KD/min) und die Herzfrequenz (HF/min) eines an $15^{\circ} \mathrm{C}$ adaptierten Aales bei verschiedenen Versuchstemperaturen. Angegeben ist jeweils die Streuung der Werte bei mehrfacher Messung unter gleichen Versuchsbedingungen

die Atemfrequenz und das Ventilationsvolumen größer. Die Ausnutzung des Atemwassers bleibt dabei über einen großen Temperaturbereich fast konstant. Nach älteren Untersuchungen von GrTTER (1933) sollen Temperaturen unter $20^{\circ} \mathrm{C}$ nur einen geringen Einfluß auf die Herzfrequenzen des Aales ausüben, während bei höheren Temperaturen ein Frequenzanstieg einsetzt und selbst dann anhält, wenn die Atmung bereits durch extreme Temperaturen vollkommen gelähmt ist. Über eine Abhängigkeit des Herzschlags intakter Aale von der Adaptationstemperatur berichtet PRECHT (1951).

Im Gegensatz zu den kurzfristigen Messungen (vgl. Tab. 11 und 12), bei denen Unterschiede in der Ventilation der Versuchstiere durch Wahl der Meßzeiten und der Narkosetiefe möglichst ausgeschaltet wurden, haben wir die Atem- und Herzfrequenzen unter Versuchsbedingungen bestimmt, wie sie bei der Messung des Sauerstoffdrucks 
in der Schwanzvene herrschten. Zur Zeit der Registrierung waren die Aale nur so flach narkotisiert, daß sie in Rückenlage unter Wasser auf dem Aalhalter verblieben; so konnten die Herzkontraktionen gut erkannt werden.

Abbildung 6 veranschaulicht die Streuung der Frequenzen im Einzelexperiment, bei hohen Versuchstemperaturen nimmt sie zu. Die in Tabelle 13 und Abbildung 7 angegebenen Mittelwerte wurden jeweils aus den durchschnittlichen Frequenzen der einzelnen Versuchstiere errechnet.

Bei allen Versuchstemperaturen ist die Zahl der Herzkontraktionen pro Minute (HF/min) höher als die Zahl der Ventilationsbewegungen $(\mathrm{KD} / \mathrm{min})$.

Tabelle 13

Atem- und Herzfrequenzen verschieden adaptierter, leicht narkotisierter Aale in Abhängigkeit von der Versuchstemperatur (VT). Beide Frequenzen wurden gleichzeitig bestimmt. Angegeben sind die Mittelwerte, ihr mittlerer Fehler und in Klammern die Anzahl der Versuche

\begin{tabular}{|lcccc|}
\hline \multirow{2}{*}{ VT } & \multicolumn{2}{c}{ AT-8 } & \multicolumn{2}{c|}{ AT-220 C } \\
& $\begin{array}{c}\text { Atemfrequenz } \\
\text { pro min }\end{array}$ & $\begin{array}{c}\text { Herzfrequenz } \\
\text { pro min }\end{array}$ & $\begin{array}{c}\text { Atemfrequenz } \\
\text { pro min }\end{array}$ & $\begin{array}{c}\text { Herzfrequenz } \\
\text { pro min }\end{array}$ \\
\hline $12^{\circ} \mathrm{C}$ & $21 \pm 1,3$ & $27 \pm 4,2$ & $14 \pm 0,7$ & $31 \pm 2,0$ \\
& $(11)$ & $(8)$ & $(8)$ & $(7)$ \\
$14^{\circ} \mathrm{C}$ & $23 \pm 0,7$ & $34 \pm 2,0$ & $17 \pm 0,8$ & $35 \pm 1,3$ \\
& $(8)$ & $(11)$ & $(10)$ & $(10)$ \\
$16^{\circ} \mathrm{C}$ & $30 \pm 1,1$ & $41 \pm 1,3$ & $22 \pm 1,8$ & $36 \pm 2,3$ \\
& $(11)$ & $(11)$ & $(10)$ & $(10)$ \\
$18^{\circ} \mathrm{C}$ & $39 \pm 1,5$ & $48 \pm 3,3$ & $26 \pm 1,1$ & $42 \pm 1,9$ \\
& $(11)$ & $(11)$ & $(10)$ & $(10)$ \\
$20^{\circ} \mathrm{C}$ & $46 \pm 0,9$ & $60 \pm 3,0$ & $36 \pm 2,2$ & $51 \pm 1,9$ \\
& $(12)$ & $(12)$ & $(13)$ & $(13)$ \\
\hline
\end{tabular}

Vergleicht man den Kurvenverlauf für verschieden adaptierte Tiere, so ist besonders bei hohen Versuchstemperaturen zu erkennen, daß die bei $8^{\circ} \mathrm{C}$ gehälterten Fische höhere Frequenzen als die an $22^{\circ} \mathrm{C}$ adaptierten Aale aufweisen. Die Leistung beider Organsysteme zeigt eine Adaptation im Sinne einer partiellen Kompensation. Zeitweilig beobachtete Synchronisationen der Ventilationsbewegung mit der Herzkontraktion werden $z$ wangsweise aufgelöst, wenn das Herz, zwar mit verminderter Frequenz, bei Atempausen weiterschlägt. Diese Atempausen treten vermehrt bei tiefen Versuchstemperaturen auf.

Es muß ferner erwähnt werden, daß durch die Narkose die Ventilationsleistung der Aale etwas stärker als ihre Herztätigkeit beeinträchtigt wird.

Der Einfluß der Versuchstemperatur auf die Ausnutzung des Atemwassers durch die Aale ergibt sich aus Abbildung 8 (zur Methode vgl. p. 332).

Bei gleicher Temperatur führen höhere Atemfrequenzen zu einer schlechteren Ausnutzung, aber zu einer besseren Blutsättigung, da sich das $\mathrm{pO}_{2}$-Gefälle zwischen Blut und Wasser vergrößert. Je tiefer die Temperatur ist, desto weniger Sauerstoff wird dem Atemwasser bei gleicher Kiemendeckelfrequenz entzogen. Bei allen Messungen des Sauerstoffdrucks im Blut narkotisierter Aale wurde darauf geachtet, die Ventilations- 


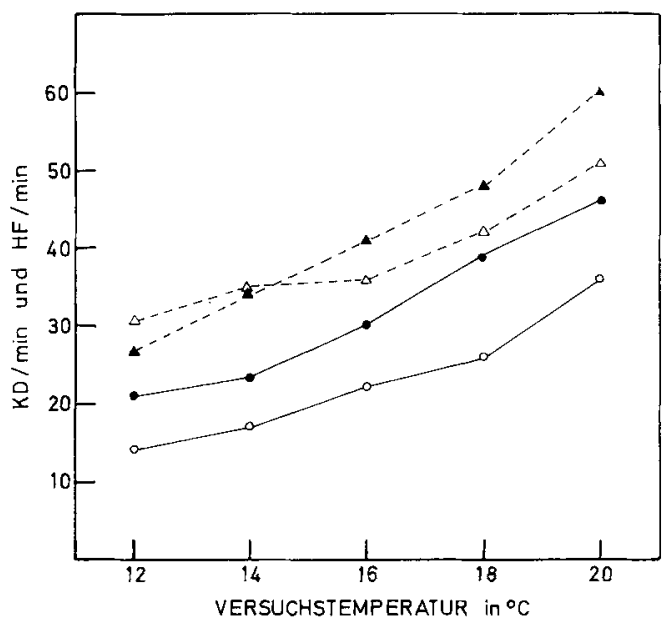

Abb. 7: Atem- und Herzfrequenz narkotisierter Aale bei mehreren Versuchstemperaturen. Die eingezeichneten Mittelwerte wurden der Tabelle 13 entnommen. AT $8^{0} \mathrm{C}: 0$ Atemfrequenz; $\boldsymbol{\Delta}=$ Herzfrequenz. AT $22^{\circ} \mathrm{C} 0=$ Atemfrequenz; $\Delta=$ Herzfrequenz

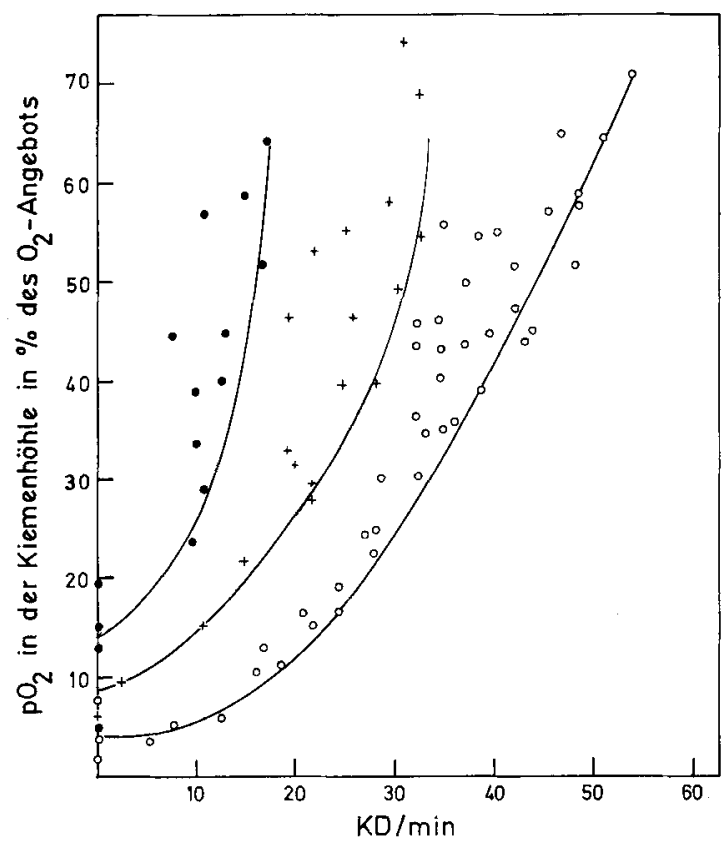

Abb. 8: Der Sauerstoffdruck des Wassers in der Kiemenhöhle in Abhängigkeit von der Atemfrequenz und der Versuchstemperatur. Ordinate: Sauerstoffdruck in der Kiemenhöhle in $\%$ der Sauerstoffspannung des Atemwassers. Abszisse: Atemfrequenz. $0=$ Versuchstemperatur $20^{\circ} \mathrm{C} ;+=$ Versuchstemperatur $15^{\circ} \mathrm{C} ; 0=$ Versuchstemperatur $10^{\circ} \mathrm{C}$. Die nach Augenmaß eingezeichneten Kurven sind an den Meßwerten orientiert, die der besten Ausnutzung des Atemwassers entsprechen. Untersucht wurden 4 bei $22^{\circ} \mathrm{C}$ gehälterte Aale 
leistung der Versuchstiere so hoch zu halten, daß der Sauerstoffgehalt des Atemwassers zur Sättigung des Blutes ausreichte.

Weiterhin war zu überprüfen, wie stark das Atemwasser etwa unter Adaptationsbedingungen ausgenutzt wird. Nach den Werten der Tabelle 14 ist der Sauerstoffdruck im Wasser der Kiemenhöhle bei den an $4^{\circ} \mathrm{C}$ und den an $10^{\circ} \mathrm{C}$ adaptierten Aalen annähernd gleich, obwohl sich die Atemfrequenzen unterscheiden. Der Ausnutzungsgrad des angebotenen Sauerstoffs liegt bei $70 \%$; dies steht größenordnungsmäßig in Einklang mit den von vaN DAM (1938) am Aal und von SAUnders (1962) an anderen Fischen ermittelten Werten. Die bei $20^{\circ} \mathrm{C}$ untersuchten warmadaptierten Aale entnehmen dem Wasser nur $50 \%$ des Sauerstoffs, weil besonders sie durch die Elektrode in der Kiemenhöhle erregt sind und deshalb stark ventilieren. Auch STEEN \& KruYsse (1964) beobachteten eine Verschlechterung der Sauerstoffentnahme bei beunruhigten Aalen. Eine 70\% \% ige Ausnutzung des Atemwassers fand dagegen van DaM, wenn der Aal bei einer Wassertemperatur von $23^{\circ} \mathrm{C}$ nur 25 Ventilationsbewegungen in der Minute vollzog. Während längerer Atempausen sinkt die Sauerstoffspannung in der

Tabelle 14

Der Sauerstoffdruck in der Kiemenhöhle und die Atemfrequenz leicht narkotisierter Aale bei Versuchstemperaturen, die annähernd den Adaptationstemperaturen entsprechen. $\mathrm{PO}_{2}-\mathrm{A}$ : Sauerstoffdruck des Atemwassers; $\mathrm{pO}_{2}-\mathrm{K}$ : Sauerstoffdrudk des Wassers in der Kiemenhöhle. Versuchszeit: Februar bis März 1967

\begin{tabular}{|c|c|c|c|c|c|c|}
\hline AT & VT & $\mathrm{pO}_{2}-\mathrm{A}$ & $\begin{array}{l}\text { Atem- } \\
\text { frequenz }\end{array}$ & $\mathrm{pO}_{2}-\mathrm{K}$ & $\begin{array}{l}\mathrm{pO}_{2}-\mathrm{K} \text { in } \% / 0 \\
\text { von } \mathrm{pO}_{2}-\mathrm{A}\end{array}$ & $\begin{array}{l}\text { Zahl der } \\
\text { Versudhe }\end{array}$ \\
\hline $4^{0} \mathrm{C}$ & $6^{\circ} \mathrm{C}$ & $138 \pm 5$ & $13,7 \pm 0,6$ & $\begin{array}{l}45 \pm 2,2 \\
25 \pm 5,3\end{array}$ & $\begin{array}{l}31 \pm 1,7 \\
18 \pm 3,8\end{array}$ & $\begin{array}{r}10 \\
6\end{array}$ \\
\hline $10^{\circ} \mathrm{C}$ & $12^{\circ} \mathrm{C}$ & $136 \pm 4$ & $21,8 \frac{ \pm}{0} 1,2$ & $\begin{array}{l}39 \pm 2,7 \\
18 \pm 3,4\end{array}$ & $\begin{array}{l}28 \pm 1,9 \\
13 \pm 2,6\end{array}$ & $\begin{array}{l}7 \\
5\end{array}$ \\
\hline $22^{\circ} \mathrm{C}$ & $20^{\circ} \mathrm{C}$ & $144 \pm 3$ & $40,0 \pm 1,6$ & $\begin{array}{r}71 \pm 2,4 \\
7 \pm 1,0\end{array}$ & $\begin{array}{r}51 \pm 1,8 \\
5 \pm 1,1\end{array}$ & $\begin{array}{r}14 \\
6\end{array}$ \\
\hline
\end{tabular}

Kiemenhöhle um so stärker ab, je höher die Temperatur ist (Tab. 14). Fällt der Sauerstoffdruck in der Kiemenhöhle unter $20 \mathrm{mmHg}$, so beenden schwach narkotisierte Aale die Atempausen. Bei der hohen Versuchstemperatur führt nur eine tiefere Narkose zu kurzfristigem Atemstillstand. Der Druck von $7 \mathrm{mmHg}$ liegt deutlich unter dem des venösen Herzblutes; vielleicht geht der Aal unter derartigen Bedingungen eine Sauerstoffschuld ein.

Der Einfluß der Versuchstemperatur auf den Sauerstoffdruck im Blut der Caudalvene

$\mathrm{Da}$ der Sauerstoffverbrauch eines Gewebes sehr stark temperaturabhängig ist, sollte geprü̈t werden, inwieweit sich Anderungen der Versuchstemperatur auf die Höhe des venösen Sauerstoffdrucks auswirken. Der steigende Bedarf eines Gewebes könnte durch ein besseres Ausnutzen des Blutes gedeckt werden. Dadurch würde die 
arterio-venöse Differenz vergrößert und die venöse Sauerstoffspannung erniedrigt. Atem- und Kreislaufregulationen könnten aber auch durch die Variierung des Angebots den Sauerstoffdruck in den Kapillaren konstant halten. Von Fischen ist die Zunahme der Atem- und Herzarbeit bei wachsendem Sauerstoffbedarf wohlbekannt, dagegen wissen wir kaum etwas über die Ausnutzung des Blutes bei gesteigertem Bedarf der Gewebe.

Wir untersuchten die Beziehung zwischen der Versuchstemperatur und der Höhe des venösen $\mathrm{pO}_{2}$ an Aalen, deren venöser Blutstrom im Schwanzbereich durch eine Meßkammer überbrückt war. Die „Kanülenmethode“ erlaubt nur Einzelmessungen; da bei ihr der Körper der Versuchstiere außerhalb des Wassers schlecht temperiert werden kann, war sie für diese Messung ungeeignet.

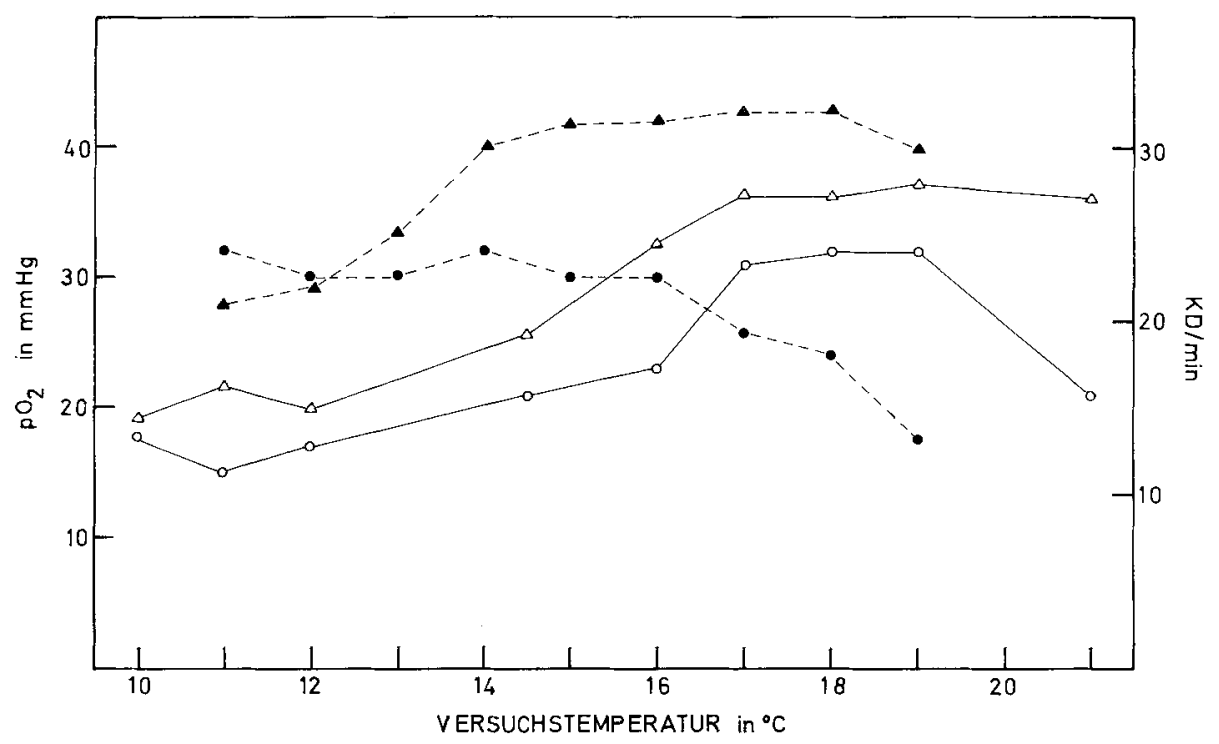

Abb. 9: Die Änderungen des Sauerstoffdrucks im Blut der Caudalvene und der Atemfrequenz. von Aalen bei kurzfristigem Wechsel der Versuchstemperatur. Adaptationstemperatur $8^{\circ} \mathrm{C}$. $0=$ Sauerstoffpartialdruck; $\Delta=$ Atemfrequenz; der durch die offenen Symbole gekennzeichnete Kurvenverlauf wurde bei Steigerung der Versuchstemperatur gewonnen; die geschlossenen Symbole $(\boldsymbol{\Lambda}, \mathbf{0})$ markieren den Kurvenverlauf bei Abkühlung des Versuchstieres. Die Anderung der Versuchstemperatur um $\mathbf{1 0}^{0} \mathrm{C}$ erfolgte in Abständen von ca. $8 \mathrm{~min}$. Die bei der Versuchstemperatur von $21^{\circ} \mathrm{C}$ eingetragenen Werte stellten sich erst nach einer Dauer von $30 \mathrm{~min}$ ein

Abbildung 9 gibt Versuche an kaltadaptierten Aalen wieder, in denen die Temperatur des Wasserbades in Abständen von jeweils 8 min um $1^{\circ} \mathrm{C}$ geändert wurde. Bei der Steigerung der Versuchstemperatur weisen die Kurven für die Atemfrequenz und für den Sauerstoffdruck einen ähnlichen Verlauf auf. Bei tiefen Temperaturen ist die Anderung beider Größen relativ gering. Zwischen 15 und $17^{\circ} \mathrm{C}$ kommt es zu einem ausgeprägten Anstieg im Sauerstoffdruck. Die Sauerstoffspannung fällt wieder auf das Ausgangsniveau zurück, wenn die Versuchsbedingungen konstant gehalten werden (30 min Meßdauer bei $21^{\circ} \mathrm{C}$ ). Beim A b k ü h l e n des Aales von 19 
auf $11^{\circ} \mathrm{C}$ tritt keine sprunghafte Ainderung im Sauerstoffdruck auf; bis $16^{\circ} \mathrm{C}$ findet sich ein stetiges Anwachsen bei unverminderter Atemfrequenz. Wird die Temperatur des Wasserbades weiter erniedrigt, so sinkt die Ventilation, während der Sauerstoffdruck nur geringfügig schwankt. Die gegebenen Beispiele sind typisch für die Änderungen der Meßwerte bei derartigen Versuchen. Das Erwärmen des Tierkörpers führt zwar zu einer Steigerung des Gewebestoffwechsels, aber nicht zu einer Abnahme des Sauerstoffgehalts im Blut der Schwanzvene. Der vermehrte Bedarf wird durch eine stärkere Sauerstoffaufnahme gedeckt, wie aus dem Anstieg der Atemfrequenzen zu ersehen ist. Die durch das Kühlen des Aales bewirkte Zunahme der venösen Sauerstoffspannung - bei gleichbleibender Ventilationsleistung - entspricht dem verringerten Stoffwechsel und Sauerstoffbedarf der Gewebe bei tieferer Temperatur. Aus dem Verlauf der Kurven ist aber auch zu entnehmen, daß sich bei einem Wechsel der Versuchstemperatur die Ventilationsleistung der Aale ebenso wie der $\mathrm{pO}_{2}$ im Blut ihrer Schwanzvene nicht einheitlich und in Hinblick auf den Sauerstoffbedarf der Gewebe teilweise unerwartet ändern. Unter den experimentellen Bedingungen spielen sich beide Größen erst nach relativ langer Versuchszeit auf ein neues konstantes Niveau ein.

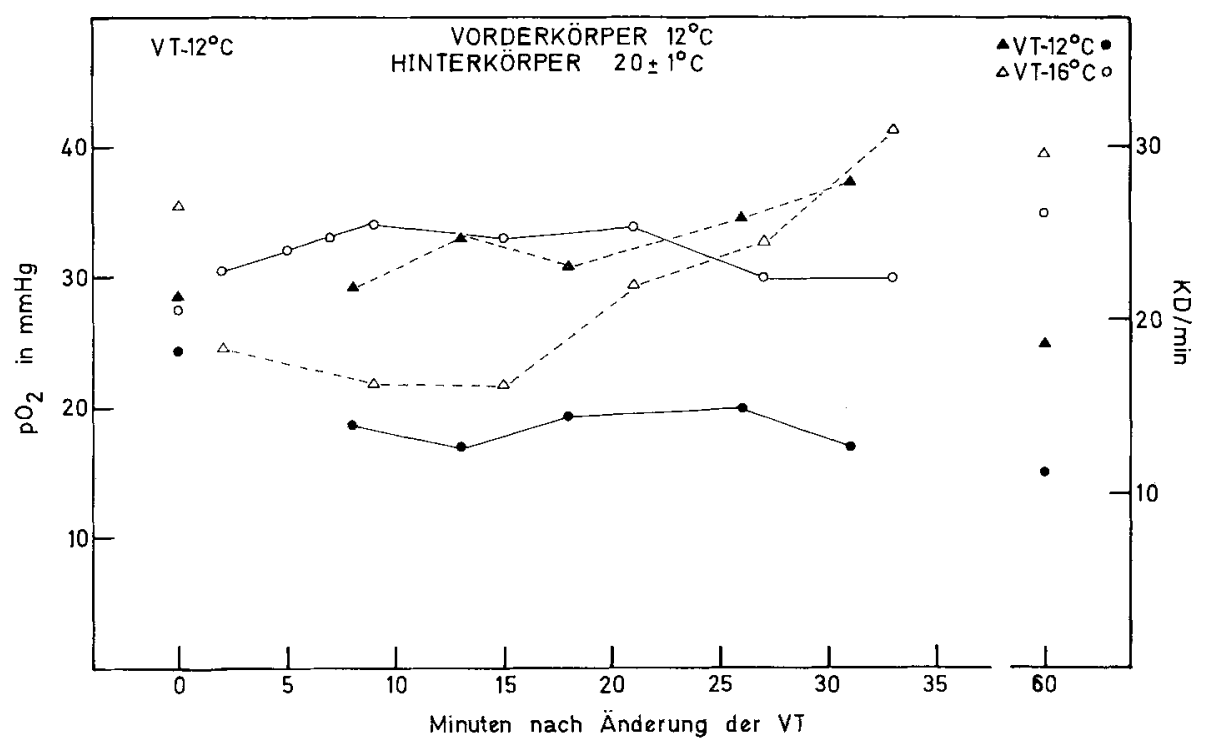

Abb. 10: Der Sauerstoffdruck im Blut der Caudalvene von Aalen bei einer Temperaturdifferenz $z$ wischen Vorder- und Hinterkörper. Die Versuchsbedingungen sind am oberen Rand der Abbildung eingetragen. Versuchstier $1\left(\mathrm{AT} 8^{0} \mathrm{C}, 354 \mathrm{~g}\right) ;-\mathrm{pO}, \boldsymbol{\Delta}=$ Atemfrequenz. Ver-

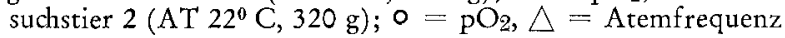

In den in Abbildung 10 dargestellten Versuchen wurden Vorder- und Hinterkörper der Aale unterschiedlich temperiert. Vor dem Erwärmen des Hinterkörpers bestimmten wir den Sauerstoffdruck und die Atemfrequenz über einen längeren Zeitraum bei der einheitlichen Wasserbadremperatur von $12^{\circ} \mathrm{C}$. Die Mittelwerte beider Größen sind links in der Abbildung 10 eingetragen (VT $12^{\circ} \mathrm{C} ; 0$ min). Nach dem Einstellen der Temperaturdifferenz -- in beiden Experimenten betrug sie zwischen dem 
vorderen Drittel des Körpers und dem Rest des Tieres $8^{\circ} \mathrm{C}$ - ändert sich die Atemfrequenz der Versuchstiere nicht gleichartig. Der bei $8^{\circ} \mathrm{C}$ gehälterte Fisch erhöht zunächst nur wenig seinen Atemrhythmus. Dagegen wirkt sich beim warmadaptierten Aal das Kühlen des Kopfes offenbar lähmend auf das Atemzentrum aus; die Atemfrequenz sinkt, und eine Erholung setzt nur langsam wieder ein. In beiden Versuchen bleibt der Sauerstoffdruck während der Zeit, in der eine Temperaturdifferenz zwischen Vorder- und Hinterkörper besteht, annähernd konstant. Etwa 30 Minuten nach Ausgleich des Temperaturunterschiedes haben wir Sauerstoffspannung und Atemfrequenz des kaltadaptierten Aales bei $12^{\circ} \mathrm{C}$, des warmadaptierten Aales bei $16^{\circ} \mathrm{C}$ bestimmt; die Mittelwerte sind rechts in der Abbildung angegeben (VT $12^{\circ} \mathrm{C}$, VT $16^{\circ} \mathrm{C}$; $60 \mathrm{~min}$ ).

Wider Erwarten führt auch eine direkte Erwärmung des Hinterkörpers zu keiner Erniedrigung des Sauerstoffdrucks im Blut der Schwanzvene; beim warmadaptierten Aal tritt sogar zunächst ein leichter Anstieg auf. Es ist bei der Deutung dieser Versuche aber zu berücksichtigen, daß die Lage und Form der $\mathrm{O}_{2}$-Dissoziationskurve und damit die Transporteigenschaften des Blutes für Sauerstoff temperaturabhängig sind. Der Einfluß der Temperatur auf die Sauerstoffaffinität des Aalhämoglobins ist von KAwAмото (1929) untersucht worden. Er fand bei einem $\mathrm{pO}_{2}$ von $160 \mathrm{mmHg}$ einen Sauerstoffgehalt von 14,5 Vol.- $\%$ bei $5^{\circ} \mathrm{C}$ und einen Gehalt von 12,2 Vol.- $\%$ bei $30^{\circ} \mathrm{C}$. Für die Äquilibrierung des Aalblutes errechnete er einen $Q_{10}$ Wert von 1,56. Auch STEEN (1963) stellte bei einem $\mathrm{pO}_{2}$ oberhalb von $53 \mathrm{mmHg}=0,07$ Atm nur eine geringe, bei niedrigen Sauerstoffdrucken jedoch eine starke Temperaturabhängigkeit der Sauerstoffkapazität fest. Letztere ist bei $8^{\circ} \mathrm{C}$ doppelt so hoch wie bei $19^{\circ} \mathrm{C}$, wenn die Bestimmung bei $\mathrm{pH} 7,5$ und einem $\mathrm{pO}_{2}$ von $30 \mathrm{mmHg}$ vorgenommen wird.

Angesichts dieser Tatsachen wird auch der geringe Anstieg des Sauerstoffdrucks im venösen Blut des Schwanzes bei einer Temperaturdifferenz zwischen Vorder- und Hinterkörper des Aales verständlich. Bei der niedrigeren Temperatur des Atemwassers nimmt das Blut mehr Sauerstoff auf, als es bei der Temperatur, die im Schwanzbereich herrscht, zu transportieren vermag. In der wärmeren Körperzone wird Sauerstoff freigesetzt, da die $\mathrm{O}_{2}$-Affinität des Hämoglobins fällt. Dieser Sauerstoff kann von den metabolisierenden Geweben verbraucht werden, er kann sich jedoch auch auf den Sauerstoffdruck in der Schwanzvene auswirken.

Jede Temperaturänderung beeinflußt rein physikalisch den Partialdruck aller im Blut gelösten Gase; bei einer Temperaturerhöhung kann diese Gasfreisetzung sehr erheblich sein. Wird z. B. der Vorderkörper eines Aales in luftgesättigtem Wasser von $14^{\circ} \mathrm{C}$ gehalten, der Hinterkörper aber auf $25^{\circ} \mathrm{C}$ temperiert, so bilden sich unter der Haut des hinteren, warmgehaltenen Körperabschnitts Gasblasen aus. Dieses Phänomen bereitet der unterschiedlichen Adaptation verschiedener Körperteile ein und desselben Aales große Schwierigkeiten (vgl. Schultze 1965).

Besteht eine Temperaturdifferenz zwischen dem Vorder- und Hinterkörper der Aale, so stellt sich nach längerer Versuchszeit ein Gleichgewicht zwischen der Ventilationsleistung und dem venösen $\mathrm{pO}_{2}$ ein, wie aus den Werten der Tabelle $15 \mathrm{zu}$ ersehen ist. Vergleicht man die Höhe der Atemfrequenz von einheitlich bei $10^{\circ} \mathrm{C}$ untersuchten Aalen mit der Ventilationsleistung der Tiere, bei denen nur der Hinterkörper auf $20^{\circ} \mathrm{C}$ erwärmt wurde, so zeigt sich bei letzteren ein deutlicher Anstieg der Atemfrequenz; ebenso ist der venöse Sauerstoffdruck leicht erhöht. 
Tabelle 15

Der Sauerstoffdruck im Blut der Caudalvene bei einer Temperaturdifferenz zwischen Vorderund Hinterkörper und bei einheitlicher Temperierung der Aale. Alle Temperaturbedingungen wurden langfristig vor und während der Messungen konstant gehalten. Adaptationstemperatur der Aale $15^{\circ} \mathrm{C}$. In Klammern: Anzahl der Versuche

\begin{tabular}{|c|c|c|c|}
\hline \multicolumn{2}{|c|}{ Versuchstemperaturen } & \multirow[b]{2}{*}{$\mathrm{pO}_{2}(\mathrm{mmHg})$} & \multirow[b]{2}{*}{$\mathrm{KD} / \mathrm{min}$} \\
\hline $\begin{array}{l}\text { Vorder- } \\
\text { körper }\end{array}$ & $\begin{array}{l}\text { Hinter- } \\
\text { körper }\end{array}$ & & \\
\hline $10^{\circ} \mathrm{C}$ & $10^{\circ} \mathrm{C}$ & $22 \pm 2,9(6)$ & $10,8 \pm 1,5$ \\
\hline $10^{\circ} \mathrm{C}$ & $20^{\circ} \mathrm{C}$ & $28 \pm 2,2(5)$ & $16,7 \pm 0,9$ \\
\hline $11^{\circ} \mathrm{C}$ & $11^{0} \mathrm{C}$ & $24 \pm 2,0(6)$ & $14,2 \pm 1,4$ \\
\hline $11^{\circ} \mathrm{C}$ & $15^{\circ} \mathrm{C}$ & $26 \pm 2,0(4)$ & $14,1 \pm 0,4$ \\
\hline $15^{\circ} \mathrm{C}$ & $15^{\circ} \mathrm{C}$ & $28 \pm 2,0(6)$ & $21,9 \pm 0,9$ \\
\hline
\end{tabular}

Wenn die Temperatur im Schwanzbereich nur um $4^{0} \mathrm{C}$ höher als die des Vorderkörpers liegt, so ändert sich die Atemfrequenz nicht. Der Sauerstoffdruck im Blut der bei $15^{\circ} \mathrm{C}$ untersuchten Fische stimmt mit dem $\mathrm{pO}_{2}$ der Tiere überein, deren Kopf bei $10^{\circ} \mathrm{C}$ und deren Hinterkörper bei $20^{\circ} \mathrm{C}$ während der Experimente gehalten werden; die Atemfrequenz der bei der mittleren Temperatur untersuchten Aale ist aber höher. Bei Untersuchungen von MisLin (1960) wurde die Atemfrequenz selbst dann kaum beeinflußt, wenn man mit Ausnahme des Kopfes den übrigen Körper des Aales Temperaturen aussetzte, die bis zu $15^{\circ} \mathrm{C}$ höher als die Temperaturen im Kopfbereich waren.

\section{Der Einfluß der Adaptationstemperatur auf den Sauerstoffdruck im Blut der Caudalvene}

Viele Autoren stimmen darin überein, daß der Stoffwechsel des Aales große individuelle Schwankungen aufweist (vgl. van Dam 1938, Precht 1961, Steen \& Kruysse 1964, Schultze 1965). Auch in der vorliegenden Arbeit wurde bereits mehrfach auf die erhebliche Variabilität der Meßwerte hingewiesen; besonders augenfällig tritt sie in den folgenden Abbildungen hervor. In der Abbildung 11 haben wir Messungen des venösen Sauerstoffdrucks bei verschiedenen Versuchstemperaturen zusammengestellt, die bei an $8^{\circ} \mathrm{C}$ adaptierten Aalen vorgenommen wurden. Abbildung 12 enthält entsprechende Messungen an Aalen, die vor den Versuchen bei Wassertemperaturen von $22^{\circ} \mathrm{C}$ gehältert waren. Jedem Sauerstoffpartialdruck ist ein Wert für die Atemfrequenz zugeordnet. Die Abbildungen enthalten nur Werte, die eine über 10 bis 15 min konstant bleibende Sauerstoffspannung repräsentieren. Die Zahl der Ventilationsbewegungen in dieser Zeitspanne wurde mehrfach bestimmt, ihr Mittelwert ist die eingetragene Atemfrequenz. Da nur bei einzelnen Versuchen der ganze Temperaturbereich gleichmäßig erfaßt werden konnte, sind die an verschiedenen Tieren gewonnenen Ergebnisse nicht kurvenmäßig dargestellt. Wie bereits in der Methode erwähnt, erfolgten die Messungen bei möglichst flacher Narkose. So kam es nicht selten vor, daß sich während eines Versuches der Aal aus der Fesselung des Halters befreite und fortschwamm. Aus diesem Grunde wurden die Kanülen auch nicht fest in das Gefäß eingebunden, um bei Bewegungen des Fisches die empfindliche Mikro-Elektrode nicht zu 
Tabelle 16

Sauerstoffdruck des venösen Blutes und Atemfrequenz verschieden adaptierter Aale in Abhängigkeit von der Versuchstemperatur. Die jeweiligen Mittelwerte wurden aus den Angaben der Abbildungen 11 und 12 berechnet. Bei den Sauerstoffdrucken sind die mittleren Fehler der Mittelwerte, bei den Atemfrequenzen die Extremwerte angeführt. N: Zahl der Messungen; E: Extremwerte

\begin{tabular}{|c|c|c|c|c|}
\hline \multirow[b]{2}{*}{ VT } & \multicolumn{2}{|c|}{$\mathrm{AT}-8^{\circ} \mathrm{C}$} & \multicolumn{2}{|c|}{$\mathrm{AT}-22^{\circ} \mathrm{C}$} \\
\hline & $\begin{array}{l}\mathrm{pO}_{2} / \mathrm{mmHg}^{(\mathrm{N})} \\
\end{array}$ & $\begin{array}{l}\text { Atemfrequenz } \\
\text { (E) }\end{array}$ & $\begin{array}{l}\mathrm{pO}_{2} / \mathrm{mmH} H \mathrm{H} \\
(\mathrm{N})\end{array}$ & $\begin{array}{l}\text { Atemfrequenz } \\
\text { (E) }\end{array}$ \\
\hline $8^{\circ} \mathrm{C}$ & $24 \underset{(6)}{ \pm} 5,9$ & $\begin{array}{c}9,9 \\
(4,0-13,5)\end{array}$ & $22 \pm 2,7$ & $\begin{array}{c}12,1 \\
(8,1-17,2)\end{array}$ \\
\hline $9^{0} \mathrm{C}$ & $22 \frac{ \pm}{(6)} 4,0$ & $\begin{array}{c}12,0 \\
(7,6-15,9)\end{array}$ & $20 \pm \frac{ \pm}{(5)} 2,0$ & $\begin{array}{c}12,1 \\
(9,0-15,4)\end{array}$ \\
\hline $10^{\circ} \mathrm{C}$ & $22 \underset{(9)}{ \pm 2,4}$ & $\begin{array}{c}13,9 \\
(9,6-19,3)\end{array}$ & $26 \pm \frac{ \pm 1,9}{(8)}$ & $\begin{array}{c}15,0 \\
(11,7-20,4)\end{array}$ \\
\hline $11^{\circ} \mathrm{C}$ & $24 \underset{(12)}{ \pm 2,7}$ & $\begin{array}{c}15,0 \\
(8,6-22,0)\end{array}$ & $23 \frac{ \pm}{(8)} 2,4$ & $\begin{array}{c}14,3 \\
(7,9-21,0)\end{array}$ \\
\hline $12^{\circ} \mathrm{C}$ & $20 \pm 1,9$ & $\begin{array}{c}16,9 \\
(10 ; 0-24,8)\end{array}$ & $23 \underset{(14)}{ \pm 2,2}$ & $\begin{array}{c}14,4 \\
(9,3-21,0)\end{array}$ \\
\hline $13^{\circ} \mathrm{C}$ & $23 \underset{(9)}{ \pm 2,2}$ & $\begin{array}{c}19,4 \\
(12,0-27,0)\end{array}$ & $24 \underset{(13)}{ \pm 2,5}$ & $\begin{array}{c}15,4 \\
(8,3-26,8)\end{array}$ \\
\hline $14^{\circ} \mathrm{C}$ & $22 \pm 2,3$ & $\begin{array}{c}20,0 \\
(12,9-28,6)\end{array}$ & $29 \underset{(15)}{ \pm 2,3}$ & $\begin{array}{c}17,4 \\
(13,8-25,8)\end{array}$ \\
\hline $15^{\circ} \mathrm{C}$ & $22 \pm 1,8$ & $\begin{array}{c}23,6 \\
(16,8-30,6)\end{array}$ & $27 \underset{(15)}{ \pm 2,1}$ & $\begin{array}{c}18,5 \\
(11,2-25,5)\end{array}$ \\
\hline $16^{\circ} \mathrm{C}$ & $25 \pm 1,7$ & $\begin{array}{c}26,4 \\
(18,8-35,2)\end{array}$ & $31 \pm 2,1$ & $\begin{array}{c}20,3 \\
(13,0-30,8)\end{array}$ \\
\hline $17^{\circ} \mathrm{C}$ & $24 \underset{(11)}{ \pm 2,1}$ & $\begin{array}{c}31,4 \\
(19,0-40,8)\end{array}$ & $29 \pm 2,1$ & $\begin{array}{c}22,6 \\
(14,0-32,1)\end{array}$ \\
\hline $18^{\circ} \mathrm{C}$ & $23 \pm 2,5$ & $\begin{array}{c}31,0 \\
(16,4-42,0)\end{array}$ & $\begin{array}{c}32 \pm 3,2 \\
(12)\end{array}$ & $\begin{array}{c}26,4 \\
(18,8-37,7)\end{array}$ \\
\hline $19^{\circ} \mathrm{C}$ & $25 \pm 2,2$ & $\begin{array}{c}36,1 \\
(23,0-46,0)\end{array}$ & $37 \pm 2,3$ & $\begin{array}{c}29,3 \\
(23,3-34,4)\end{array}$ \\
\hline $20^{\circ} \mathrm{C}$ & $\begin{array}{c}26 \pm 2,1 \\
(14)\end{array}$ & $\begin{array}{c}39,9 \\
(27,0-63,0)\end{array}$ & $38 \underset{(13)}{ \pm 2,8}$ & $\begin{array}{c}31,0 \\
(24,8-38,0)\end{array}$ \\
\hline $21^{\circ} \mathrm{C}$ & $25 \pm 1,9$ & $\begin{array}{c}48,0 \\
(26,3-73,0)\end{array}$ & $\begin{array}{c}39 \pm 3,1 \\
(13)\end{array}$ & $\begin{array}{c}33,3 \\
(28,0-40,0)\end{array}$ \\
\hline
\end{tabular}

beschädigen. Bei den kaltadaptierten Aalen schwanken die registrierten Sauerstoffdrucke zwischen 10 und $40 \mathrm{mmHg}$. Warmgehaltene Aale weisen hauptsächlich bei Versuchstemperaturen oberhalb von $13^{\circ} \mathrm{C}$ höhere Sauerstoffspannungen auf.

Die Streuung erstreckt sich auch hier über einen Bereich von $40 \mathrm{mmHg}$ bei den gemessenen Sauerstoffdrucken. In der Tabelle 16 sind mit Ausnahme weniger gänzlich herausfallender Werte die Daten der Abbildungen 11 und 12 zu Mittelwerten zusammengefaßt. Bei kaltadaptierten Aalen differieren diese Mittelwerte der Sauerstoffpartialdrucke nur um einige $\mathrm{mmHg}$ über den ganzen untersuchten Temperaturbereich. 


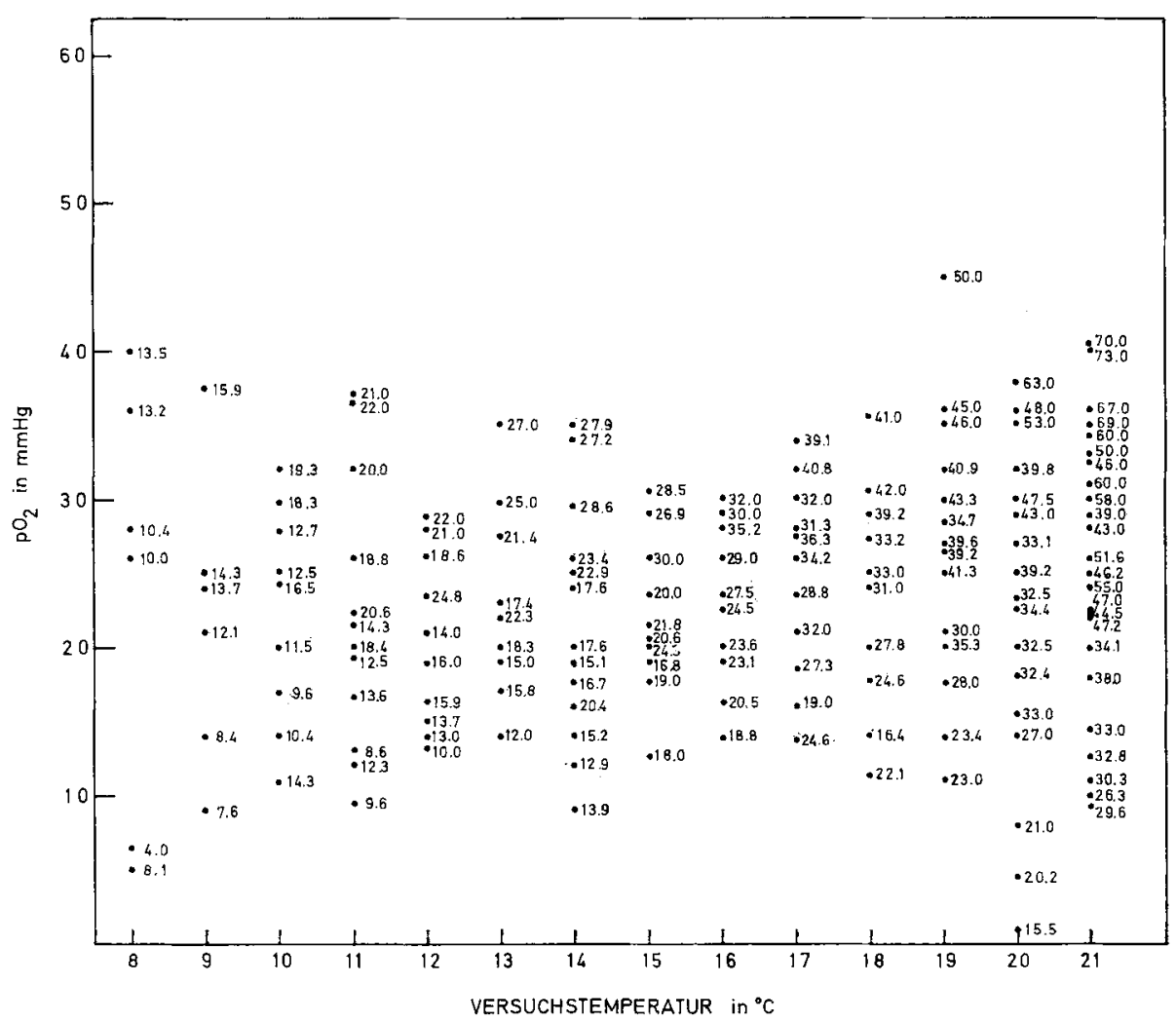

Abb. 11: Der Sauerstoffdruck im Blut der Caudalvene kaltadaptierter Aale bei verschiedenen Versuchstemperaturen. Jeder Punkt entspricht einem über ca. 10 bis 15 min konstant bleibenden Partialdruck; die während dieser Mcßzeit bestimmte Atemfrequenz ist jeweils angegeben. Adaptationstemperatur $8^{\circ} \mathrm{C}$; Zahl der untersuchten Tiere: 12; Gewichte zwischen 225 und 390 g. Versuchszeit: November 1965 bis Februar 1966

Dagegen erhöht sich der Mittelwert des Sauerstoffpartialdrucks bei warmgehaltenen Tieren von $20 \mathrm{mmHg}$ - gemessen bei $9^{\circ} \mathrm{C}$ - auf $39 \mathrm{mmHg}$ - gemessen bei $21^{\circ} \mathrm{C}$. Beide Tiergruppen zeigen den zu erwartenden Anstieg der Atemfrequenzen mit zunehmender Versuchstemperatur. Bereits die Mittelwerte lassen im oberen Temperaturbereich erkennen, daß die Adaptationstemperatur die Höhe des Sauerstoffdrucks beeinflußt. Die an $22^{\circ} \mathrm{C}$ adaptierten Aale haben bei niedrigerer Atemfrequenz eine höhere Sauerstoffspannung im Blut der Schwanzvene als die kaltgehaltenen Fische. Dies wird noch deutlicher, wenn man die Atemfrequenzen nach Gruppen etwa gleicher Intensität aufschlüsselt und für jede Gruppe die zugehörigen Sauerstoffdrucke in $\mathrm{Ab}$ hängigkeit von der Versuchstemperatur darstellt (Abb. 13 und 14). Der Vergleich beider Kurvenscharen beweist, daß in fast allen Fällen gleich hohe Atemfrequenzen mit größeren Sauerstoffdrucken bei den warmadaptierten Aalen korreliert sind. Die Sauerstoffspannung im Blut nimmt mit steigender Versuchstemperatur ab, wenn man konstante Atemfrequenzen berücksichtigt. Dieser Abfall ist bei den verschieden adap- 


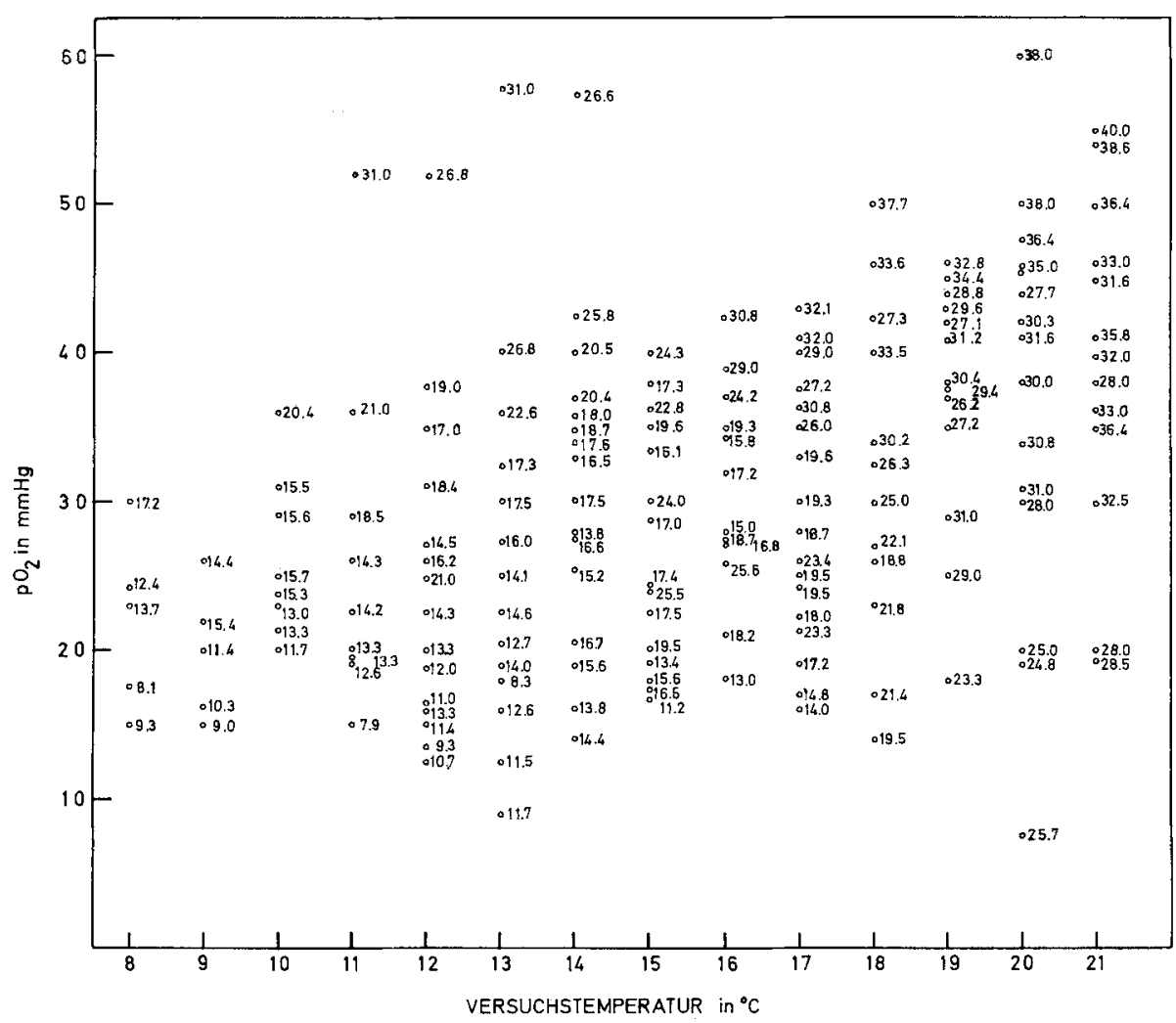

Abb. 12: Der Sauerstoffdruck im Blut der Caudalvene warmadaptierter Aale bei verschiedenen Versuchstemperaturen. Adaptationstemperatur $22^{\circ} \mathrm{C} ; 14$ Versuchstiere; im Gewicht zwischen 260 und $420 \mathrm{~g}$. Versuchszeit: November 1965 bis Februar 1966 sowie Dezember 1966

tierten Fischen nicht übereinstimmend. Unerwartet ist der teilweise flache Kurvenverlauf in dem für die warmadaptierten Tiere gezeichneten Diagramm. Unterschiede in der Atmungstiefe und in der Kiemendurchblutung bei den Fischen beider Adaptationsgruppen scheinen insbesondere bei tieferen Versuchstemperaturen zu bestehen. Die kräftigeren Ventilationsbewegungen wurden fast immer bei den an $8^{\circ} \mathrm{C}$ angepaßten Aalen beobachtet.

Jede durch den Stoffwechsel des Gewebes hervorgerufene Abnahme des Sauerstoffgehalts im Blut zieht natürlich auch Änderungen der Kohlendioxydspannung nach sich. Der $\mathrm{CO}_{2}$-Druck im Blut beeinflußt nicht nur seine biochemischen Eigenschaften, sondern wirkt gleichzeitig auf die Ausnutzung des Atemwassers. Ein Anstieg führt zu einer Hyperventilation (SAUNDERS 1962) und verändert die Sauerstoffaffinität des Hämoglobins, die Bindungskurve wird nach rechts verschoben und abgeflacht. Das Ausmaß dieses Bohreffekts ist bei den einzelnen Fischarten verschieden; er ist bei Cypriniden, Welsen und Fischen, die in stagnierendem Wasser leben und wie der Aal ihr Hämoglobin bereits bei niedrigen Sauerstoffdrucken sättigen, gering (FRY 1957). 


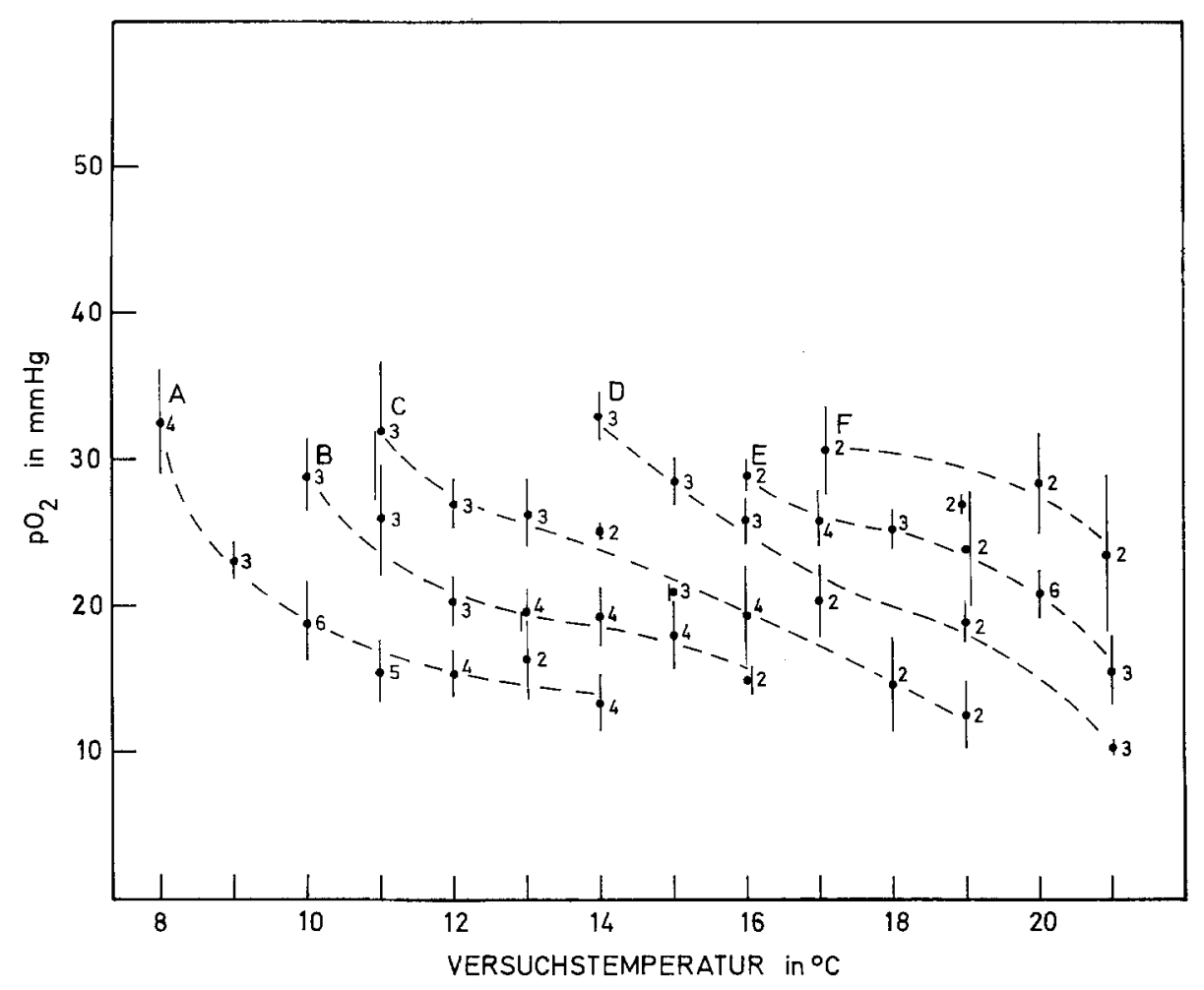

Abb. 13: Der Sauerstoffdruck im Blut der Caudalvene kaltadaptierter Aale in Abhängigkeit von der Atemfrequenz. Die Meßwerte wurden der Abbildung 11 entnommen und die Atemfrequenzen in folgende Gruppen aufgeschlïsselt: A 10-15, B 16-20, C 21-25, D 26-30, E 31-35, F 36-40 Kiemendeckelbew egungen pro min. Wenn bei der jeweiligen Versuchstemperatur mindestens 2 Atemfrequenzen derselben Gruppe zugehörten, wurde der Mittelwert gebildet und unter Angabe seines mittleren Fehlers in das Diagramm eingetragen. Die Verbindung der Meßpunkte zu Kurven erfolgte nach Augenmaß

Es finden sich nur spärlich neue Angaben über die $\mathrm{CO}_{2}-$ Konzentration im Fischblut. Nach Koyama (1960) hat das venöse Karpfenblut eine $\mathrm{CO}_{2}$-Spannung um $32 \mathrm{mmHg}$, das arterielle um $13 \mathrm{mmHg}$. Nach BLACK et al. (1966) enthält das venöse Blut von Salvelinus fontinalis bei $1^{\circ} \mathrm{C} 22$ bis 27 Vol.- $\% \mathrm{CO}_{2}$; dies entspricht einem Druck von $6,5 \mathrm{mmHg}$. Beim Bachsaibling ist die Größe des Bohreffekts beträchtlich, sie wird durch eine Adaptation an Sommer- und Wintertemperaturen jedoch nicht geändert. Bei einer Versuchstemperatur von $7^{\circ} \mathrm{C}$ liegt der arterielle $\mathrm{CO}_{2}$-Gehalt im Aalblut zwischen 20 und 25 Vol.- $\%$, bei $15^{\circ} \mathrm{C}$ zwischen 20 und 30 Vol. $-\%$ und der pH-Wert bei 7,5 (Berg \& Steen 1965). Unter in-vitro-Bedingungen fällt der Sauerstoffgehalt des Aalblutes um $40 \%$, wenn der $\mathrm{pH}$-Wert von der arteriellen Höhe 7,8 auf 7,0 vermindert wird (STEEN 1963). Am stärksten tritt dieser ROOT-Effekt bei $8^{\circ} \mathrm{C}$ im pH-Bereich 7,3 bis 7,0, bei $19^{\circ} \mathrm{C}$ zwischen 7,5 und 7,3 auf. Dies bedeutet, daß bei tiefen Versuchstemperaturen erst eine stärkere Ansäuerung des Blutes seine Sauerstoffkapazität herab- 


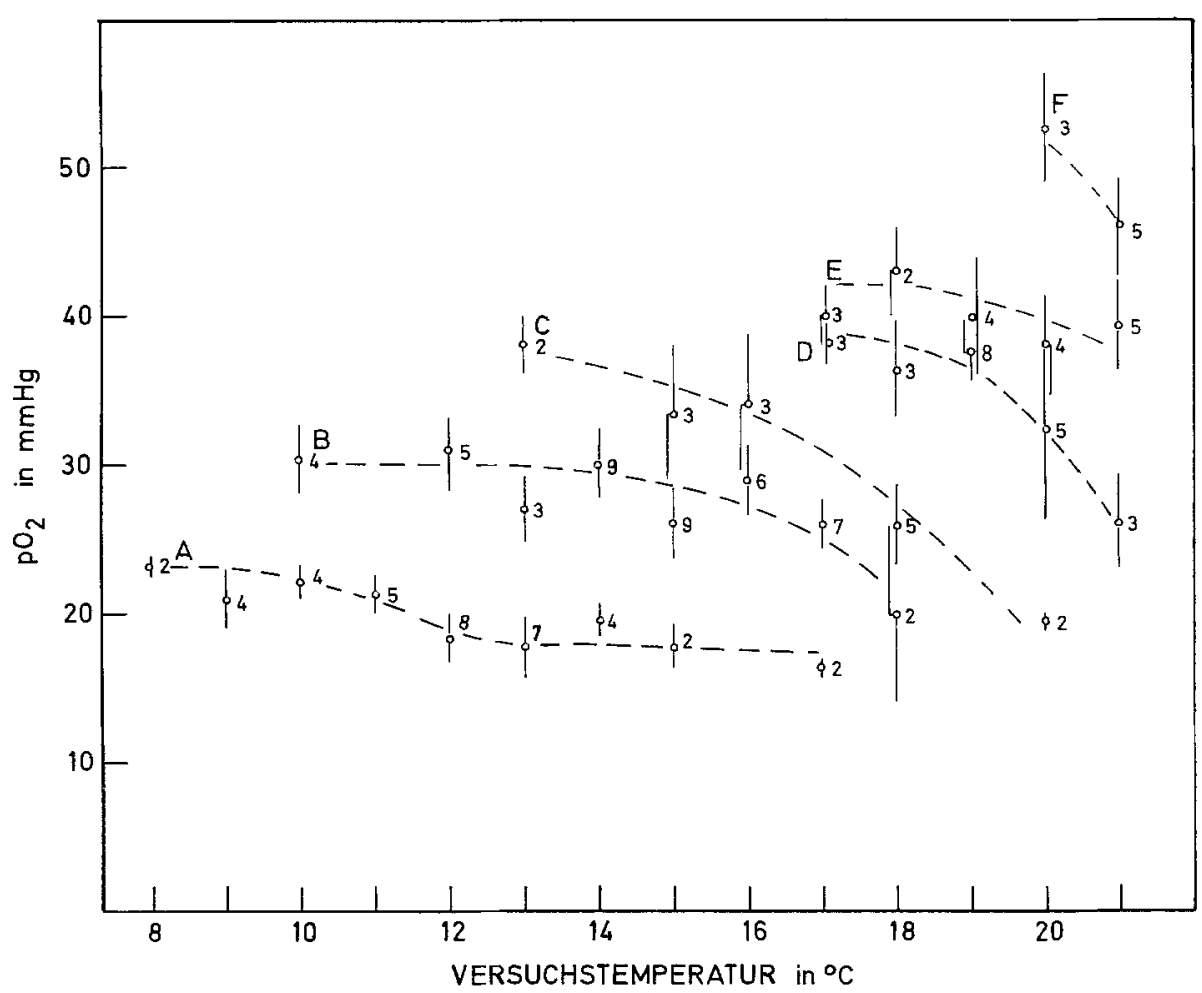

Abb. 14: Der Sauerstoffdruck im Blut der Caudalvene warmadaptierter Aale in Abhängigkeit von der Atemfrequenz. Die Meßwerte wurden der Abbildung 12 entnommen und die Atemfrequenzen in folgende Gruppen aufgeschlüsselt: A 10-15, B 16-20, C 21-25, D 26-30, E 31-35, F 36-40 Kiemendeckelbewegungen pro min. Einzelheiten der Darstellung sind aus der Legende der Abbildung 13 zu ersehen

setzt und die schlechtere Abatmung des $\mathrm{CO}_{2}$ bei niedrigen Atemfrequenzen sich somit nicht nachteilig auswirkt.

$\mathrm{Da}$ in vorliegender Arbeit der $\mathrm{CO}_{2}$-Druck und der $\mathrm{pH}$-Wert im Blut nicht gemessen wurden, muß die Frage, inwieweit die Adaptationstemperatur beide Größen beeinflußt, offenbleiben. Die stärkere Atmung der roten Muskulatur kaltadaptierter Aale dürfte mit einem Anstieg des $\mathrm{pCO}_{2}$ im Blut verbunden sein; es läßt sich daraus aber keine Erniedrigung des $\mathrm{pH}$-Wertes folgern, da von ihr mehr glykolytische Metaboliten verbrannt werden könnten als von der Muskulatur warmadaptierter Aale.

\section{Der Sauerstoffdruck in der Skelettmuskulatur des Aales}

Da im allgemeinen die Stoffwechselhöhe eines Gewebes mit seiner Durchblutung korreliert ist, war zu prüfen, ob bei unterschiedlich adaptierten Aalen der Sauerstoffdruck in der Muskulatur geändert ist. Ein Einfluß der Adaptationstemperatur auf den Sauerstoffdruck der dorsalen Skelettmuskulatur besteht nicht; die Höhe der Sauerstoff- 


\section{Tabelle 17}

Der Sauerstoffdruck in der dorsalen Rückenmuskulatur von Aalen bei wechselnden Adaptationsund Versuchstemperaturen. Angegeben ist die Streuung der Werte bei wiederholter, jeweils 10 min dauernder Messung

\begin{tabular}{|ccc|}
\hline AT/VT & $\begin{array}{c}\text { Vorderköper } \\
\text { pO } / \mathrm{mmHg}\end{array}$ & $\begin{array}{c}\text { Hinterkörper } \\
\mathrm{pO} / \mathrm{mmHg}\end{array}$ \\
\hline $4^{\circ} \mathrm{C} / 6^{\circ} \mathrm{C}$ & $2-4$ & $3-5$ \\
$10^{\circ} \mathrm{C} / 4^{\circ} \mathrm{C}$ & $1,5-3$ & $1-4$ \\
$10^{\circ} \mathrm{C} / 12^{\circ} \mathrm{C}$ & $0,5-4$ & $0,5-4$ \\
$15^{\circ} \mathrm{C} / 15^{\circ} \mathrm{C}$ & $1-2$ & $1-3$ \\
$15^{\circ} \mathrm{C} / 20^{\circ} \mathrm{C}$ & $1-8$ & $1-4$ \\
$22^{\circ} \mathrm{C} / 12^{\circ} \mathrm{C}$ & $2-5,5$ & $1-6$ \\
$22^{\circ} \mathrm{C} / 16^{\circ} \mathrm{C}$ & $0,5-1$ & $0,5-1,5$ \\
$22^{\circ} \mathrm{C} / 20^{\circ} \mathrm{C}$ & $0,5-2$ & $0,5-3$ \\
\hline
\end{tabular}

spannung ist sehr gering (Tab. 17). Bei einem so schwach durchbluteten Gewebe, wie dem der tetanischen Aalmuskulatur, überrascht der Befund nicht. Sticht man die Elektrode in gut durchblutete Bereiche in der Nähe des Hämalkanals, so werden höhere Sauerstoffspannungen gemessen ( 9 bis $13 \mathrm{mmHg}$ ). Selbst in Säugergeweben ist der Sauerstoffdruck niedrig; im Rattenhoden wurden 9 bis $10 \mathrm{mmHg}$, im Gehirn dieser Tiere 14 bis $16 \mathrm{mmHg}$ ermittelt (Gross \& SILVER 1962). Eine eingehende mathematische Analyse der Faktoren, die die Verteilung des Sauerstoffs in lebenden Geweben beeinflussen, geben Hudson \& Cater (1965) (vgl. auch Grothe \& Thews 1962 sowie SCHMidt et al. 1965).

\section{ZUR TEMPERATURABHANGIGKEIT DES STOFFWECHSELS DES AALES}

Bei einer Besprechung der Temperaturadaptation des Aales sind folgende Befunde zu berücksichtigen:

(a) Der Sauerstoffverbrauch intakter Aale wie auch die Succinatveratmung ihres Muskelgewebes zeigen eine Leistungsadaptation im Sinne einer Kompensation (PRECHT 1951, Schultze 1965).

(b) Nach SCHULTZE wird die Ganztieratmung nur durch die thermale Vorbehandlung des Vorderkörpers (Körperteil zwischen der Kopfspitze und der Analöffnung) beeinflußt; sie hängt nicht von der des Hinterkörpers ab, obwohl tiefe Adaptationstemperaturen die in vitro gemessene Atmung der Schwanzmuskulatur steigern.

(c) Die unter (b) genannten Versuche sprechen nicht unbedingt für eine direk te Wirkung der Temperatur auf das Muskelgewebe. Die Adaptation der Gewebeatmung könnte auf einer Anderung der spinalen Innervierung beruhen, da sich die Frequenzen der tonischen spikes in der Körperwandmuskulatur hinsichtlich der Vorbehandlungstemperatur ähnlich wie die Succinatveratmung verhalten (Prosser et a. 1965).

(d) Die Skelettmuskulatur des Aales besteht zum überwiegenden Teil aus weißen Fasern; ihre oxydative Kapazität wird jedoch in erster Linie von der Enzymausstattung der peripheren, roten Muskelfasern bestimmt (vgl. Tab. 9 und 10). Die Adaptation der Gewebeatmung (a) manifestiert sich somit hauptsächlich in der roten Muskulatur (durch unveröffentlichte Untersuchungen von MALEsSA bekräftigt). 
(e) Der $\mathrm{pO}_{2}$ ist in der weißen Muskulatur bei warm- und kaltadaptierten Aalen gleich niedrig (vgl. Tab. 17).

(f) Entsprechend der Ganztieratmung weisen Atem- und Herzfrequenzen leicht narkotisierter Aale eine Temperaturadaptation im Sinne einer Kompensation auf (vgl. Tab. 13).

(g) Der $\mathrm{pO}_{2}$ im Herzblut ist bei kaltadaptierten Aalen niedriger als bei warmadaptierten Tieren, wenn die Messungen bei übereinstimmender Atemfrequenz und Versuchstemperatur vorgenommen werden (vgl. Tab. 11).

(h) Bei etwa gleich hoher Ventilation verschieden adaptierter Aale unterscheidet sich der $\mathrm{pO}_{2}$ im Blut der caudalen Aorta nicht, dagegen steigt er im Blut der caudalen Vene mit höherer Adaptationstemperatur an (vgl. Tab. 12).

(i) Eine kontinuierliche Steigerung der Versuchstemperatur erhöht die Atemfrequenz und den $\mathrm{pO}_{2}$ im Blut der Caudalvene; bei entsprechenden Temperatursenkungen beobachtet man ebenfalls einen Anstieg des $\mathrm{pO}_{2}$ (vgl. Abb. 9).

(k) Wird während der Messungen jede Versuchstemperatur längere Zeit beibehalten, so ist bei kaltadaptierten Aalen der $\mathrm{pO}_{2}$ des venösen Blutes über den gesamten Bereich von 8 bis $21^{\circ} \mathrm{C}$ weitgehend konstant; bei warmadaptierten Tieren trifft dies nur für Temperaturen zwischen 8 und $13^{\circ} \mathrm{C}$ zu, höhere Versuchstemperaturen führen zu einem größeren $\mathrm{pO}_{2}$ (vgl. Mittelwerte der Tab. 16).

(l) Ordnet man die $\mathrm{pO}_{2}$-Werte nach der Höhe der Atemfrequenz, so sind zwischen 10 und $21^{\circ} \mathrm{C}$ die höheren Werte jeweils bei warmadaptierten Aalen zu finden (vgl. Abb. 13 und 14).

(m) Wenn die Temperatur im Schwanzbereich der Versuchstiere um $10^{\circ} \mathrm{C}$ gegenüber der des Vorderkörpers gesteigert wird, treten bei langfristigen Messungen eine ausgeprägte Zunahme der Atemfrequenz und ein leichter Anstieg im venösen $\mathrm{pO}_{2}$ auf (vgl. Tab. 15).

Die vorliegenden Untersuchungen (siehe $g, h, l$ ) zeigen, daß unter vergleichbaren experimentellen Bedingungen die Gewebe kaltadaptierter Aale den angebotenen Blutsauerstoff stärker ausnutzen als die Gewebe warmadaptierter Tiere; die Leistungsadaptation der Gewebeatmung in vitro (a) steht hiermit in Ubereinstimmung.

Anderungen der Versuchstemperatur beeinflussen den $\mathrm{pO}_{2}$ des venösen Blutes kaltadaptierter Aale kaum (k); zwar nimmt in dem als „Modell“ dienenden Schwanzende des Aales der Sauerstoffbedarf des Muskelgewebes mit höheren Temperaturen $\mathrm{zu}$, aber durch die beschleunigte Atem- und Herzfrequenz wird auch das Sauerstoffangebot verbessert. Bei warmadaptierten Aalen sind Kreislaufintensität, Ventilationsarbeit und Gewebeatmung herabgesetzt. Die stärkere Abhängigkeit des Sauerstoffdrucks im Blut ihrer Schwanzvene von der Versuchstemperatur dürfte mit unterschiedlichen $\mathrm{Q}_{10}$-Werten der beteiligten Größen zusammenhängen; der Sauerstoffverbrauch wird dann weniger als das Sauerstoffangebot anwachsen. Wegen der Leistungsadaptation der Atem- und Kreislauftätigkeit im Sinne einer Kompensation ( $f$ ) unterscheidet sich die arterio-venöse Differenz bei warm- und kaltadaptierten Aalen nicht so stark, als wenn die Messungen bei gleicher Atem- und Herzfrequenz vorgenommen werden (1). Bei ungestörten Aalen wird der arterielle Sauerstoffgehalt normalerweise so tief wie möglich gehalten, wobei die Sauerstoffaufnahme nicht nur durch die Ventilationsleistung, sondern auch durch die Kiemendurchblutung geregelt wird; Adrenalininjek- 
tionen verbessern die Durchblutung der Kiemen und erhöhen somit den $\mathrm{pO}_{2}$ im arteriellen Blut (Steen \& Kruysse 1964, vgl. auch Laffont \& Labat 1966). Als Maß für das arterielle Sauerstoffangebot wählte ich nur die Atemfrequenz (h). Die zentralnervös gesteuerte Ganztieratmung des Aales richtet sich nach dem Bedarf aller Gewebe des Körpers; als primäre Regelgröße für die Sauerstoffaufnahme kommt der $\mathrm{pO}_{2}$ Wert im Blut der Caudalvene nicht in Betracht. Obwohl er bei einer Temperaturänderung des Hinterkörpers ansteigt, führt der Mehrverbrauch des Muskelgewebes zu einer stärkeren Ventilation (m). Der venöse Sauerstoffdruck in den caudalen Gefäßen hängt neben dem arteriellen Angebot und dem Sauerstoffverbrauch der Gewebe auch von der Durchblutung der verschiedenen Organe ab; bei einer Steigerung der Versuchstemperatur scheint zunächst die kaum beanspruchte Muskulatur schlechter mit Blut versorgt zu werden als die im Vorderkörper gelegenen Organe (i). Solche cardiovaskulären Anpassungen sind auf Grund der schwachen Zirkulationsleistung des Aalkreislaufs zu erwarten. Das Blutvolumen beträgt etwa $2,9 \mathrm{ml}$ je $100 \mathrm{~g}$ Körpergewicht (Close 1955). Das Blut benötigt $6 \mathrm{sec}$, um durch die Kiemen, aber etwa 1 min, um vom Herzen zum hinteren Ende der Cardinalvenen zu strömen. Dabei sinkt der Blutdruck von 30 bis $40 \mathrm{mmHg}$ in der ventralen Aorta auf Werte zwischen 16 und $20 \mathrm{mmHg}$ hinter dem Kapillarnetz der Kiemen ab (Mотт 1950, 1951). Auch Chester JoNEs et al. (1966) ermittelten an Süßwasseraalen einen arteriellen Blutdruck von durchschnittlich $26 \mathrm{mmHg}$, an Salzwassertieren einen von ca. $17 \mathrm{mmHg}$. RandalL et al. (1966) haben bei der Regenbogenforelle den Blutdruck in der dorsalen Aorta bei sehr unterschiedlichem Sauerstoffverbrauch der Fische gemessen; er änderte sich selbst dann nur minimal, wenn der Sauerstoff verbrauch um $100 \%$ zunahm. Eine Vergrößerung der arterio-venösen Differenz bei gesteigertem Sauerstoffbedarf wird von RANDALL et al. als mögliche Erklärung ihrer Befunde diskutiert. Nach den unter (b) genannten Untersuchungen wirkt sich eine Leistungsadaptation der Atmung der Schwanzmuskulatur nicht auf die Höhe der Ganztieratmung der Aale aus. Wie ist dies zu erklären?

Beim Aal hängt die oxydative Kapazität der Muskulatur weitgehend von den Enzymaktivitäten der roten Fasern ab, ihr prozentualer Anteil am gesamten Körpergewicht ist gering (d). Es ist deshalb fraglich, ob bei Messungen der Ganztieratmung nicht zu große Verschiebungen in der Sauerstoffaufnahme der roten Muskulatur überhaupt erfaßbar sind. Bei ruhigen Aalen wird die maximale Atmungskapazität der Muskulatur nicht ausgeschöpft; es werden bei der Ganztieratmung Änderungen im Sauerstoffbedarf der Organe des Vorderkörpers stärker ins Gewicht fallen.

Es bleibt aber auch zu bedenken, daß bei ruhigen, langsam ventilierenden Aalen die arterielle Sauerstoffsättigung niedrig ist und wahrscheinlich eine Regulierung der peripheren Durchblutung die Sauerstoffversorgung der Muskulatur begrenzt. Sofern die geäußerten methodischen Bedenken nicht zutreffen, muß nach den Versuchen von Schultze diese Regulation vom Kopfende her erfolgen und somit zentralen oder/und hormonalen Ursprungs sein. Eine größere Atmung des Muskelgewebes könnte sich durch eine derartige Regulierung weniger auswirken als es bei den Messungen in vitro der Fall war. Weitere Versuche über den Einfluß der Vorbehandlungstemperatur auf den Kreislauf der Fische und die Sauerstoffausnutzung ihres Blutes sind notwendig und auch geplant. 


\section{ZUSAMMENFASSUNG}

1. Untersuchungen ïber die Temperaturadaptation des Fischstoffwechsels wurden an Orfen (Idus idus L.) und an Aalen (Anguilla vulgaris L.) vorgenommen.

2. Beim isolierten Kiemen-, Muskel- und Lebergewebe der Orfe wurden der Sauerstoffverbrauch bei Zusatz verschiedener Substrate und die Aktivitäten der Aldolase und der Malatdehydrogenase bestimmt. Ferner sind die anaerobe Säurebildung des isolierten Kiemen- und Muskelgewebes sowie die Aktivität der Cytochromoxydase in der Skelettmuskulatur gemessen worden.

3. Der Sauerstoffverbrauch der Kiemen und der Rumpfmuskulatur zeigt eine Temperaturabhängigkeit im Sinne einer Kompensation (höhere Werte bei kaltadaptierten Fischen); gleiches gilt für die Cytochromoxydaseaktivität in der Muskulatur und für die Aktivitäten der Aldolase und Malatdehydrogenase in Kieme, Muskel und Leber. Der durch die Vorbehandlungstemperatur bedingte Unterschied im Sauerstoffverbrauch der Muskulatur ist unabhängig vom Zusatz exogener Substrate. Die Succinatveratmung der Leberhomogenate und die anaerobe Säurebildung isolierter Kiemen lassen keinen Einfluß der Adaptationstemperatur erkennen. Fructose-1,6-diphosphat wird besser von Leberhomogenaten warmadaptierter Orfen verwertet.

4. Durch Injektion von Thyreotropin wird nur die Malatdehydrogenase in der Leber kaltadaptierter Orfen signifikant erhöht.

5. Beim Aal sind die Atemfrequenz, die Herzfrequenz und die Sauerstoffspannungen in der dorsalen Rumpfmuskulatur, im Herzblut und im Blut der caudalen Hauptgefäße gemessen worden. Außerdem wurden Bau und oxydative Kapazität der Rumpfmuskulatur untersucht.

6. Die Atmungsintensität der Aalmuskulatur wird überwiegend durch den Anteil roter Muskelfasern bestimmt.

7. Atem- und Herzfrequenz der Aale weisen eine Temperaturanpassung im Sinne einer Kompensation auf.

8. Die niedrige Sauerstoffspannung in der weißen Rumpfmuskulatur und der Sauerstoffdruck im Blut der Schwanzarterie differieren nicht bei unterschiedlich angepaßten Aalen; dagegen hängt die Höhe der Sauerstoffspannung im venösen Blut von der thermalen Vorbehandlung ab.

9. An langfristigen Registrierungen des venösen Sauerstoffdrucks ließ sich seine Abhängigkeit von den Adaptations- und Versuchsbedingungen genauer analysieren. Schnelle Steigerungen der Versuchstemperaturen erhöhen die Atemfrequenz und die Sauerstoffspannung; ein Gleichgewicht zwischen der Sauerstoffaufnahme der Muskulatur und dem Sauerstoffgehalt des Blutes stellt sich erst nach längerer Versuchszeit ein. Beim Abkühlen der Versuchstiere verringert sich die arterio-venöse Differenz ohne Verzögerung. Wird zwischen dem Vorder- und Hinterkörper des Aales ein Temperaturunterschied längere Zeit aufrechterhalten, so ändert sich die Sauerstoffspannung, wie sie in der Caudalvene gemessen wird, kaum. Bei übereinstimmender Ventilationsleistung liegt die venöse Sauerstoffspannung der an $22^{\circ} \mathrm{C}$ adaptierten Aale höher als die der an $8^{\circ} \mathrm{C}$ adaptierten Fische; dies gilt für den gesamten Temperaturbereich zwischen $10^{\circ} \mathrm{C}$ und $21^{\circ} \mathrm{C}$. 
10. Die in-vitro-Befunde an Orfen und die in-vivo-Messungen an Aalen bestätigen eine Leistungsadaptation des Gewebestoffwechsels im Sinne einer Kompensation. Die Temperaturabhängigkeit des Stoffwechsels des Aales wird diskutiert.

Für die vielfache Unterstützung der Untersuchungen möchte ich auch an dieser Stelle meinem verehrten Lehrer, Herrn Professor Dr. H. PrECHT, herzlich danken. Diese Arbeit wurde mit Unterstützung der Deutschen Forschungsgemeinschaft durchgeführt.

\section{ZITIERTE LITERATUR}

BARETs, A., 1961. Contribution à l'étude des systemes moteurs «lent» et «rapide» du muscle latéral des Teléostéens. Archs Anat. microsc. Morph. exp. 50 (1), 91-187.

Barrington, E. J. W., Barron, U. \& Piggins, J., 1961. The influence of thyroid powder and thyroxine upon the growth of rainbow trout (Salmo gairdnerii). Gen. comp. Endocr. 1, $170-178$.

Beisenherz, G., Boltze, H. J., Bücher, Th., Czok, R., Carbade, K. H., Meyer-Arendt, E. \& Pfleiderer, G., 1953. Diphosphofructose-Aldolase, Phosphoglyceraldehyd-Dehydrogenase, Milchsäure-Dehydrogenase, Glycerophosphat-Dehydrogenase und Pyruvat-Kinase aus Kaninchenmuskulatur in einem Arbeitsgang. Z. Naturf. (B) 8, 555-577.

Berg, T. \& Steen, J. B., 1965. Physiological mechanisms for aerial respiration in the eel. Comp. Biochem. Physiol. 15, 469-484.

Bergmeyer, H.-U. (Hrsg.), 1962. Methoden der enzymatischen Analyse. Verlag Chemie, Weinheim, $1065 \mathrm{pp}$.

Berkholz, G., 1966. Über die Temperaturadaptation des Nerflings (Idus idus L., Pisces) nach inkonstanter Vorbehandlung. Z. wiss. Zool. 174, 377-399.

Berlin, J. D. \& Dean, J. M., 1967. Temperature-induced alterations in hepatocyte structure of rainbow trout (Salmo gairdneri). J. exp. Zool. 164, 117-132.

Br.ack, E. C., Kirkpatrick, D. \& Tucker, H. H., 1966. Oxygen dissociation curves of the blood of brook trout (Salvelinus fontinalis) acclimated to summer and winter temperatures. J. Fish. Res. Bd Can. 23, 1-13.

BoNE, Q., 1966. On the function of the two types of myotomal muscle fibre in elasmobranch fish. J. mar. biol. Ass. U. K. 46, 321-349.

BUdDENBRoCK, E. voN, 1960. Über die Temperaturabhängigkeit der Narkosewirkung bei wechselwarmen Tieren. Z. wiss. Zool. 164, 173-187.

Buddendrock, W. von, 1967. Vergleichende Physiologie. Birkhäuser, Basel, Bd 6, 466 pp.

BurcK, H.-C., 1966. Histologische Technik. Thieme, Stuttgart, 144 pp.

Carlsen, H., 1953. Der Cocarboxylasegehalt des Aales (Anguilla vulgaris L.) Z. vergl. Physiol. 35, 199-208.

Chester Jones, J., Henderson, J. W., Chan, D. K. O., Rankin, J. C. \& Mosley, W., 1965. Pressor activity in extracts of the corpuscles of stannius from the european eel (Anguilla anguilla L.). J. Endocr. 34, 393-408.

Close, R. I., 1955. Resistance to blood flow in gills of Anguilla. M. S. Thesis, Victoria Univ. Coll., New Zealand, 44 pp. (Zitiert nach Prosser, C. L. \& F. A. Brown: Comparative animal physiology. 2nd ed. 1962. Saunders, Philadelphia, $\mathrm{Pa}, 413$, Ref. 37.)

Cross, B. A. \& Silver, J. A., 1962. Some factors affecting oxygen tension in brain and other organs. Proc. R. Soc. (B) 156, 483-499.

DAM, L. van, 1938. On the utilization of oxygen and regulation of breathing in some aquatic animals. Doctoral Thesis, Groningen.

DAs, A. B., 1967. Biochemical changes in tissues of goldfish acclimated to high and low temperatures. II. Synthesis of protein and RNA of subcellular fractions and tissue composition. Comp. Biochem. Physiol. 21, 469-485. 
- \& Prosser, C. L., 1967. Biochemical changes in tissues of goldfish acclimated to high and low temperatures. I. Protein synthesis. Comp. Biochem. Physiol. 21, 449-467.

DEAN, J. M. \& Goodnight, C. J., 1964. A comparative study of carbohydrate metabolism in fish as affected by temperature and exercise. Physiol. Zoöl. 37, 280-299.

Dische, Z., 1930. Uber einige neue charakteristische Farbreaktionen der Thymonucleinsäure und eine Mikromethode zur Bestimmung derselben in tierischen Organen mit Hilfe dieser Reaktionen. Mikrocbemie 8, 4-32.

EKBERG, D. R., 1958. Respiration in tissues of goldfish adapted to high and low temperatures. Biol. Bull. mar. biol. Lab., Woods Hole 114, 308-316.

- 1962. Anaerobic and aerobic metabolism in gills of crucian carp adapted to high and low temperatures. Comp. Biochem. Physiol. 5, 123-129.

Evans, R. M., Purdie, F. C. \& Hickman, C. P., 1962. The effect of temperature and photoperiod on the respiratory metabolism of rainbow throut (Salmo gairdneri). Can.J. Zool. 40, $107-118$.

FERGUSON, R. G., 1958. The preferred temperature of fish and their midsummer distribution in temperature lakes and streams. J. Fish. Res. Bd Can. 15, 607-624.

FISHER, K. C., 1958. An approach to the organ and cellular physiology of adaptation to temperature in fish and small mammals. In: Physiological adaptation. Ed. by C. L. ProsSER. Society of General Physiologists, Washington, 3-48.

- \& Sullivan, C. M., 1958. The effect to temperature on the spontaneous activity of speckled trout before and after various lesions of the brain. Can. J. Zool. 36, 49-63.

FREED, J. M., 1965. Changes in activity of cytochrome oxidase during adaptation of goldfish to different temperatures. Comp. Biochem. Physiol. 14, 651-659.

FRY, F. E. J., 1957. The aquatic respiration of fish. In: The physiology of fishes. Ed. by M. E. Brown. Acad. Press, New York, Vol. 1, 1-53.

- 1964. Animals in aquatic environments: fishes. In: Handbook of physiology. Section 4. Ed. by D. B. Dill, E. F. Adolph \& C. G. Wilber. American Physiological Society, Washington, D. C., 715-728.

- 1967. Responses of vertebrate poikilotherms to temperature. In: Thermobiology. Ed. by A. H. Rose. Acad. Press, New York, 375-410.

GeORgE, J. C. \& SCARIA, K. S., 1958. A histochemical study of dehydrogenase activity in the pectoralis major muscle of the pigeon and certain other vertebrate skeletal muscles. Q. $\mathrm{Jl}$. microsc. Sci. 99, 469-473.

GrTter, A., 1933. Untersuchungen über die Herztätigkeit der Fische. 5. Z. vergl. Physiol. 18, 654-666.

Grax, D. E. \& Deluca, H. A., 1956. Use of desoxyribonucleic acid as a reference standard in metabolic experiments. Am. J. Physiol. 184, 301-303.

Gross, W. L., Fromm, P. O. \& Roelofs, E. W., 1963. Relationship between thyroid and growth in green sunfish, Lepomis cyanellus (Rafinesque). Trans. Am. Fish. Soc. 92, 401-408.

Grothe, J. \& Thews, G., 1962. Die Bedingungen der Sauerstoffversorgung des Herzmuskelgewebes. Pflügers Arch. ges. Physiol. 276, 142-155.

Hoar, W. S., 1966. Hormonal activities of the pars distalis in cyclostomes, fish and amphibia. In: The pituitary gland. Ed. by G. W. HARRIS \& B. T. Donovan. Butterworths, London, 242-294.

HochachкA, P. W., 1962. Thyroidal effects on pathways for carbohydrate metabolism in a teleost. Gen. comp. Endocr. 2, 499-505.

- 1965. Isoenzymes in metabolic adaptation of a poikilotherm: subunit relationship in lactic dehydrogenases of goldfish. Archs Biochem. Biophys, 111, 96-103.

- \& Hayes, F. R., 1962. The effect to temperature acclimation on pathways of glucose metobolism in the trout. Can. J. Zool. 40, 261-270.

Hudson, J. A. \& Cater, D. B., 1965. Analysis of factors affecting tissue oxygen tension. Proc. R. Soc. (B) 161, 247-274.

ITAZAWA, Y., 1959. Gas content of the blood in response to that of medium water in fish. 2. Bull. jap. Soc. scient. Fish. 25, 301-306. 
Jaeger, K. H., Leybold, K., Mittenzwei, H., Staudinger, HJ. \& Waldstätten, L. von, 1965. Die Förderung der Zellatmung durch einen Blutextrakt. Arzneimittel-Forsch. 15, 750-754.

JANKOWSKY, H.-D., 1960. Uber die hormonale Beeinflussung der Temperaturadaptation beim Grasfrosch (Rana temporaria L.). Z. vergl. Physiol. 43, 392-410.

- 1964a. Die Bedeutung der Hormone für die Temperaturanpassung im normalen Temperaturbereich. Helgoländer wiss. Meeresunters. 9, 412-419.

- 1964b. Der Einfluß des Blutes auf den Sauerstoffverbrauch des isolierten Muskelgewebes von Schleien (Tinca tinca L.). Zool. Anz. 172, 233-239.

- 1968. On the structure and the metabolic rate of the skeletal muscle of the eel (Anguilla vulgaris L.). (Im Druck.)

- \& Korn, H., 1965. Der Einfluß der Adaptationstemperatur auf den Mitochondriengehalt des Fischmuskels. Naturwissenschaften 52, 642-643.

JANSKY, L., 1963. Body organ cytochrome oxidase activity in cold-and warm-acclimated rats. Can. J. Biochem. Physiol. 41, 1847-1854.

Kawamoto, N, 1929. Physiological studies on the eel. 2. The influence of temperature and the relative volumes of the red corpuscles and plasma upon the haemoglobin dissociation curve. Sci. Rep. Toboku Univ. (4. Ser.) 4, 643-659.

Kanungo, M. S. \& Prosser, C. L., 1959. Physiological and biochemical adaptation of goldfish to cold and warm temperatures. 2. Oxygen consumption of liver homogenate; oxygen consumption and oxidative phosphorylation of liver mitochondria. J. cell. comp. Pbysiol. 54, 265-274.

Kasвoнm, P., 1967. Der Einfluß des Lichtes auf die Temperaturadaptation bei Rana temporaria. Helgoländer wiss. Meeresunters. 16, 157-178.

KINNE, O., 1964. Non-genetic adaptation to temperature and salinity. Helgoländer wiss. Meeresunters. $9,433-458$.

KLICKA, J., 1965. Temperature acclimation in goldfish: lack of evidence for hormonal involvement. Physiol. Zoöl. 38, 177-189.

Konishi, J. \& Hickman, C. P., 1964. Temperature acclimation in the central neryous system of rainbow trout (Salmo gairdnerii). Comp. Biochem. Physiol. 13, 433-442.

Koyama, 'T., 1960. A preliminary study on gas exchange in carp. Jap. J. Ichthyol. 8, 11-19.

Krogh, A. \& LeITCH, I., 1919. The respiratory function of the blood in fishes. J. Pbysiol. $52,288$.

Krompecher, St., Leray, C., Allemand, B., Olah, E. H., Laszlo, M. B. \& Ladanyx, P., 1966. Comparative study on the lactic acid and hexosamine content as well as on the glycolytic and cytochrome oxidase activities of some lower animals. Acta biol. bung. 16, 389-396.

KRÜGeR, G., 1962. Uber die Temperaturadaptation des Bitterlings (Rhodeus amarus Bloch). Z. wiss. Zool. 167, 87-104.

Laffont, J. \& Labat, R., 1966. Action de l'adrénaline sur la fréquence cardiaque de la Carpe commune: effet de la température du milieu sur l'intensité de la réaction. J. Pbysiol., Paris, 58, 351-355.

LaRoche, G., Woodall, A. N., Johnson, C. L. \& Halver, J. E., 1966. Thyroid function in the rainbow trout (Salmo gairdnerii RrcH.). 2. Effects of thyroidectomy on the development of young fish. Gen. comp. Endocr. 6, 249-266.

Litwack, G. \& Kritchevsky, D., 1964. Actions of hormones on molecular processes. Wiley \& Sons, New York, 583 pp.

Maximow, A. A. \& Bloom, W., 1957. A textbook of histology. Saunders, Philadelphia.

Mejbaum, W., 1939. Über die Bestimmung kleiner Pentosemengen insbesondere in Derivaten der Adenylsäure. Z. physiol. Chem. 258, 117-120.

Mews, H.-H., 1957. Uber die Temperaturadaptation der eiweißspaltenden und -synthetisierenden Zellfermente von Fröschen. Z. vergl. Physiol. 40, 356--362.

Mrscin, H., 1960. Zur Funktionsanalyse des lymphatischen Kaudalherzens beim Aal (Anguilla anguilla L.). Revue suisse Zool. 67, 262-269.

Mотт, J. C., 1950. Radiological observations on the cardiovascular system in Anguilla anguilla. J. exp. Biol. 27, 324-333. 
- 1951. Some factors affecting the blood circulation in the common eel (Anguilla anguilla). J. Pbysiol., Lond. 114, 387-398.

Murphy, B., 1961. Tissue metabolism of goldfish (Carassius auratus) acclimated to warm and cold temperatures. Ph. D. Thesis. (Zitiert nach C. L. Prosser, 1962. Acclimation of poikilothermic vertebrates to low temperatures.)

NiSFI, S., 1938. Muskelsystem. [Versch. Beitr.] In: Handbuch der vergleichenden Anatomie der Wirbeltiere. Hrsg. von L. Bolk, E. Göppert, E. Kallius \& W. Lubosch. Urban \& Schwarzenberg, Berlin, Bd 5, 344-365.

Ogur, M. \& Rosen, G., 1950. The nucleic acids of plant tissues. 1. The extraction and estimation of desoxypentose nucleic acid and pentose nucleic acid. Archs Biochem. 25, 262-276.

Pätau, K., 1943. Zur statistischen Beurteilung von Messungsreihen. (Eine neue t-Tafel.) Biol. Zbl. 63, 152-168.

Palayer, P., 1963. Influence de la température sur la morphologie du pancréas de l'anguille (Anguilla anguilla, L.). Bull. Mus, natn. Hist. nat. 35, 247-252.

Partmann, W., 1965. Zur Frage der Artspezifität des Musters an Reststickstoffsubstanzen bei Knochenfischen. Zool. Jb. (Abt. allg. Zool. Physiol. Tiere) 71, 261-286.

Petтe, D., 1966. Energieliefernder Stoffwechsel des Muskels unter zellphysiologischem Aspekt. In: Progressive Muskeldystrophie. Myotonie. Myasthenie. Symposium v. 30. 11. bis 4. 12. 1965. Hrsg. von E. KuHn. Springer, Berlin, 492-506.

PотTER, V. R., 1957. The homogenate technique. In: Manometric techniques. Ed. by W. W. Umbreit, R. H. Burris \& J. F. Stauffer. Burgess, Minneapolis, Minn., 170-187.

PRECHT, H., 1951. Der Einfluß der Temperatur auf die Atmung und auf einige Fermente beim Aal (Anguilla vulgaris L.). Biol. Zbl. 70, 71-85.

- 1961. Beiträge zur Temperaturadaptation des Aales (Anguilla vulgaris L.). 1. Z. vergl. Pbysiol. 44, 451-462.

- 1964a. Über die Bedeutung des Blutes für die Temperaturadaptation von Fischen. Zool. Jb. (Abt. allg. Zool. Physiol. Tiere) 71, 313-327.

- 1964b. Anpassungen der wechselwarmen Tiere im normalen Temperaturbereich und ihre Ursachen. Naturwiss. Rdsch., Stuttg. 17, 438-442.

Prosser, C. L., 1958. Physiological adaptation. Ed. by C. L. Prosser. Society of General Physiologists, Washington, D. C., 185 pp.

- 1962. Acclimation of poikilothermic vertebrates to low temperatures. In: Comparative physiology of temperature regulation. Ed. by J. P. Hannon \& E. VIereck. Arctic Aeromedical Laboratory, Fort Wainwright, Alaska, 1-44.

- 1967a. Metabolic and central nervous acclimation of fish to cold. In: The cell environmental temperature. Ed, by A. S. Troshin. Pergamon Press, Oxford, 375-383.

- 1967b. Molecular mechanisms of temperature adaptation in relation to speciation. In: Molecular mechanisms of temperature adaptation. Ed. by C. L. Prosser. American Association for the Advancement of Science, Washington, D. C., 351-376. (Publ. Am. Ass. Advmt Sci. 84.)

- \& FARHi, E., 1965. Effects of temperature on conditioned reflexes and on nerve conduction in fish. Z. vergl. Pbysiol. 50, 91-101.

- Precht, H., Jankowsky, H.-D., 1965. Nervous control of metabolism during temperature acclimation of fish. Naturwissenschaften 52, 168-169.

Ranoall, D. J., Smith, L. S. \& Brett, J. R., 1965. Dorsal aortic blood pressures recorded from the rainbow trout (Salmo gairdneri). Can. J. Zool. 43, 863-872.

RAO, K. P., 1966. Some aspects of the biochemical basis of metabolic adaptation. Helgoländer wiss. Meeresunters. 14, 439-450.

- 1967. Some biochemical mechanisms of low temperature acclimation in tropical poikilotherms. In: The cell and environmental temperature. Ed. by A. S. Troshrn. Pergamon Press, Oxford, 98-112.

RIgGs, A., 1951. The oxygen equilibrium of the hemoglobin of the eel, Anguilla rostrata. J. gen. Pbysiol. 35, 41-44. 
RoberTs, J. L., 1964. Metabolic responses of fresh-water sunfish to seasonal photoperiods and temperatures. Helgoländer wiss. Meeresunters. 9, 459-473.

- 1966. Systemic versus cellular acclimation to temperature by poikilotherms. Helgoländer wiss. Meeresunters. 14, 451-461.

Roots, B. I. \& Prosser, C. L., 1962. Temperature acclimation and the nervous system in fish. J. exp. Biol. 39, 617-629.

SAUnders, R. L., 1962. The irrigation of the gills in fishes. 2. Efficiency of oxygen uptake in relation to respiratory flow activity and concentrations of oxygen and carbon dioxide. Can J. Zool. 40, 817-862.

Schmidt, K., Niesel, W. \& Bickel, D., 1965. Ermittlung der O2-Entsättigungs- und Aufsättigungszeiten am Herzmuskel und ihr Vergleich mit Beredhnungen nach dem KroGHschen Versorgungsmodell. Pflïgers Arch. ges. Physiol. 285, 178-192.

Schultze, D., 1965. Beiträge zur Temperaturadaptation des Aales (Anguilla vulgaris L.). 2. Z. wiss. Zool. 172, 104-133.

Shelton, G. \& Randall, D. J., 1962. The relationship between heart beat and respiration in teleost fish. Comp. Biochem. Physiol. 7, 237-250.

SteEN, J. B., 1963. The physiology of the swimbladder of the eel Anguilla vulgaris. 1. The solubility of gases and the buffer capacity of the blood. Acta physiol. scand. 58, 124-137.

- \& KRuYsse, A., 1964. The respiratory function of teleostean gills. Comp. Biochem. Physiol. $12,127-142$.

SUDAK, F. N., 1965. Some factors contributing to the development of subatmospheric pressure in the heart chambers and pericardial cavity of Mustelus canis (MrtchilL). Comp. Biochem. Physiol. 15, 199-215.

Sullivan, C. M. \& Frsher, K. C., 1953. Seasonal fluctuations in the selected temperature of speckled trout, Salvelinus fontinalis (MIтchILL). J. Fish. Res. Bd Can. 10, 187-195.

Thomson, R. Y., Hutchison, F. C. \& Davidson, J. N., 1953. The desoxyribonucleic acid content of the rat cell nucleus and its use in expressing the results of tissue analysis, with particular reference to the composition of liver tissue. Biochem J. 53, 460-474.

Thurow, F., 1957. Uber den Trockensubstanz- und Fettgehalt von Aalen aus der Kieler Bucht und Kieler Förde. Arch. FischWiss, B, 79-93.

TRIFonova, A. N., 1958. The increase in general resistance as a result of adaptation to the action of injurious agents. Zh. obshch. Biol. 19, 187-201.

Uematsu, H., 1954. Studies on the mitochondria of the "chiai“ muscle (red muscle) of the fish. Okajimas Folie anat. jap. 26, 51-66.

Walls, E. W., 1960. The microanatomy of muscle. In: Structure and function of muscle. Ed. by G. H. Bourne. Acad. Press, New York, 1, 38.

Wittenberger, C. \& Diaciuc, I. V., 1965. Effort metabolism of lateral muscles in carp. J. Fish. Res. Bd Can. 22, 1397-1406.

ZAHN, M., 1962. Die Vorzugstemperaturen zweier Cypriniden und eines Cyprinodonten und die Adaptationstypen der Vorzugstemperatur bei Fischen. Zool. Beitr. (N. F.) 7, 15-25. 